TOPICAL REVIEW • OPEN ACCESS

\section{Progress and prospects of hard hexaferrites for permanent magnet applications}

To cite this article: C de Julián Fernández et al 2021 J. Phys. D: Appl. Phys. 54153001

View the article online for updates and enhancements.
You may also like

- Structural and magnetic properties of $\mathrm{Cu}-\mathrm{V}$
Substituted M-type barium hexaferrites
Sami H Mahmood, Ahmad Awadallah,
Yazan Maswadeh et al.
- A comparative study of $\mathrm{Ba}_{4} \mathrm{Sr}_{4 .} \mathrm{Fe}_{42} \mathrm{O}_{49}$
$\frac{\text { ferrite permanent magnets prepared by }}{\text { ball milling and sol-gel routes }}$
Eman S Al-Hwaitat, Mohammad K Dmour,
lbrahim Bsoul et al.
- Magnetic performance enhancement in
La-Ca-Co doped SrFe
permanent magnets via cold isostatic
pressing
Z W Geng, M Haseeb, X K Quan et al.

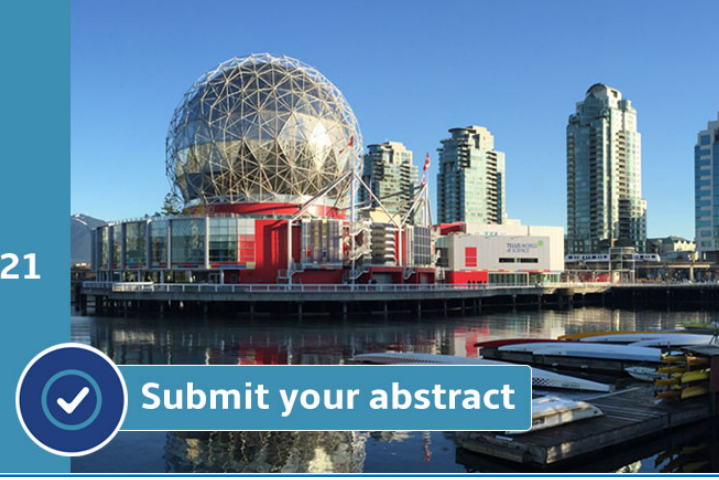




\title{
Progress and prospects of hard hexaferrites for permanent magnet applications
}

\author{
C de Julián Fernández ${ }^{1}, \mathbf{C}$ Sangregorio ${ }^{2}, \mathrm{~J}$ de la Figuera ${ }^{3}$, B Belec $^{4}{ }^{\mathbb{D}}, \mathrm{D} \mathrm{Makovec}^{5}$ \\ and $A$ Quesada ${ }^{6, *}$ (B)
}

${ }^{1}$ IMEM-CNR Parco Area delle Scienze, 43124 Parma, Italy

${ }^{2}$ ICCOM—CNR and Department of Chemistry 'U. Schiff', University of Fslorence, 50019

Sesto Fiorentino, Italy

${ }^{3}$ Instituto de Química Física 'Rocasolano', CSIC, Madrid 28006, Spain

${ }^{4}$ Materials Research Laboratory, University of Nova Gorica, Ajdovščina, Slovenia

${ }^{5}$ Department for Materials Synthesis, Jožef Stefan Institute, Ljubljana, Slovenia

${ }^{6}$ Instituto de Cerámica y Vidrio, CSIC, Madrid 28049, Spain

E-mail: a.quesada@icv.csic.es

Received 28 September 2020, revised 18 November 2020

Accepted for publication 10 December 2020

Published 28 January 2021

\begin{abstract}
Permanent magnets based on hard hexaferrite represent the largest family of magnets being used today by volume. They generate moderate remanence induction, but present crucial advantages in terms of availability, cost, resistance to demagnetization and corrosion and absence of eddy current losses. As a consequence, ferrites are the most logical candidate for substitution of rare-earths in selected applications that do not demand the best performing magnets. If the remanence of ferrite-based magnets was to be improved, even mildly, the door to a larger scale substitution could be opened. In this framework, we review here current strategies to improve the properties of hexaferrites for permanent magnet applications. We first discuss the potential of exploring the nanoscale. Second, progress related to controllably doping hexaferrites is revised. Third, results achieved by fabricating hard-soft magnetic composites using ferrites as the hard phase are presented. Finally, future prospects and new potential end applications for ferrite magnets are discussed.
\end{abstract}

Keywords: permanent magnets, hexaferrites, review, rare-earth substitution, doping, exchange-coupling

(Some figures may appear in colour only in the online journal)

\footnotetext{
* Author to whom any correspondence should be addressed.
} 


\section{Introduction}

\subsection{The importance of hexaferrite magnets}

Permanent magnets, in the form of lodestone [1], and later of magnetized steel, have been used by humankind for several millennia. During most of history, their practical use was limited to the compass, and they remained not much more than a kind of magician trick for most people. It is only with the industrial revolution that magnets began to be used on a large scale. Nowadays, permanent magnet materials are employed in many devices, specially in electrical to mechanical (and the converse mechanical to electrical) transductor devices, for information storage and in sensors. Since the beginning of the 20th century materials have been developed with the specific goal to improve those historic magnetic materials [2], thanks to the improved knowledge of material science and the parallel technological evolution. This path [3] provided a series of metallic alloys culminating in the Alnico family discovered by Mishima in the 30s, continuing with the hard ferrites developed by Phillips in the 50s, and reaching the $\mathrm{SmCo}$ and $\mathrm{NdFeB}$ rare-earth magnets developed in the 70s and 80s, respectively. This evolution has been accompanied by a corresponding increase in the tuning of the properties required for a hard magnet, specially the magnetic anisotropy.

Nowadays, the current market of ferrite magnets is dominated by the hard ferrites: the M-type hexaferrites $\mathrm{BaFe}_{12} \mathrm{O}_{19}$ (BFO), $\mathrm{SrFe}_{12} \mathrm{O}_{19}$ (SFO) and related materials [4]. Thus, the story of industrial age use of ferrites can be considered to start with the research of Takeshi Takei in Japan in the first half of the 20th century, in collaboration with Professor Kato [5]. While BFO was already known in the first part of the 20th century, it was only after the second World War that at Philips Laboratories, under the direction of Snoek, it was shown to have the same structure of magnetoplumbite $\left(\mathrm{PbFe}_{12} \mathrm{O}_{19}\right)$. Phillips moved on to develop a series of ferrites with the magnetoplumbite structure. During the 1950s all the main hexaferrite phases were studied, as shown in the classic Smit and Wijn's book [4]. It was in 1952 when the barium hexaferrite material was commercialized.

Ferrites exhibit relatively large coercivity $\left(H_{\mathrm{C}}\right)$ up to $380 \mathrm{kA} \mathrm{m}^{-1}$, but modest saturation magnetization $\left(M_{\mathrm{S}}\right.$ or magnetization induction $\left.B_{\mathrm{S}}=\mu_{0} M_{\mathrm{S}}\right)$, specific saturation $\left(\sigma_{\mathrm{S}}\right)$ and remanence $\left(M_{\mathrm{R}}\right.$ or remanence induction, $\left.B_{\mathrm{R}}=\mu_{0} M_{\mathrm{R}}\right)$. A useful parameter to empirically establish the suitability of a given material to realize compact permanent magnet with no shape constraints is the magnetic hardness, $\kappa$. This is defined by the ratio of anisotropy, $K_{1}$, to magnetostatic energy, $\kappa=\left(K_{1} / m_{0} M_{\mathrm{S}}^{2}\right)^{1 / 2}$, and it is assumed that $\kappa>1$ is the criterion for a material to be classified as hard. M-type hexaferrite have hardness higher than 1 (for example for BFO $\kappa=1.34$ ), which explains why, despite the relatively low $M_{\mathrm{S}}$ and moderate anisotropy, they are largely used to realize permanent magnets. The highest grade ferrite magnets in the market (Hitachi Metals NMF-15 series) reach maximum values of remanence induction of $480 \mathrm{mT}$. The highest grade ferrite magnets in the market (Hitachi Metals NMF-15 series) reach maximum values of remanence induction of $480 \mathrm{mT}$.
Their maximal energy product $\left(\mathrm{BH}_{\max }\right)$, figure of merit for the strength of magnets, reaches $44 \mathrm{~kJ} \mathrm{~m}^{-3}$. These values are low when compared to that of rare-earth based materials, such as $\mathrm{Nd}-\mathrm{Fe}-\mathrm{B}$, who typically present (Hitachi Metals NEOMAX Series) remanence inductions of $1.3 \mathrm{~T}$, coercivities of $1500 \mathrm{kA} \mathrm{m}^{-1}\left(\mu_{0} H_{\mathrm{c}}=1,85 \mathrm{~T}\right)$ and energy products of $350 \mathrm{~kJ} \mathrm{~m}^{-3}$ [6].

However, ferrites do have some important advantages. The main one is definitely the availability and low cost of raw material powders, of approximately $1.5 \$ \mathrm{~kg}^{-1}$, while $\mathrm{NdFeB}$ powders approximately cost $60 \$ \mathrm{~kg}^{-1}$. They also exhibit excellent chemical stability and high electrical resistivity. For these reasons, ferrite magnets are widely used in mass applications that do not require large energy products and/or where increasing the weight of the device is not an issue-since the low flux density can be compensated by increasing the volume of magnetic material. These include inductors, transformers and electromagnets due to the low eddy current losses they entail. As a consequence of these advantages, ferrite magnets constitute by far the most widely used permanent magnet by weight [7].

Hexaferrites are the subject of a continuing research effort, both from fundamental and applied perspectives [8, 9]. In the last two decades the research on ferrites has been, however, mainly focused on ferrite nanomaterials. The systematic research devoted to ferrite nanoparticles lead to novel applications, ranging from engineering (e.g. magnetic recording media, magnetic seals, ferrofluids, magnetic separation, etc) [10-18] to medicine (e.g. magnetic hyperthermia, magnetic resonance imaging, drug delivery, etc) [19-28]. Based on ferrite nanoparticles new attractive magneto-responsive materials were developed, including ferromagnetic fluids (i.e. liquids exhibiting a spontaneous magnetic ordering, in contrast to superparamagnetic (SPM) ferrofluids) [29-32], magneto-optical suspensions and solid composites [33-35], soft magneto-electric [36], if we mention just a few. The acquired knowledge related to nanomagnetism, synthesis, and processing of the nanoparticles can also be crucial for the renaissance of most traditional applications of ferrites, i.e. for permanent magnets.

\subsection{Structure and properties}

The family of hard-ferrites is based on the magnetoplumbite structure, $\mathrm{PbFe}_{12} \mathrm{O}_{19}$, which belongs to the hexagonal space group $\mathrm{PG}_{3} / \mathrm{mmc}$. Thus, four indices are usually employed to indicate the planes, with the last one indicating the $c$-axis and the first three indicating the in-plane orientation of the unit vectors at $120^{\circ}$ from each other. The crystal structure [37] is based on a close-packed arrangement of oxygen cations with the divalent $\left(\mathrm{Ba}^{2+}, \mathrm{Sr}^{2+}\right.$ or $\left.\mathrm{Pb}^{2+}\right)$, and $\mathrm{Fe}^{3+}$ cations occupying the voids. A way to visualize the structure is to consider it to be built from two different building blocks. The first is the two layer S (for spinel) block. The $\mathrm{S}$ block presents the same occupancy of tetrahedral and octahedral sites as the spinel crystal structure, and thus it has the $\mathrm{Fe}_{6} \mathrm{O}_{8}{ }^{2+}$ composition. The other block, $\mathrm{R}$, is built from a three-layer $h c p$ sequence, with 


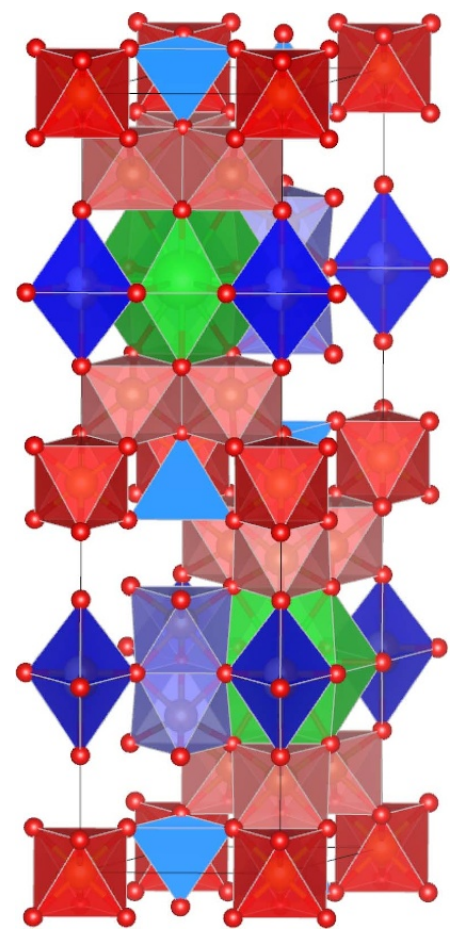

Figure 1. Schematic of the M-hexaferrite structure of BFO. Polyhedrals are colored: dodecahedral $\mathrm{Ba}^{2+}$ (green), and the $\mathrm{Fe}^{3+}$ sites: octahedral $2 \mathrm{a}$ (dark red), tetrahedral $4 \mathrm{f}_{1}$ (medium blue), bipyramidal $2 \mathrm{~b}$ (dark blue), distorted octahedral $4 \mathrm{f}_{2}$ (gray), octahedral $12 \mathrm{k}$ (light red). The spin direction is parallel to the net direction for cations inside polyhedral colored red, and opposite for atoms inside polyhedral colored blue-gray (drawing made with VESTA [41]).

a quarter of the oxygen anions substituted in the intermediate hexagonal layer by the large divalent cation $\left(\mathrm{Ba}^{2+}, \mathrm{Sr}^{2+}\right)$. Considering the interstitial $\mathrm{Fe}$ atoms, the composition of this block is $\mathrm{BaFe}_{6} \mathrm{O}_{11}{ }^{2-}$. The full unit cell is obtained by ordering the blocks along the $c$ direction, following the sequence $\mathrm{RSR}^{*} \mathrm{~S}^{*}$, where the star indicates a rotation of $180^{\circ}$, giving a repeat distance of $2.2-2.3 \mathrm{~nm}$. The in-plane unit cell constant is $0.56 \mathrm{~nm}$, and corresponds to about four times the radius of the oxygen anion [38-40]. The iron cations thus occupy five unique interstitial sites, indicated by the Wickoff positions $2 \mathrm{a}$, $2 \mathrm{~b}, 4 \mathrm{f}_{1}, 4 \mathrm{f}_{2}$ and $12 \mathrm{k}$. The five-fold coordinated (2b) has been found to correspond to two statistically half-occupied pseudo tetragonal 4 sites [37]. The other sites are the tetrahedral and octahedral sites of the $\mathrm{S}$ block $\left(4 \mathrm{f}_{1}\right.$ and $\left.2 \mathrm{a}\right)$, distorted octahedral sites in the R block $\left(4 \mathrm{f}_{2}\right)$ and distorted octahedral sites at the boundary between $\mathrm{R}$ and $\mathrm{S}$ blocks (which we assign to the $\mathrm{R}$ block). A drawing is shown in figure 1 .

The magnetic structure of the M-hexaferrites can be described by the Néel model of antiferromagnetism. The spin orientation of each iron cation is coupled by superexchange interaction through the oxygen anions. The $\mathrm{Fe}^{3+}$ cations have a spin-only magnetic moment. In the $\mathrm{S}$ block, the octahedral sites point in the net magnetization direction (i.e. the spin up direction), while the tetrahedral ones point in the opposite direction (spin down). Two octahedral sites of the R-block can be better described as distorted tetrahedral, and thus point in the spin down. The bipyramidal site is along with the three octahedral ones, giving a net of another two magnetic moments. Considering the magnetic moment at each temperature of each site $x, m_{x}$, and the site occupancy $\left(n_{x}\right)$, the magnetic moment per cell is:

$$
m_{\mathrm{c}}=n_{12 \mathrm{k}} m_{12 \mathrm{k}}+n_{2 \mathrm{a}} m_{2 \mathrm{a}}+n_{2 \mathrm{~b}} m_{2 \mathrm{~b}}-\left(n_{4 \mathrm{f} 1} m_{4 \mathrm{f} 1}+n_{4 \mathrm{f} 2} m_{4 \mathrm{f} 2}\right)
$$

Considering the occupancy of the M-type ferrites $\left(n_{12 \mathrm{k}}=6\right.$, $n_{2 \mathrm{a}}=1, n_{2 \mathrm{~b}}=1, n_{4 \mathrm{f} 1}=2, n_{4 \mathrm{f} 2}=2$ ) and a spin-only magnetic moment at $0 \mathrm{~K}$ of $\mathrm{Fe}^{3+}$ ions of $5 \mu_{\mathrm{B}}$, a magnetic moment per formula unit of $20 \mu_{\mathrm{B}}$ is expected, which is close to the experimental value measured at $77 \mathrm{~K}\left(19.9 \mu_{\mathrm{B}}, 100 \mathrm{~A} \mathrm{~m}^{2} \mathrm{~kg}^{-1}\right)$ [42].

The saturation magnetization at room temperature of the M-hexaferrites is not too low if compared to a ferrimagnetic oxide (for example magnetite, which is a high-saturation specific magnetization oxide and has $\sigma_{\mathrm{S}} \sim 90-95 \mathrm{~A} \mathrm{~m}^{2} \mathrm{~kg}^{-1}$ ), but it is very low when compared to the saturation magnetization of most materials used for permanent magnets. The reason for the use of hexaferrites actually lies in their large uniaxial magnetocrystalline anisotropy field $(1.8 \mathrm{~T})$, which yields large coercive fields. As a consequence, the coercive field can be larger than the remanence induction, which leads to robust resistance to demagnetization and large energy products. In this case the working point of the ferrite magnets depends weakly on their morphology.

The origin of the high magnetocrystalline anisotropy relies on the strong contribution to the single-ion term from $\mathrm{Fe}^{3+}$ ions placed in the trigonal bipyramidal $2 \mathrm{~b}$ cavities, and to a minor extent in tetrahedral and octahedral distorted sites. On the other hand, the hexagonal structure makes the anisotropy to lie along the $c$-axis. The magnetocrystalline anisotropy is indeed well described, even at low temperature, as an uniaxial type with a second order term $K_{1}$ anisotropy constant. $K_{1}$ takes at room temperature a value of $3.5 \times 10^{5} \mathrm{~J} \mathrm{~m}^{-3}$ for SFO and $3.25 \times 10^{5} \mathrm{~J} \mathrm{~m}^{-3}$ for BFO [42]. Considering that magnetocrystalline anisotropy is uniaxial, the anisotropy field, $H_{\mathrm{A}}$ which is equal to $2 K_{1} / \mu_{0} M_{\mathrm{s}}$ is $1.35 \mathrm{MA} \mathrm{m}^{-1}(1.7 \mathrm{~T})$ and $1.43 \mathrm{MA} \mathrm{m}^{-1}(1.8 \mathrm{~T})$, for BFO and SFO, respectively [4, 42].

A common problem when considering the feasibility of a new material for potential applications as permanent magnet material arises from the way its properties are often described in the literature. For example, the measurement of the magnetization saturation can be performed under different maximum applied magnetic fields, often at values that are not high enough to fully saturate the material or to overcome the irreversibility field (minor loop). In most of the studies, the changes of the magnetization are reported in terms of the specific magnetization, $\sigma$ in $\mathrm{A} \mathrm{m}^{2} \mathrm{~kg}^{-1}$ or, emu $\mathrm{g}^{-1}$, since this quantity is not affected by powder packing or porosity in sintered samples. However for evaluating the performances of a ferrite as a magnet the proper magnitude is the magnetization $\left(M_{\mathrm{S}}\right.$ in $\left.\mathrm{A} \mathrm{m}^{-1}\right)$ or the saturation induction $\left(B_{\mathrm{S}}\right.$ in $\left.\mathrm{T}\right) . \sigma_{\mathrm{S}}$ is preferable because uncertainty for mass is much lower than for volume measurement required to determine $M_{\mathrm{S}}$. On the other hand, there is also the uncertainty that the change of $\sigma_{\mathrm{s}}$ can be due to modification of the $M_{\mathrm{s}}$ and/or the mass density. 
Another key issue to be considered is how to determine the changes in $H_{\mathrm{A}}$ and of the symmetry of anisotropy with respect to the bulk. The measurement of these properties requires Singular Point detection technique $[43,44]$ in powders, nuclear magnetic resonances or ferromagnetic resonance experiments $[42,45]$. However, often published works rely on the 'approximation law to the saturation' to the magnetization curves to estimate the anisotropy, a procedure that can present problems [46] to investigate nanomaterials and hybrid composites.

\subsection{The potential and the challenges to improve ferrite magnets}

Rare-earth elements are critical raw materials that present supply risk, price volatility and environmental problems. For these reasons, considerable efforts are being dedicated to reduce our dependence on them, which directly affect the permanent magnet value chain. The strategies include improving the recyclability of rare-earth materials and devices, fabricating competitive devices that are rare-earth-free and finding alternative magnets that could replace $\mathrm{NdFeB}$ and $\mathrm{SmCo}$ magnets. As the most widely used magnet by volume in the world, ferrites constitute an interesting candidate to attempt substitution with. However, to enable a wider replacement in more applications, the magnetic properties of ferrites need to be improved. Of course this substitution is generally realistic in applications where magnets with moderate $(\mathrm{BH})_{\max }\left(50-200 \mathrm{~kJ} \mathrm{~m}^{-3}\right)$ are needed, but it is important to remark that substitution by ferrites can be attempted in important applications that are expected to drive the permanent magnet market in the next few years and increase the $\mathrm{NdFeB}$ demand. Generators for wind turbines and automotive applications fall within this category, and the development of competitive devices based on highgrade/improved ferrites could entail large scale substitution. In light of this need, the importance of ferrite based magnets is being reinvigorated.

The $(\mathrm{BH})_{\max }$ value of hexaferrites in sintered ceramics is around $40 \mathrm{~kJ} \mathrm{~m}^{-3}$. Most of the $H_{\mathrm{C}}$ values used to estimate $(\mathrm{BH})_{\max }$ have been frozen for more than 40 years. Considering that the large magnetic anisotropy field of the BFO and SFO, 1.7 T and 1.8 T, respectively is much larger than $\mathrm{H}_{\mathrm{C}}$ and $\mathrm{B}_{\mathrm{S}}$, both sintered and bonded commercial magnets have coercive fields similar to the remanence induction and near of the saturation induction $(0.4 \mathrm{~T})$. In such a case, the $(\mathrm{BH})_{\max }$ is near the maximum achievable value, $B_{\mathrm{S}}{ }^{2} / \mu_{0}$. Hence, the first strategy to increase the $(\mathrm{BH})_{\max }$ requires the improvement of the saturation induction. However, for permanent magnets it should be considered that $H_{\mathrm{C}}$ should be larger than $N_{\mathrm{ef}} M_{\mathrm{S}}$ to prevent demagnetization, where $N_{\text {ef }}$ represents the demagnetizing factor due to the shape of the magnet. Thus, a second target is to improve the coercive field to keep $H_{\mathrm{C}}>N_{\mathrm{ef}} M_{\mathrm{s}}$. Because the $H_{\mathrm{C}}$ is proportional to the anisotropy field and hence to $K_{1} / \mu_{0} M_{\mathrm{s}}$, the targets of improvement both $H_{\mathrm{C}}$ and $M_{\mathrm{S}}$ by improving a single phase material require that a further increment of the magnetic anisotropy, $K_{1}$, should take place.

On the other hand, the modification of the magnetic structure can lead to other changes in the features of the ceramics that should be taken into account. First is the change of the exchange interactions and hence of the Curie temperature, $T_{\mathrm{C}}$. In the particular case of the decreasing of the Curie temperature, the magnetization could decrease faster than in standard ceramics. This can impact negatively the use of magnets working in high temperature environments.

Another factor to take into account is that the negative thermal coefficient of hexaferrites makes the coercive field increase with temperature. This makes ferrite magnets perform often better up to $100{ }^{\circ} \mathrm{C}$ than at room temperature. The temperature dependence of $H_{\mathrm{C}}$ depends on the relative temperature dependences of both $K_{1}$ and $M_{\mathrm{S}}$ [42] that should vary with the doping due to the change of the $T_{\mathrm{C}}$. Any changes to each component might thus negatively affect the resulting useful temperature range.

In the framework of the current need for better ferrite magnets, we review here the most promising strategies, as well as recent results, to improve the performance of the hexaferrite based materials for their use in permanent magnets. We present three main pathways for future improvements. First, we consider how engineering the shape and size of hexaferrite nanoparticles can improve the magnetic properties of the commercial ones. In the second section, we consider how substituting one or more of the cations of the hexaferrites can improve the magnetic properties, considering three main themes: the improvement of the well-know LaCo-doped BFO, doping changes oriented towards improving the saturation magnetization, and changes oriented towards improving the coercivity. In the third section, we consider first exchange coupled composites, either with metal or oxide components. We comment on promising results of highly coherent magnetite-hexaferrite platelets and discuss the possibilities of exploiting the internal magnetostatic interactions for improving composites properties. Finally, the conclusions and future prospects of ferrite magnets are addressed.

\section{Reducing the size to the nanoscale}

\subsection{The effect of the size}

Among all, the reduction of the grain size down to the nanoscale is generally recognized as a useful route to improve the coercivity of a magnetic material. Indeed, one of the best examples of permanent magnet, Alnico alloys, is actually a nanocomposite. Alnico alloys, which 90 years after their introduction still today play a relevant role in the permanent magnet market, indeed, consist of elongated FeCo-rich ferromagnetic nanograins dispersed in a weakly magnetic Al-Ni matrix. The energy product of the material can be further enhanced through the application of an external magnetic field during the annealing process [47].

In a bulk ferro(ferri)-magnetic material the process of reversal of magnetization may occur through different mechanisms such as nucleation and propagation of reverse domains and domain walls pinning. However, on squeezing the volume of the material a critical size is reached below which the formation of domain walls is no longer energetically favored, and a single domain (SD) spin configuration is attained. The magnetic behavior of the SD particle can then 


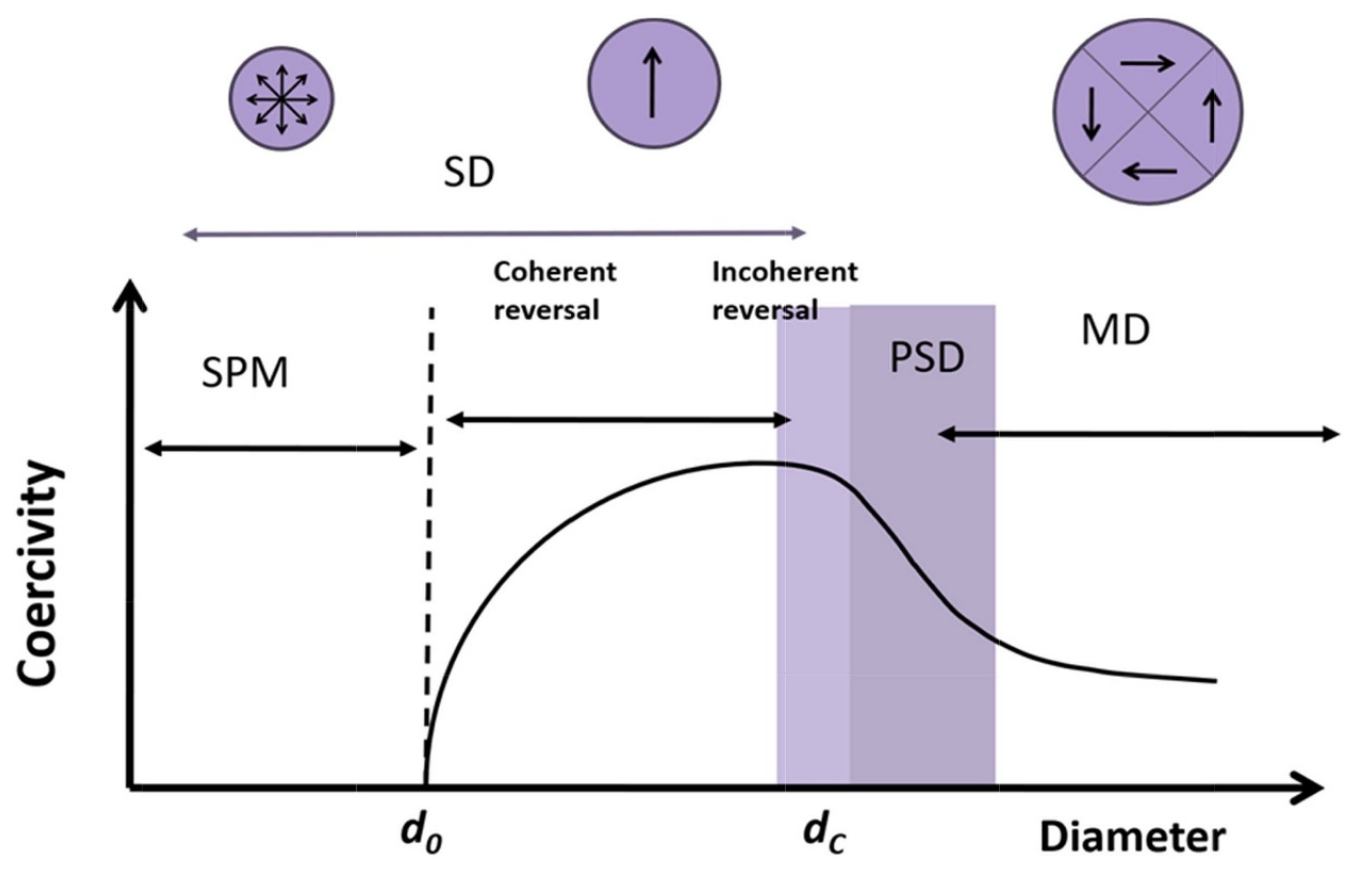

Figure 2. Scheme of the room temperature variation of coercivity with the grain size from SPM to SD and MD states. PSD denotes the pseudo-single domain region (PSD) while the light grey zone indicates the size range where incoherent reversal processes might occur. Reproduced from [60] with kind permission of Società Italiana di Fisica.

be described by a giant magnetic moment $\mu=M_{\mathrm{S}} V$, where $V$ is the volume, arising from the combination of the individual atomic spins, which reverses its orientation through the coherent rotation of the single spins. For a given material the critical diameter, $d_{\mathrm{C}}$, for the SD spin configuration state depends on the competition between three energy terms, magnetostatic energy, magnetic anisotropy constant, $K$, and exchange energy, $A$. For a spherical nanocrystal, $d_{\mathrm{C}}$, is expressed as [48]:

$$
d_{\mathrm{C}}=\left(18 E_{\sigma}\right) /\left(\mu_{0} M_{\mathrm{S}}^{2}\right)=(36 \sqrt{ } A K) /\left(\mu_{0} M_{\mathrm{S}}^{2}\right)
$$

where $\mu_{0}$ is the vacuum permeability and $E_{\sigma}=2(A K)^{1 / 2}$ is the surface energy of a domain. Typical values of $d_{\mathrm{C}}$ for most common magnetic materials, range from few tens up to several hundreds of $\mathrm{nm}$. For Ba-ferrite theoretical and experimental estimates suggest $d_{C}$ is ca. $500 \mathrm{~nm}[49,50]$, although higher values up to $1 \mu \mathrm{m}$ have been often observed [49, 51]. Critical diameters in the micron scale, up to $1,5 \mu \mathrm{m}$, have been also reported for SFO [52, 53]. González and coworkers estimated the activation volume, i.e. the size of the nucleus that gives rise to magnetization reverse, of a series of Ba-ferrite particles with sizes between $65 \mathrm{~nm}$ and the micrometric range. A jump in the coercive field from $200 \mathrm{kA} \mathrm{m}^{-1}$ to $320 \mathrm{kA} \mathrm{m}^{-1}$ was observed when the particle size decreased below $800 \mathrm{~nm}$, while the activation size decreased from $40 \mathrm{~nm}$ to $25 \mathrm{~nm}$ along the series. The authors concluded that the reversal process in the particles above $800 \mathrm{~nm}$ occurs by domain wall propagation, while the coherent rotation is the basic reversal process for the smaller particles [54].

The transition from the multidomain (MD) to the SD state is not sharp and several non-uniform reversal modes as curling and buckling can occur, where unlikely coherent reversal, the exchange energy does not remain constant [55, 56]. For example Chan et al measured by magnetic force microscopy the switching field of a series of isolated nanoparticles of doped barium ferrite and found the Stoner-Wohlfarth model was followed only for average size up to $50 \mathrm{~nm}$; on increasing the size above this limit incoherent reversal modes produced a decrease of the switching field [57]. Moreover, an investigation by electron holography of the magnetic domain structure on isolated Ba-ferrite particles obtained by heat treatment at $1100{ }^{\circ} \mathrm{C}$ of a mixture of $\mathrm{BaO} \cdot \mathrm{Fe}_{2} \mathrm{O}_{3}$ and an additive of $\mathrm{Bi}_{2} \mathrm{O}_{3}$, demonstrated the coexistence of single-domain and two-domain magnetic states over the whole investigated range $0.1-2 \mu \mathrm{m}[51]$.

As a result of the size dependence of the reversal process, the coercivity increases with decreasing the grain size, as schematically shown in figure 2, as long as the SD threshold is reached. On further shrinking the size, in fact the nanoparticles become unstable against thermal demagnetization till magnetic irreversibility completely disappears and the SPM state is attained. The threshold size below which superparamagnetism can be observed for a given measuring time, depends on the shape and crystal quality (presence of defects and impurities) of the grains. For Ba-ferrite and $\mathrm{Sr}$-ferrite it is generally assumed SPM relaxation becomes dominant for size below 40-60 nm [58, 59]. However, it should be considered that these limits refer to time scale characteristics of laboratory experiments (typically from $10^{2}$ to $10^{4} \mathrm{~s}$ ), which are much shorter than the shelf life required for a permanent magnet (the loss of magnetization must be less than 5\% over 100 years).

The expected trend of the coercivity with the particle size was nicely confirmed by a systematic study performed on a 


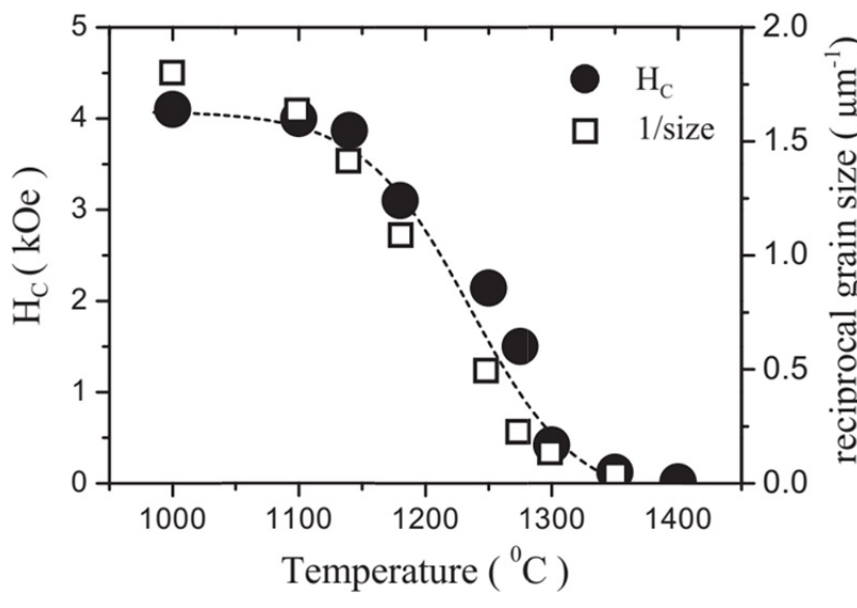

Figure 3. Trend of the coercive field (left) and of the reciprocal grain size (right) as a function of the annealing temperature for a series of BFO particles prepared by conventional ceramic route. Reprinted from [61], Copyright 2005, with permission from Elsevier.

family of polycrystalline BFO samples prepared through conventional solid-state reaction [61]. The size of the particles was tuned between $500 \mathrm{~nm}$ and several microns by increasing the calcination temperature from $1000{ }^{\circ} \mathrm{C}$ to $1400{ }^{\circ} \mathrm{C}$, while the coercive field was observed to decrease with the grain size from $318 \mathrm{kA} \mathrm{m}^{-1}$ for the smallest samples down to only $100 \mathrm{~A} \mathrm{~m}^{-1}$ for the largest one, as shown in figure 3 . The authors argued that at the small size, coercivity is determined by pinning of the magnetization at grain boundaries, which extent scales with the reciprocal of the size. Conversely, they suggested that in the larger multi-domain grain, the coercivity originated by nucleation and domain wall pinning is small. This study on one hand demonstrated how the coercivity of $\mathrm{Ba}$-ferrite can be easily controlled by the grains size, and on the other confirm the critical single domain size is close to $500 \mathrm{~nm}$

\subsection{The effect of the shape}

In addition to the size, also the shape of the particles plays a relevant role in determining the coercive field. According to the Stoner-Wohlfarth model [65], in fact, for noninteracting single domain spheroidal particles, the anisotropy field, $H_{\mathrm{A}}$, can be expressed as $H_{\mathrm{A}}=H_{\mathrm{K}}+D_{\mathrm{N}} M_{\mathrm{S}}$ where $H_{\mathrm{K}}=2 K_{1} / \mu_{0} M_{\mathrm{S}}$ is the magnetocrystalline anisotropy and $D_{\mathrm{N}}$ is the demagnetizing term, which assumes positive or negative value depending whether the easy axis is parallel or perpendicular to the main axis of the spheroid. M-type ferrites naturally tend to assume a regular hexagonal thin platelet shape with the $c$-axis, which coincides with the magneto-crystalline easy axis, along the short dimension. Such a shape corresponds to the growth of low energy 001 crystallographic faces. However, often acicular platelets are formed, depending on the synthesis conditions ([66] and Refs. therein). In this situation, a strong demagnetizing field appears when the magnetization is along the easy axis. The decrease of the magnetic anisotropy due to the shape contribution is given by $H_{\mathrm{A}}=H_{\mathrm{K}}-D_{\mathrm{N}} M_{\mathrm{S}}$. $D_{\mathrm{N}}$ is a

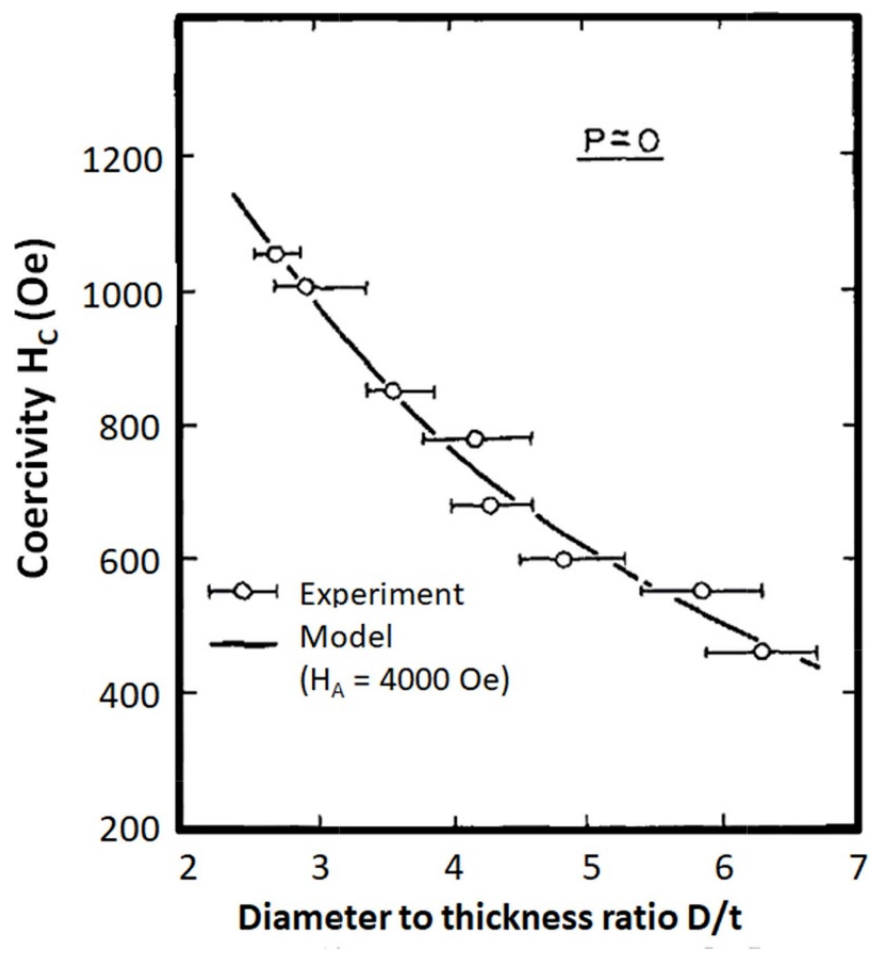

Figure 4. Coercivity as a function of the diameter to thickness ratio in Ti-doped barium ferrite nanoparticles. The solid line represents the theoretical curve calculated according to the Stoner-Wohlfarth model assuming the particle shape as an ellipsoid of revolution. Reprinted from [56], with the permission of AIP Publishing.

tensor, but here for simplicity, can be treated as a scalar. The $D_{\mathrm{N}}$ term depends on the diameter $(D)$ to thickness $(t)$ ratio: $D_{\mathrm{N}}=1$ when $t \ll D$, as is the case of narrow platelets, then it decreases with $D / t$, reaching zero for equiaxial morphology $(D / t=1)$. For $D / t<1, D_{\mathrm{N}}$ changes sign and $H_{\mathrm{A}}$ increases with respect to $H_{\mathrm{K}}$. This discussion highlights how the proper design of the particle shape is critical to optimize the effective anisotropy of the ferrite.

The relevance of the shape has been indeed experimentally verified by several authors. For example, Kubo et al [56] investigated the effect of the particles shape on the coercivity of $\mathrm{Ba}-$ ferrite nanoparticles pure and doped with a small amount of $\mathrm{Co}$ and $\mathrm{Ti}$ prepared by the glass-crystallization method. They found that $H_{\mathrm{C}}$ decreased with increasing the diameter $(d)$ to thickness $(t)$ ratio down to ca. $32 \mathrm{kA} \mathrm{m}^{-1}$ for $d / t$ ca. 6 (figure 4).

On the other hand the platelet morphology offers the advantage of making small particles (i.e. below $100 \mathrm{~nm}$ ) more easily orientable, either magnetically or mechanically. This is a fundamental feature since grain orientation along the $c$ axis allows for increasing the reduced remanence from half the saturation magnetization, which is the value obtained for isotropic magnets fabricated from powders composed of single domain, randomly oriented particles $(0.5$ is the theoretical value predicted by the Stoner-Wohlfart model and it corresponds to $(\mathrm{BH})_{\max }$ of approximately $8 \mathrm{~kJ} \mathrm{~m}^{-3}$ ) up to values close to 1 . The Stoner-Wohlfart model also predicts that the 
coercive field increases upon orientation: in fact, while in noninteracting randomly oriented particles $H_{\mathrm{C}}=0.49 H_{\mathrm{A}}$, for oriented particles $H_{\mathrm{C}}$ coincides with $H_{\mathrm{A}}$. Thanks to the platelet morphology, particles can be thus easily oriented and coercive field and remanence can be maximized, making the processing from powders to bulk magnets simpler. A similar result can be reached by piling up platelets. In such a situation interparticle interactions determine the decreasing of platelets' internal field that can improve the magnetic properties.

\subsection{Experimental methods to prepare nanosized hexagonal ferrite nanoparticles}

The control of the shape and of particle size down to the nanoscale is thus crucial for the fabrication of high-performance permanent magnets. Accordingly, attempts to prepare Mhexaferrite nanoparticles, nanorods and nanofibers, appeared in the literature since the $80 \mathrm{~s}$, at the very beginning of the nanomaterial era. However, it should be stressed that most of the recent literature is focused on the fabrication of nanosized M-hexaferrites with properties optimized for applications other than permanent magnets. M-type hexagonal ferrites, indeed, can be employed in several technologies such as microwave devices, magnetic recording or electromagnetic wave absorber, just to mention a few, where the nanostructuration can have a significant impact [66]. The many techniques developed so far include solid-state reaction [72, 73], sol-gel [74, 75], co-precipitation [76-78], milling [79, 80], microemulsion [81, 82], aerosol pyrolysis [83], combustion synthesis [84], glass crystallization [85, 86], and hydrothermal techniques [87-91]. Particularly, low temperature chemical routes demonstrated to be effective to prepare M-hexaferrite nanostructures with controlled size and shape and good magnetic properties. Sol-gel has been largely employed to prepare nanoparticles of pure and substituted $\mathrm{Ba}$ - and Sr-ferrite [74, 92-95]. Importantly, the main efforts have been spent in the rationalization of the role of each parameter of the synthesis. Indeed, it has been shown that a fine control over the several parameters is required to avoid the formation of secondary phases as hematite or goethite, to control the size and to optimize the magnetic properties. Nga and coworkers studied the influence of $\mathrm{pH}, \mathrm{Fe} / \mathrm{Sr}$ molar ratio and calcination temperature and time on the structure and magnetic properties of SFO particles prepared by a sol-gel method using metal nitrates in citric acid as precursors [96]. They found that pure nanometric particles with hexagonal morphology could be obtained with $\mathrm{Fe} / \mathrm{Sr}$ molar ratio of 10.5 and $\mathrm{pH}=1$ and after calcination at $850{ }^{\circ} \mathrm{C}$. The particles had $M_{\mathrm{S}}$ of $56 \mathrm{~A} \mathrm{~m}^{2} \mathrm{~kg}^{-1}$ and $H_{\mathrm{C}}=525 \mathrm{kA} \mathrm{m}^{-1}$. A Ba/Fe molar ratios of 11.5 was instead found has the best one to obtain well-crystalline Mtype $\mathrm{Ba}$-ferrite powder with crystallite size $22 \mathrm{~nm}$, and better magnetic properties $\left(H_{\mathrm{C}}=420 \mathrm{kA} \mathrm{m}^{-1}\right)$ by the sol-gel auto combustion technique [97]. Similarly, Yu and Huang investigated the role of $\mathrm{pH}$ and citric acid/metal ion molar ratio in the sol-gel synthesis of BFO. Single domain particles with magnetization at $2.39 \mathrm{MA} \mathrm{m}^{-1}$ of $61.7 \mathrm{~A} \mathrm{~m}^{2} \mathrm{~kg}^{-1}$, remanence of $30.8 \mathrm{~A} \mathrm{~m}^{2} \mathrm{~kg}^{-1}$ and coercivity of $406 \mathrm{kA} \mathrm{m}^{-1}$ were obtained at $\mathrm{pH}=3$ and calcination at $900{ }^{\circ} \mathrm{C}$ [98]. In a previous work it was suggested that adding a pre-decomposition step of the gel at $450^{\circ} \mathrm{C}$, in a standard sol-gel method with $\mathrm{Fe}: \mathrm{Ba}=11.5$ and sintering at $900{ }^{\circ} \mathrm{C}, \mathrm{Ba}$-ferrite nanoparticles with average size ca. $100 \mathrm{~nm}$, saturation magnetization of as high as $70 \mathrm{~A} \mathrm{~m}^{2} \mathrm{~kg}^{-1}$ and coercivity of $473 \mathrm{kA} \mathrm{m}^{-1}$ could be obtained [74].

A tight control on the synthesis parameter is required also when nanosized M-type hexaferrites are prepared by the hydrothermal technique. This synthesis route has been largely proved to be effective to this goal [23, 89-91, 99, 100]. Moreover, as is the case of the sol-gel method, hydrothermal technique is simple and cost-effective, and can be easily scaled to industrial production. Despite many advantages, several studies have demonstrated how the properties of the final materials depend on many, often intertwined, synthesis parameters such as temperature, time, precursor molar ratio, nature of the base and its concentration, just to name the most important. This aspect, in one hand expands the potentiality of the technique in designing hexaferrites with tailored properties for each given application, on the other hand can make rather tricky the determination of the optimal preparation conditions to get the desired result. In this framework, some interesting results were recently reported by Saura-Muzquiz and coworkers, who demonstrated the fundamental role of the concentration of the metal ion solution, when adding the precipitating $\mathrm{NaOH}$ solution in the precursor preparation, in the synthesis of $\mathrm{Sr}$-ferrite nanoparticles by a hydrothermal route [62]. By changing the iron concentration from 0.05 to $0.75 \mathrm{M}$, hexagonal platelet-like particles with mean diameters from $48 \mathrm{~nm}$ to $254 \mathrm{~nm}$, whose magnetic properties were strongly dependent on the average size (specific remanence, $\sigma_{\mathrm{R}}$, from 20 to $31 \mathrm{~A} \mathrm{~m}^{2} \mathrm{~kg}^{-1}$ and $H_{\mathrm{C}}$ from 68 to $175 \mathrm{kA} \mathrm{m}^{-1}$ ) could be obtained. Notably, it was also shown that, in contrast to the bulk, in the thinnest nanoplatelets the termination layer was the Sr-containing one. Interestingly, the authors addressed the critical issue of processing the as-prepared nanopowders to obtain bulk magnets. By using spark plasma sintering (SPS) they managed to produce high-density (more than $95 \%$ of the bulk density) SFO magnets. X-ray pole figure measurements demonstrated that, thanks to the anisotropic shape, self-induced alignment of the nanoplatelets occurred during SPS (figure 5). This texturing, which was accompanied by the increase of the platelet thickness, provided highperformance permanent magnets with square hysteresis loop and $(\mathrm{BH})_{\max }$ of $30 \mathrm{~kJ} \mathrm{~m}^{-3}$ (figure 5). The $(\mathrm{BH})_{\max }$ could be further enhanced up to $36 \mathrm{~kJ} \mathrm{~m}^{-3}$ by annealing at $850^{\circ} \mathrm{C}$. This energy product was claimed by the authors to exceed those of the best dry-processed commercial ferrites.

In another work, Raghuram and coworkers used the hydrothermal method to prepare a series of $\mathrm{Ba}_{1-x} \mathrm{Sr}_{x} \mathrm{Fe}_{12} \mathrm{O}_{19}$ nanoparticles with variable composition $(x=0-0.8)$ [101]. The particles exhibited average size between 15 and $20 \mathrm{~nm}$ and their shape evolved from plate-shaped grains to nanorods as a function of dopant. A marked decrease of $M_{\mathrm{S}}$ with $x$ and an increase of both coercivity (from 159.1 to $189.5 \mathrm{kA} \mathrm{m}^{-1}$ ) and critical temperature (from $703 \mathrm{~K}$ to $753 \mathrm{~K}$ ) were observed as a function of $x$. However, the cation replacement was not found to be the only factor responsible for the observed trend. In 


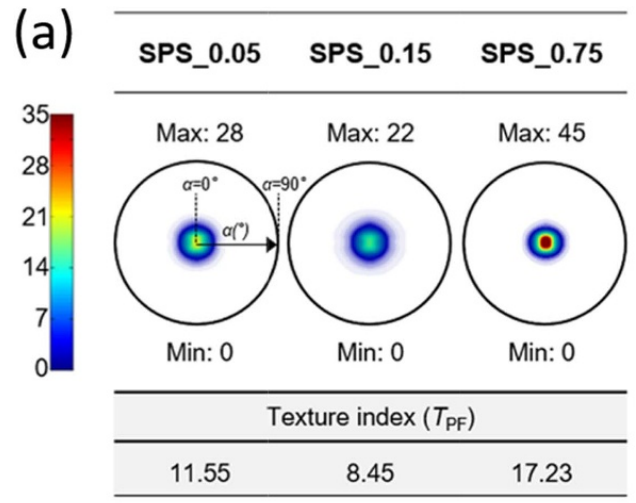

(b)

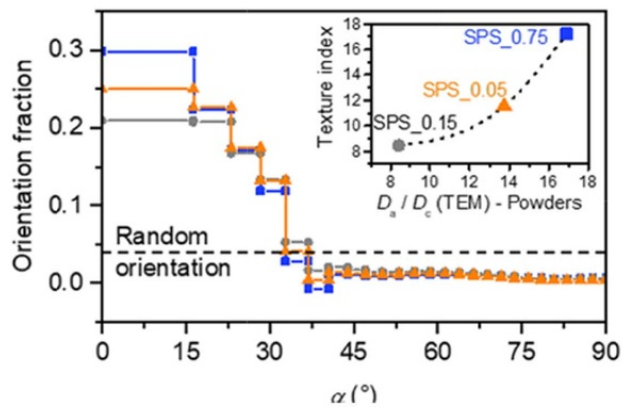

(c)
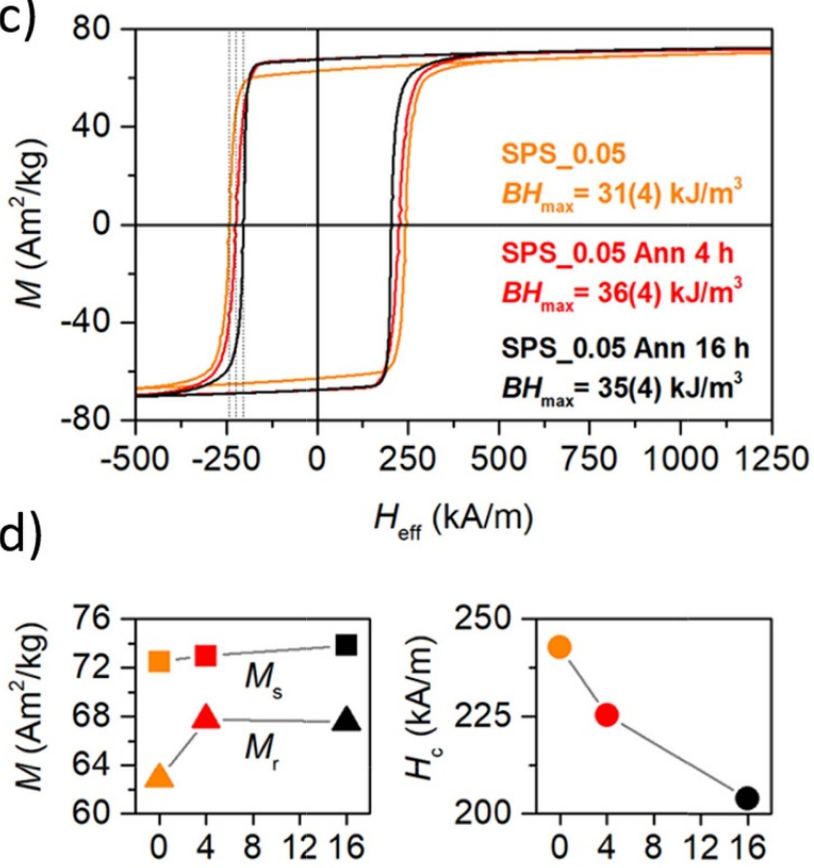

Annealing time (h)

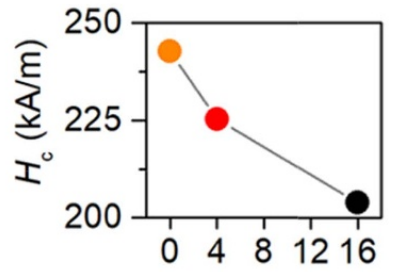

Annealing time (h)

Figure 5. Properties of the pellet obtained by SPS of Sr-ferrite nanoplatelets SPS_XX, where XX denotes the initial iron molar concentration: (a) reconstructed (001) x-ray pole figures and texture index of SPS_005, SPS_015 and SPS_075; the texture index of a randomly oriented sample is 1.0; (b) fraction of oriented crystallites as a function of the $\alpha$ angle; the inset depicts the dependence of the texture index on the aspect ratio of the starting nanopowders; (c) hysteresis loop of SPS_005 pellet before (orange line) and after annealing at $850{ }^{\circ} \mathrm{C}$ for $4 \mathrm{~h}$ (red) and $16 \mathrm{~h}$ (black); (d) saturation magnetization, $M_{\mathrm{S}}$, remanence, $M_{\mathrm{R}}$, and coercivity, $H_{\mathrm{C}}$, variation with the annealing time. Reprinted (adapted) with permission from [62]. Copyright 2018 American Chemical Society.

all cases the magnetic properties were far from those required for the realization of permanent magnets. The same observation was reported by Al-Hwaita and coworkers who systematically investigated micrometric $\mathrm{Ba}_{x} \mathrm{Sr}_{1-x} \mathrm{Fe}_{12} \mathrm{O}_{19}$ ferrites prepared by solid state reaction and sol-gel methods and found that replacing $\mathrm{Ba}$ with $\mathrm{Sr}$ was not the only critical parameter for improving the magnetic properties, but other parameters as grain size and phase purity were similarly crucial [102].

Water-in-oil microemulsions have also been applied to prepare single domain M-type hexaferrite particles. Koutzarova and coworkers used a reverse microemulsion containing cetyltrimethylammonium bromide as cationic surfactant, $n$-butanol as co-surfactant, n-hexanol as a continuous oil phase, and water to obtain, after a calcination step at $900{ }^{\circ} \mathrm{C}$, pure Baferrite nanoparticles with average size $280 \mathrm{~nm}$ [103]. Most of the particles were found to have an almost perfect hexagonal shape with average aspect ratio diagonal/thickness of 7.7 , although the smallest ones (ca. $100 \mathrm{~nm}$ ) exhibited spheroidal or irregular shape, indicating that the growth process towards the most energetically favored hexagonal shape is incomplete. However, the particles exhibited low saturation magnetization of $48.9 \mathrm{~A} \mathrm{~m}^{2} \mathrm{~kg}^{-1}$ and coercivity, $240 \mathrm{kA} \mathrm{m}^{-1}$ for both temperatures, which was attributed to the presence of small nanoparticles and the incomplete filling of the bipyramidal $2 b$ sites by $\mathrm{Fe}^{3+}$ ions.

Low temperature solid state reaction represents a simple and efficient alternative method for the preparation of strontium ferrite nanoparticles. Kiani et al [72] reported that sintering at $750{ }^{\circ} \mathrm{C}$ a powder obtained by mixing and grinding the corresponding metal chlorides and sodium hydroxide, yields pure, highly crystalline, hexagonally shaped SFO nanoparticles, with size ranging from 30 to $150 \mathrm{~nm}$. The control of the $\mathrm{Na}^{+} / \mathrm{Sr}^{2+}$ and $\mathrm{Fe}^{3+} / \mathrm{Sr}^{2+}$ molar ratios was found to be essential to tune the size and morphology of the particles and avoid the formation of impurity phases as haematite and $\mathrm{SrFe}_{2} \mathrm{O}_{4}$. The as obtained nanoparticles exhibited high coercivity $\left(412 \mathrm{kA} \mathrm{m}^{-1} ; 0.52 \mathrm{~T}\right)$, saturation magnetization of $58.7 \mathrm{~A} \mathrm{~m}^{2} \mathrm{~kg}^{-1}$ and reduced remnant magnetization, $M_{\mathrm{R}} / M_{\mathrm{S}}=0.49$, close to the theoretical value for randomly oriented single domain nanoparticles. Following a similar procedure some of us obtained SFO nanoparticles with a platelet morphology and average diameter ca. $70 \mathrm{~nm}$. The nanoparticles displayed extremely good magnetic properties with $\sigma_{\mathrm{S}}=68 \mathrm{~A} \mathrm{~m}^{2} \mathrm{~kg}^{-1}$ and a coercive field of $525 \mathrm{kA} \mathrm{m}^{-1}$, as shown in figure 6 [104]. Since the proposed method is very simple, solvent-free, uses low cost reactants, and leads to high yield, it is very promising for the large-scale industrial production of nanoscale M-hexaferrite particles.

\subsection{D nanostructures}

One-dimensional magnetic nanostructures also received considerable attention since the high aspect ratio and the large surface may provide a remarkable contribution to the total 

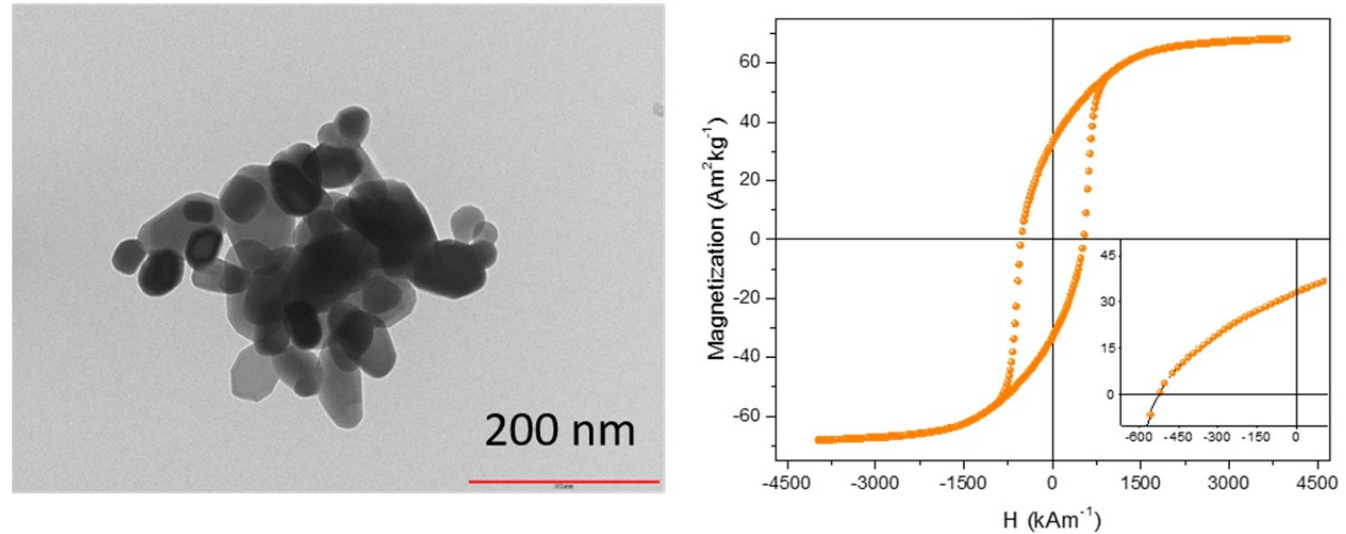

Figure 6. Representative bright field TEM image (left) and hysteresis loop (right) of M-type Sr-ferrite nanoparticles prepared according to the procedure described in [72]. The inset is the enlargement of the low filed loop in the II quadrant. Reproduced from [104]. () IOP Publishing Ltd. All rights reserved.
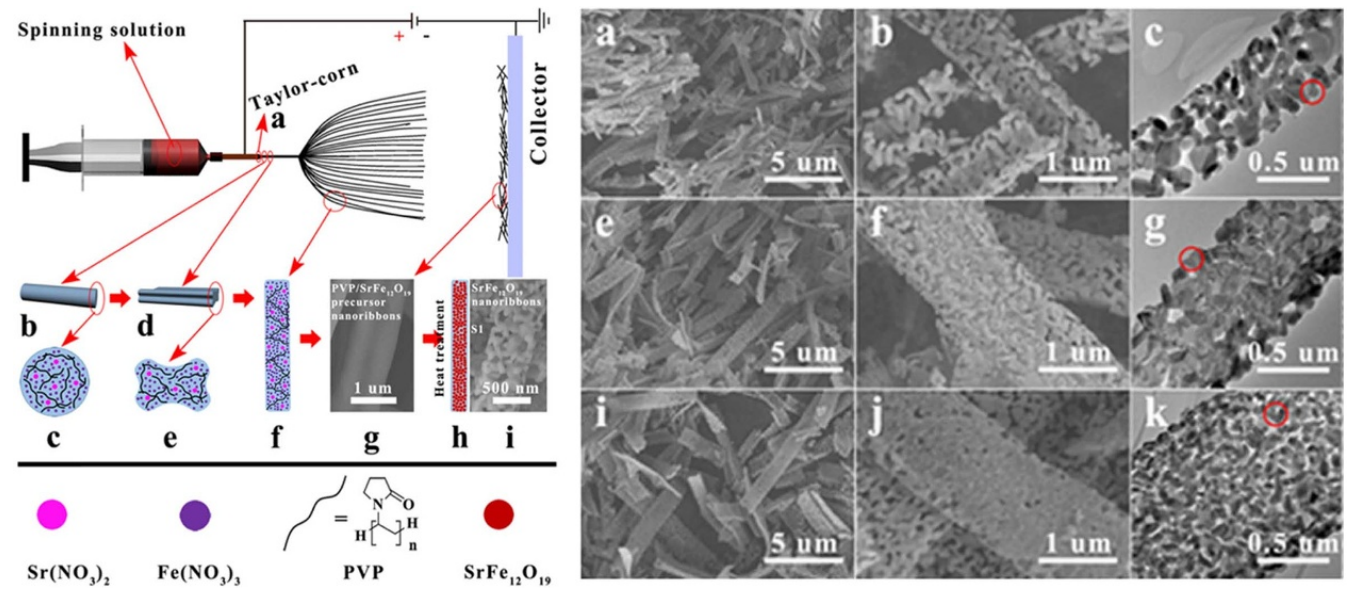

Figure 7. Left: schematic diagram of the mechanism of formation of $\mathrm{Sr}$-ferrite nanoribbons by the polymer-sol assisted single-spinneret electrospinning route followed by heat treatment in air at $800^{\circ} \mathrm{C}$ for $2 \mathrm{~h}$; Right: representative field emission scanning electron microscopy (first and second columns) and transmission electron microscopy (third column) images of three samples prepared from spinning solutions with PVP concentrations of $8.5 \%$ (a)-(c), 10.4\% (e)-(j) and 12.3\% (i)-(k), respectively. Reproduced from [63]. CC BY 4.0.

magnetic anisotropy, strongly modifying the coercivity. For example, an infinitely long chain of stacked platelets theoretically can have enough shape anisotropy to increase coercivity up to $1000 \mathrm{kA} \mathrm{m}^{-1}$ [105]. In this context, several attempts have been carried out to realize mono-dimensional hexagonal M-hexaferrite structures and, among the methods developed so far electrospinning has been established as one of the most promising. SFO ribbons with average width in the submicrometric range, from $484 \pm 15$ to $1099 \pm 18 \mathrm{~nm}$, were successfully fabricated via a polyvinylpyrrolidone sol-gel assisted electrospinning method followed by heat treatment in air [63]. The nanoribbons, shown in figure 7 were formed by the assembling of smaller, strongly interacting ferrite nanoparticles whose average size decreased with increasing the width of the nanoribbon (from $131 \pm 3 \mathrm{~nm}$ to $76 \pm 3 \mathrm{~nm}$ ). Both the width of the ribbon and the size of the constituent nanoparticles could be simply tuned through the polymer concentration in the spinning solution. The peculiar ribbons structure together with the high crystallinity of the nano- particles granted for high coercive fields and good $M_{\mathrm{S}}$ and $M_{\mathrm{R}}$ values $\left(H_{\mathrm{C}}=582 \mathrm{kA} \mathrm{m}^{-1}, \sigma_{\mathrm{S}}=67.9 \mathrm{~A} \mathrm{~m}^{2} \mathrm{~kg}^{-1}\right.$ and $\sigma_{\mathrm{R}}=37.3 \mathrm{~A} \mathrm{~m}^{2} \mathrm{~kg}^{-1}$ for the best sample).

BFO nanofibers of average length $1.5 \mu \mathrm{m}$ consisting of randomly oriented, single nanoparticles of average diameter $70 \mathrm{~nm}$, stacked along the nanofiber axis, were also prepared by electrospinning a homogeneous PVP/barium nitrate/iron nitrate precursor sol-gel solution, followed by calcination at $800{ }^{\circ} \mathrm{C}$ [64]. The authors investigated the growth mechanism and proposed a model which involves a series of phase transformations occurring at increasing temperatures, with $\mathrm{Fe}_{2} \mathrm{O}_{3}, \mathrm{BaO}, \mathrm{BaCO}_{3}$ and $\mathrm{BaFe}_{2} \mathrm{O}_{4}$ as intermediate species (figure 8 ). The resulting nanofibers showed at room temperature $\sigma_{\mathrm{S}}=71.5 \mathrm{~A} \mathrm{~m}^{2} \mathrm{~kg}^{-1}$, reduced remanence of ca. 0.5 and $H_{\mathrm{C}}=473 \mathrm{kA} \mathrm{m}^{-1}$, lower than the theoretical expected value. Interestingly, the magnetization reversal mechanism of the BFO single-particle-chain nanofibers was theoretically analyzed and found to fit a curling model. 


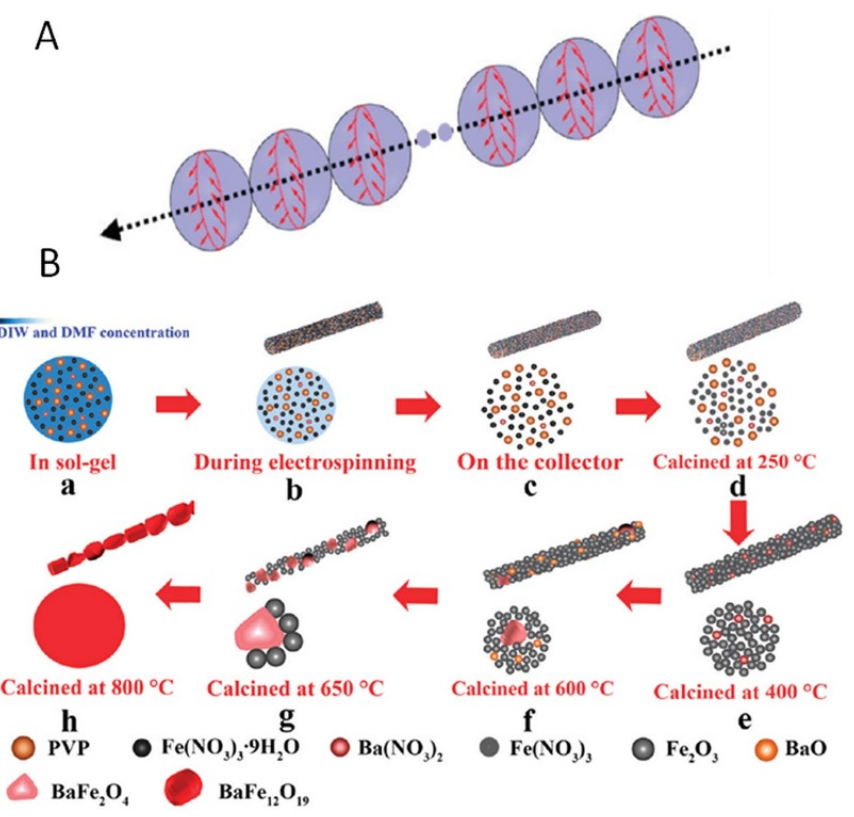

Figure 8. Schematic description of the reversal mechanism ((A), top) and of the formation of the BFO single-particle-chain nanofibers ((B), bottom). Reprinted with permission from [64]. Copyright 2012 American Chemical Society.

On the other hand, Liu and coworkers used a combined approach based on electrostatic spinning and high-temperature heating treatment, to prepare, by properly varying the experimental conditions, BFO hexagonal ferrites with different geometry (nanowire, nanoribbon and nanotube) [106]. The comparison of the magnetic properties of the samples demonstrated that while the nanostructure had similar saturation magnetization (46-49 $\mathrm{A} \mathrm{m}^{2} \mathrm{~kg}^{-1}$ ), the coercivity was largely dependent on the morphology, increasing from nanowires $\left(190 \mathrm{kA} \mathrm{m}^{-1}\right)$ to nanoribbons $\left(224 \mathrm{kA} \mathrm{m}^{-1}\right)$ and nanotubes (259 $\mathrm{kA} \mathrm{m}^{-1}$ ). Despite the obtained coercivities are lower than those of many other hexagonal $\mathrm{Ba}$-ferrites, this work nicely demonstrates the versatility of the technique for the fabrication of material with controlled properties for different applications.

\section{Controlling doping}

The structure of the M-hexaferrites suggests a direct way to improve their magnetic properties by substituting some of the cations of specific sites of the magnetoplumbite structure. The progress in this subject up to the early 80 s was reviewed by Kojima [42]. However, there was a lack of reviews in the field between that work until the recent overviews by Pullar [66], Mahmood [9], and Lisjak et al [18]. Considering this large number of studies, here we will select and discuss the works reporting larger values of the magnetization, of the coercive field, or of the anisotropy field, than those of the best commercial hexaferrite magnets $\left(\sigma_{\mathrm{S}}=70 \mathrm{~A} \mathrm{~m}^{2} \mathrm{~kg}^{-1}\right.$, $H_{\mathrm{C}} \geqslant 398 \mathrm{kA} \mathrm{m}^{-1}, \mu_{0} H_{\mathrm{C}}=0.5 \mathrm{~T}$, and $H_{\mathrm{A}}=1.43 \mathrm{MA} \mathrm{m}^{-1}$, $\left.\mu_{0} H_{\mathrm{A}}=1.8 \mathrm{~T}\right)$.
The doping of the M-type ferrites is in general designed to affect the intrinsic magnetic structure of this magnetoplumbite crystal in which magnetic properties are determined by the occupancy of five sites and their magnetic coupling through oxygen-driven superexchange interactions. Such design should take into account that the spin and orbital moments of the cations depend on the site and charge distribution [107], through the spin configuration (high spin, low or intermediate spin) that determines the net magnetic moment and the local anisotropy of an ion. In this framework, different scenarios of substitution can be considered. One is to change the total magnetization. Another is to enhance the magnetocrystalline anisotropy by increasing locally the magnetic anisotropy due to the contribution of the orbital moment or the change of the crystal and chemical structures. In general, the substitution of all the ions that are present in the structure has been explored $[9,42,66]$. However, the most common approach considers the substitution of cations, although changing even the oxygen anions have been tried [42]. We briefly enumerate the rationale for changing the cations:

- Substitution of Fe with non magnetic cations. An increase of the magnetization could be obtained if non-magnetic atoms like $\mathrm{Al}^{3+}, \mathrm{Ti}^{2+}$ substitute $\mathrm{Fe}$ in the spin-down sites giving an increase of the net moment. However this also leads to a weakening of the exchange interactions that can reduce the Curie temperature, reducing the room temperature magnetization, or weakening or modifying the anisotropy symmetry [42, 108-110].

- Substitution of Fe with magnetic ions. For the first goal, $\mathrm{Fe}^{3+}$ and $\mathrm{Mn}^{2+}$ are the $3 \mathrm{~d}$ transition metal ions with the largest magnetic moments (figure 2), and heavy rare earth ions [107, 111] have even larger magnetic moments. Hence the doping with other $3 \mathrm{~d}$ metals could increase the total magnetization if ions occupy the spin down sites. Regarding the increase of the magnetocrystalline anisotropy, the substitution of ions with spin orbit contribution could be the main strategy. However, except in some cases [107, 112], the high symmetry of the octahedral and tetrahedral sites quenches the orbital moment. Hence the occupancy in the bipyramidal $2 \mathrm{~b}$ site is the target. In addition, the anisotropy that finally results in the occupancy of any site [113], analysed in terms of the single ion model, depends on the spin orbit coupling and electronic configuration of the cation and the link in the charge distribution of the site. For example, $\mathrm{Co}^{2+}$ occupancy in CoTi-SFO changes the anisotropy from uniaxial to planar giving a ferrite with soft magnetic properties. In general, the contribution of the higher symmetry sites to the anisotropy cannot be neglected [108].

- Substitution of $\mathrm{Ba}^{2+}$ or $\mathrm{Sr}^{2+}$ ions. Non magnetic $\mathrm{La}^{2+}$, $\mathrm{Ca}^{2+}$, or $\mathrm{Ag}^{+}$ions, or rare earth ions $\mathrm{RE}^{3+}$ [114] or others modify the crystal structure, thus modifying the exchange interactions and the magnetic anisotropy. For example, the slightly larger magnetic anisotropy of SFO $\left(K_{1}=35 \mathrm{~kJ} \mathrm{~m}^{-3}\right)$ compared with BFO $\left(K_{1}=32.5 \mathrm{~kJ} \mathrm{~m}^{-3}\right)$ is correlated with the smaller size of $\mathrm{Sr}^{2+}(1.13 \AA)$ compared with $\mathrm{Ba}^{2+}(1.35 \AA)$. This is explained because the smaller cell size implies a decreased $\mathrm{Fe}-\mathrm{O}$ distance in the 
$2 \mathrm{~b}$ sites, increasing the crystal field and zero-field splitting of $\mathrm{Fe}^{3+}$ and the magnetic anisotropy. As can be seen in figure 1(a), the $4 \mathrm{f}_{2}$ and $2 \mathrm{~b}$ sites have three $\mathrm{Sr}^{2+}$ ions in their vicinity. Thus the substitution of $\mathrm{Ba}^{2+} / \mathrm{Sr}^{2+}$ ions by others induces a change of both the symmetry and the charge density around these sites [115].

Often the substitution of the ions is analyzed in terms of their charge, by their nominal oxidation state: divalent, trivalent or others $[9,66]$. The selected ion can affect the synthesis and sintering processes, but the main influence is due to the required charge neutrality of the resulting hexaferrite. The doping with divalent cations or other multivalence ions can lead to the presence of $\mathrm{Fe}^{2+}$ instead of $\mathrm{Fe}^{3+}$ to maintain the charge neutrality. $\mathrm{Fe}^{2+}$ ions, in addition to contributing to the anisotropy, provide a possible charge transfer mechanism that can lead to an undesired increase of the electrical and thermal conductivity that are key features of the hexaferrites for many magnetic applications.

The main result can be obtained from the literature is that the changes of the properties induced by the doping are extremely difficult to predict and understand. In the following, the properties of LaCo hexaferrites, the only doped ferrite present in the market, are discussed first. Then the recent results are split in works that aim to increase the saturation magnetization and ones that try to increase $\mathrm{Hc}$ with features above the commercial ones.

\subsection{LaCo-SFO magnets}

The only successful story of doping hard hexaferrites is that of lanthanum and cobalt doping of SFO. Commercial magnets are produced by Hitachi [6] and TDK [116]. Considering the TDK catalogue, strontium ferrite magnets exhibit a maximum $B_{\mathrm{R}}$ up to $0.45 \mathrm{~T}$ and intrinsic $H_{\mathrm{C}}$ up to $319 \mathrm{kA} \mathrm{m}^{-1}$ while LaCo-doped ferrites reach a $B_{\mathrm{R}}$ of $0.47 \mathrm{~T}$ and an intrinsic $H_{\mathrm{C}}$ of $343 \mathrm{kA} \mathrm{m}^{-1}$, being the maximum $(\mathrm{BH})_{\max }$ of $38 \mathrm{~kJ} \mathrm{~m}^{-3}$ for the first and $44 \mathrm{~kJ} \mathrm{~m}^{-3}$ for the doped ferrites. Moreover, they keep low electrical and thermal conductivities, positive temperature $H_{\mathrm{C}}$ coefficient $\left(0.1-0.4 \% \mathrm{~K}^{-1}\right)$, and $T_{\mathrm{C}}$ (around $430^{\circ} \mathrm{C}-$ $460{ }^{\circ} \mathrm{C}$ ). Early work was performed by Yamamoto et al [117] but their properties were identified at the end of XX's century $[118,119]$. The commercial LaCo-ferrites exhibit a weak improvement of the magnetic properties, a $10 \%$ in remanence and in the $(\mathrm{BH})_{\max }$, respect to those of the state of art SFO ferrites, demonstrating the high potential in the research of alternatives to the conventional hard ferrites.

Research has focused in the composition range $0 \leqslant x \leqslant 0.4$ of $\left(\mathrm{Sr}_{x} \mathrm{La}_{1-x}\right)\left(\mathrm{Fe}_{12-x} \mathrm{Co}_{x}\right) \mathrm{O}_{19}$ where $\mathrm{La}^{3+}$ and $\mathrm{Co}^{2+}$ substitute for $\mathrm{Sr}^{2+}$ and $\mathrm{Fe}^{3+}$. Most of the studies report that a single phase magnetoplumbite structure is present in this composition range with a decreasing c-parameter while the aparameter does not vary. In general, as it can be seen in figure 9 , the $M_{\mathrm{S}}$ and $M_{\mathrm{R}}$ values increase slightly while $H_{\mathrm{C}}\left(H_{\mathrm{C}}\right.$ from the $J$ versus $H$ curves) exhibit a maximum value for a $x$ between 0.2 and 0.4 depending on the preparation method [117, 118, 120-123]. Early studies of Iida et al [121]. reported that $\mathrm{LaCo}-\mathrm{SFO}$ sintered at $1200{ }^{\circ} \mathrm{C}$ present an increase of
$H_{\mathrm{C}}$ from $319 \mathrm{kA} \mathrm{m}^{-1}$ of $383 \mathrm{kA} \mathrm{m}^{-1}$ when doping from $x=0$ to $x=0.3$. The remanence increases weakly reaching a maximum at $x=0.4$. For larger $x$ both $M_{\mathrm{R}}$ and $H_{\mathrm{C}}$ decrease. Nishio et al [123] indicate that the doping that optimizes $H_{\mathrm{C}}$ depends on the thermal treatment. Nowadays, the work of Kikuchi et al [124] reports the maximum $H_{\mathrm{C}}$ of $0.8 \mathrm{~T}$ but with a small decrease in $M_{\mathrm{s}}$. Likewise, $H_{\mathrm{A}}$ is also larger than for SFO and $\mathrm{BFO}$ and increases almost linearly with $x$ up to $x=0.4$. However, the $H_{\mathrm{A}}$ values depend on the preparation route and they go from 1.35 $\mathrm{MA} \mathrm{m}^{-1}$ [124] to $1.91 \mathrm{MA} \mathrm{m}^{-1}$ [125]. The anisotropy is described in terms of a uniaxial anisotropy with a single second order constant $K_{1}$ as in SFO. At lower temperatures, higher order anisotropy constants need to be considered. At higher temperatures, a continuous increase of the $H_{\mathrm{A}}$ is correlated to the faster temperature dependent decrease of the magnetization rather than changes in anisotropy [125].

Mössbauer spectroscopy [122, 127], and NMR [45] and Xray magnetic dichroism [128] studies indicate that the $\mathrm{Co}^{2+}$ ions occupy both $2 \mathrm{a}$ (spin up) and $4 \mathrm{f}_{2}$ (spin down) sites. The weak increase of the magnetization should indicate an almost equipartition of the Co cations between the two locations. On the other hand, the increase of the anisotropy field, even if the magnetization remains constant, is an indication of the increase of the magnetocrystalline anisotropy as reported in [126]. It can be explained by the contribution of the orbital moment of the $\mathrm{Co}^{2+}$ cations. In the case of Co-Ti hexaferrites, Co cations occupy other sites and the result is the change of the symmetry of the anisotropy and the decrease of the $H_{\mathrm{C}}$ [118]. The decrease of volume and the increase of the charge due to $\mathrm{La}^{3+}$ also stabilizes the $\mathrm{Co}^{2+}$ in the $2 \mathrm{a}$ and $4 \mathrm{f}_{2}$ sites. On the other hand, Morel et al [122] showed by Mössbauer and resistivity studies that the $\mathrm{Fe}^{2+}$ is present in powders obtained by the ceramic method. The imperfect distribution of $\mathrm{La}$ and $\mathrm{Co}$ ions could give rise to the $\mathrm{Fe}^{+3}$ cations replacement by $\mathrm{Fe}^{2+}$ ions, mainly in 2a site [126]. Also, the presence of $\mathrm{Fe}^{2+}$ cations has been demonstrated recently in single crystals $[129,130]$. However, increasing the population of $\mathrm{Fe}^{2+}$ decreases the electrical resistivity.

However, the changes in $M_{\mathrm{R}}$ and $H_{\mathrm{C}}$ have been discussed in terms of the influence of the microstructure and morphology in the reversal process $[118,119,131,132]$. Shape morphology of the particles determine intra and interparticle demagnetizing fields [133]. Typical platelet morphology of SFO leads to internal demagnetizing fields (i.e. shape anisotropy) that decreases the anisotropy field and thus the coercive field. Grossinger et al [120] explain in this way the drop of $H_{\mathrm{C}}$ above $x=2$ in this way, even if $H_{\mathrm{A}}$ increases. Another factor is the particle size distribution, with the presence of single domain vs. multi domain particles. The reversal process of single domain particles is determined by the coherent rotation modes and gives rise to a high coercivity. Nishio et al [123] calculated the single domain critical size for these oxides that is around 1 micron, similar to that of SFO. In multi domain particles, the domain reversal is dominated by domain wall motion and lower switching fields are obtained. Hence the magnetic properties of these new magnets are determined both by the changes of the magnetic structure and by microstructural features. 

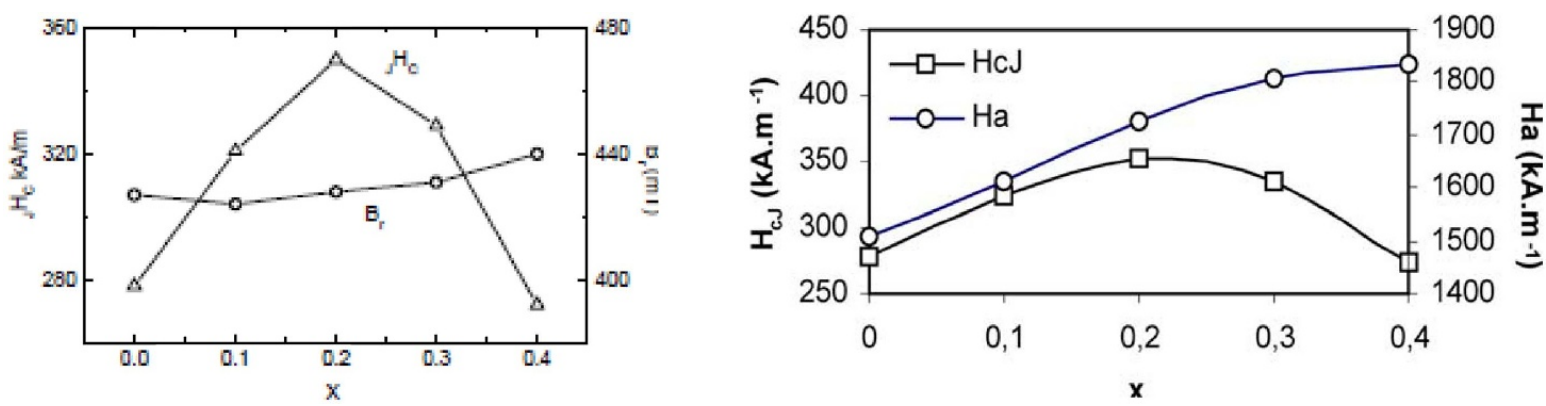

Figure 9. (Left) intrinsic coercivity $\left(\mathrm{J}_{\mathrm{C}}\right)$ and remanent induction $\left(B_{\mathrm{R}}\right)$ as a function of doping content (Reprinted from [120], Copyright 2004, with permission from Elsevier) and (Right) composition dependence of the anisotropy field $H_{\mathrm{A}}$ and ${ }_{\mathrm{J}} H_{\mathrm{C}}$ of $\mathrm{Sr}_{1-x} \mathrm{La}_{x} \mathrm{Fe}_{12-x} \mathrm{Co}_{x} \mathrm{O}_{19}$ ferrite magnets measured at room temperature (Reprinted from [126], Copyright 2004, with permission from Elsevier).

Table 1. Data of doped-ferrites with specific magnetization larger than $70 \mathrm{~A} \mathrm{~m}^{2} \mathrm{~kg}^{-1} \cdot x$ corresponds to the doping content, $H_{\mathrm{C}}$, the coercive field, and $\sigma_{\mathrm{s}}$ the specific saturation magnetization.

\begin{tabular}{|c|c|c|c|c|c|c|}
\hline Doping & Formula & Synthesis route & $x$ & $H_{\mathrm{C}}\left(\mathrm{kA} \mathrm{m}^{-1}\right)$ & $\sigma_{\mathrm{S}}\left(\mathrm{A} \mathrm{m}^{2} \mathrm{~kg}^{-1}\right)$ & Ref. \\
\hline $\mathrm{Ni}$ & $\mathrm{BaFe}_{12-x} \mathrm{Ni}_{x} \mathrm{O}_{19}$ & Sol-gel & 0.8 & 24 & 101 & [139] \\
\hline $\mathrm{Zn}, \mathrm{Ti}$ & $\mathrm{Ba} \mathrm{Fe}_{12-2 x} \mathrm{Zn}_{x} \mathrm{Ti}_{x} \mathrm{O}_{19}$ & Chemical route & 0.4 & & $110^{\mathrm{a}}$ & [140] \\
\hline $\mathrm{Zn}-\mathrm{Zr}$ & $\mathrm{SrFe}_{2-2 x} \mathrm{Zn}_{x} \mathrm{Zr}_{x} \mathrm{O}_{19}$ & Mechanochemistry & 1 & 24 & 108 & [141] \\
\hline $\mathrm{Zn}-\mathrm{Sn}$ & $\mathrm{SrFe}_{12-2 x} \mathrm{Sn}_{x} \mathrm{Zn}_{x} \mathrm{O}_{19}$ & Sol-gel & 2.5 & & 97 & [142] \\
\hline $\mathrm{Zn}-\mathrm{Ni}$ & $\mathrm{SrFe}_{12-2 x} \mathrm{Ni}_{x} \mathrm{Zn}_{x} \mathrm{O}_{19}$ & Sol-gel auto combustion method & & 160 & 99 & [143] \\
\hline $\mathrm{Zn}-\mathrm{Sb}, \mathrm{V}, \mathrm{Nb}$ & $\mathrm{SrFe}_{12-2 x} \mathrm{Y}_{x} \mathrm{Zn}_{x} \mathrm{O}_{19}$ & Ceramics & 0.2 & 238.7 & 75 & [144] \\
\hline $\mathrm{Zn}, \mathrm{La}$ & $\mathrm{ZnLa}-\mathrm{SFO}$ & Ceramics & & 191 & 74 & [145] \\
\hline $\mathrm{Al}, \mathrm{Cr}$ & $\mathrm{BaFe}_{12-2 x} \mathrm{Al}_{x} \mathrm{Cr}_{x} \mathrm{O}_{19}$ & Sol-gel auto combustion method & 4 & 318 & 88 & [146] \\
\hline
\end{tabular}

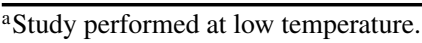

Nowadays, several investigations consider the improvement of these LaCo-hexaferrites, mainly using Ca-doping using different synthesis methods [134-137]. Chen et al [136] obtained $\mathrm{Ca}$ doped LaCo-ferrites employing microwave calcination with $H_{\mathrm{C}}$ up to $397.9 \mathrm{kA} \mathrm{m}^{-1}$ and $B_{\mathrm{R}}$ of $0.44 \mathrm{~T}$. Du et al [138] used doping with $\mathrm{Al}^{3+}$. In these ferrites the magnetization decreases and the $H_{\mathrm{c}}$ increases linearly with the doping, reaching a $H_{\mathrm{C}}$ of $716.2 \mathrm{kA} \mathrm{m}^{-1}$ and specific magnetization of around $50 \mathrm{~A} \mathrm{~m}^{2} \mathrm{~kg}^{-1}$.

\subsection{Doping for increasing the magnetization}

Several approaches have been attempted to increase the magnetization of M-hexaferrites by doping: substitution with a single non-magnetic element, substitution with a single magnetic element, or substitution with several (magnetic and non-magnetic elements). Table 1 summarizes the studies in which the specific magnetizations above the threshold of $70 \mathrm{~A} \mathrm{~m}^{2} \mathrm{~kg}^{-1}$ of the high quality SFO and BFO.

$A b$ initio calculations by Dixit et al [147] predicted that $\mathrm{Bi}$, $\mathrm{Sb}, \mathrm{Sn}$, and $\mathrm{Sc}$ ions can increase the magnetization. However, until now, no experimental result has obtained an increase in the magnetization. The case of $\mathrm{Al}^{3+}$ has been extensively studied, but without success. For a single magnetic cation the only work that reports an improvement is Wang et al [139], who studied the synthesis of magnetic Ni-doped BFO grown by sol-gel. They found a specific magnetization of $101 \mathrm{~A} \mathrm{~m}^{2} \mathrm{~kg}^{-1}$ for $x=0.8$. The authors suggest the origin is the occupancy of $4 \mathrm{f}_{2}$ spin down sites with $\mathrm{Ni}^{2+}$ coupled to the presence of $\mathrm{Fe}^{2+}$ in $4 \mathrm{f}_{1}$ and $4 \mathrm{f}_{2}$ sites.

More promising is the approach of doping with multiple cations with a general formula $(\mathrm{Sr}) \mathrm{BaFe}_{12-2 x} \mathrm{Y}_{x} \mathrm{Z}_{x} \mathrm{O}_{19}$ where $\mathrm{Y}, \mathrm{Z}$, are different cations. Often the substitution is performed with non magnetic ions (paramagnetic or diamagnetic) and there is substitution of $\mathrm{Fe}^{3+}$ by equal amounts of divalent and tetravalent cations to assure charge neutrality. Larger specific magnetizations were observed by $\mathrm{Zn}^{2+}$ doping combined with other diamagnetic ions, Ti [140], Zr [141], Sn [142], Nb [144], V [144], Sb [144], La [145] or with paramagnetic Ni cations [139] that gives rise to ferrites with $\sigma_{\mathrm{S}}$ between 75 and $110 \mathrm{~A} \mathrm{~m}^{2} \mathrm{~kg}^{-1}$. Also the double doping of BFO with diamagnetic $\mathrm{Al}^{3+}$ and paramagnetic $\mathrm{Cr}^{3+}$ cations [146] gives rise to a ferrite with a maximum specific magnetization of $88 \mathrm{~A} \mathrm{~m}^{2} \mathrm{~kg}^{-1}$ for $x=0.4$.

In general, it was observed that the net magnetization and the specific magnetization do not exhibit monotonic trends with the doping. Wartewig et al [140] show that in $\mathrm{Zn}^{2+}$ and $\mathrm{Ti}^{4+}$ doped BFO synthesized by coprecipitation the magnetization at low temperatures first increases and then decreases above a doping of 0.4 as can be seen in figure 10 (left). The authors suggest that for small doping, $\mathrm{Zn}^{2+}$ occupies the tetragonal $4 \mathrm{f}_{1}$ sites while Ti cations go to the octahedral spin down $4 \mathrm{f}_{2}$ and spin up 12k sites and after $x>1.2$ a small amount of $\mathrm{Zn}$ is placed at the $2 \mathrm{~b}$ site and of Ti at the $2 \mathrm{a}$ site. At room temperature, Abdellhi et al [141] observed the similar doping dependence in mechanical milling $\mathrm{Zn}-\mathrm{Zr}-\mathrm{SFO}$ microparticles, with a maximum magnetization of $108 \mathrm{~A} \mathrm{~m}^{2} \mathrm{~kg}^{-1}$ 
for $x=1\left(\mathrm{SrFe}_{10} \mathrm{ZnZrO}_{19}\right)$. Li et al [148] also reports the presence of a maximum in the magnetization but for lower $\mathrm{Zr}$ $\mathrm{Zn}$ content and only at low temperatures. Ghasemi et al [142] have doped BFO with $\mathrm{Sn}^{4+}$ and $\mathrm{Zn}^{2+}$ synthesized by sol-gel $\left(\mathrm{SrFe}_{12-2 x} \mathrm{Sn}_{x} \mathrm{Zn}_{x} \mathrm{O}_{19}\right)$. An increasing doping dependence of the magnetization is found, with a maximum of $87 \mathrm{~A} \mathrm{~m}^{2} \mathrm{~kg}^{-1}$ at $x=2.5$, as can be seen in figure 10 (right). Mössbauer studies indicate that both $\mathrm{Sn}$ and $\mathrm{Zn}$ cations occupy spin down $4 \mathrm{f}_{2}$ and spin up $2 \mathrm{~b}$ sites. In contrast, Fang et al [149] observed a continuous decrease of the magnetization using co-precipitation. Widyastuti et al [143] report the combination of $\mathrm{Ni}$ and $\mathrm{Zn}$ substituted BFO synthesized by sol-gel auto combustion method and further annealing. They obtain $94 \mathrm{Am}^{2} \mathrm{~kg}^{-1}$ in doped BFO with $2 \%$ wt Ni and $4 \%$ wt of $\mathrm{Zn}$. Also, Sapoleva et al [144] report the same trend in $\mathrm{ZSb}, \mathrm{ZnNb}$ and $\mathrm{ZnV}$ doped SFO.

The enhancement of the magnetization has been observed also in other compositions. Trudel et al [146] investigated the double substitution of $\mathrm{Al}^{+}$and $\mathrm{Cr}^{3+}$ cations in $\mathrm{BaFe}_{12-2 x} \mathrm{Al}_{x} \mathrm{Cr}_{x} \mathrm{O}_{19}$ obtained by auto combustion sol-gel. For $x=0.4$ the doped ferrite exhibits a specific magnetization of $88 \mathrm{~A} \mathrm{~m}^{2} \mathrm{~kg}^{-1}$, larger than the corresponding BFO (81 $\mathrm{A} \mathrm{m}^{2} \mathrm{~kg}^{-1}$ ) and similar mass density. The improvement of the magnetization does not follow a linear dependence. The authors propose that the increase of the magnetization takes place when $\mathrm{Cr}^{3+}$ begins to occupy the $4 \mathrm{f}_{2}$ site. Bsoul et al investigated doping with non magnetic $\mathrm{Ti}^{2+}$ and $\mathrm{Ru}^{4+}$ cations of BFO [150] and SFO [151]. In the two oxides a broad maximum in the magnetization versus the doping is observed. The specific magnetizations with substitution of $x=0.2$ reach up to $10 \%$ respect to values of around $60 \mathrm{~A} \mathrm{~m}^{2} \mathrm{~kg}^{-1}$ for both undoped oxides. Mössbauer spectroscopy studies reveal that $\mathrm{Ti}^{2+}$ and $\mathrm{Ru}^{4+}$ ions substitute $\mathrm{Fe}^{3+}$ ions at both the spin down $4 \mathrm{f}_{2}$ and $4 \mathrm{f}_{1}$ sites and the spin up $2 \mathrm{a}$ and $2 \mathrm{~b}$ sites, for $x$ values up to 0.2 and at the $12 \mathrm{k}$ site for $x>0.2$.

Considering the mentioned results it appears that two-ion doping, mostly performed with non magnetic ions, allows to increase the magnetization in a certain doping range above which the magnetization decreases. In most of the discussed cases, cations occupy the two spin-down sites before reaching the maximum in the magnetization, while for higher doping the cations begin to occupy the spin-up sites giving rise to the reduction of the magnetization. The decrease of the magnetization is also related to the weakening of the superexchange interactions between the different sites due the presence of a large number of nonmagnetic cations in the spin down sites. This is also expected to be correlated with a decrease of the Curie temperature, although this point has not been investigated in the mentioned studies. However, as a rule the cation site distribution depends on the chemical process used to grow the material, as demonstrated for example by the magnetic properties of ZnTi [140, 152] and ZnZr [141, 148] doped hexaferrites.

A crucial point is that in all the previous cases reported $H_{\mathrm{C}}$ is reduced by doping. This is explained as in most cases the doping involves non-magnetic ions that weaken the magnetic order. As can be seen in table 1 ferrites with $\sigma_{\mathrm{s}}>100 \mathrm{~A} \mathrm{~m}^{2} \mathrm{~kg}^{-1}$ cannot be considered for hard magnets. The ferrites with $\sigma_{\mathrm{S}}<100 \mathrm{~A} \mathrm{~m}^{2} \mathrm{~kg}^{-1}$ (22-24) exhibit $H_{\mathrm{c}}>159 \mathrm{kA} \mathrm{m}^{-1}$ similar to those of standard hard hexaferrites. The only exception is the work of Trudel et al [146] in AlCr-BFO. For $x=0.4$ the doped ferrite exhibits both a larger specific magnetization $\left(88 \mathrm{~A} \mathrm{~m}^{2} \mathrm{~kg}^{-1}\right.$ ) and a coercive field $\left(318 \mathrm{kA} \mathrm{m}^{-1}\right)$ than the corresponding magnetization (81 $\left.\mathrm{A} \mathrm{m}^{2} \mathrm{~kg}^{-1}\right)$ and $H_{\mathrm{C}}\left(127 \mathrm{kA} \mathrm{m}^{-1}\right)$ of BFO. The authors explain this increase due to the smaller particle size of the doped ferrites and the consequent increase of the coercivity by the single domain behavior of these particles.

\subsection{Doping ferrites with high coercive field and the anisotropy}

Given that most works that attempted to increase the magnetization reduced the anisotropy, we consider now works that have increased the latter. There is a large number of studies that report increases of $\mathrm{Hc}$ of M-hexaferrites by comparing the effect of different cations [108, 153, 154]. In this review, the discussion will be focused on selected studies that report materials with a coercive field larger than those of the best commercial SFO and BFO magnets, i.e. above of $400 \mathrm{kA} \mathrm{m}^{-1}$ $(\sim 0.5 \mathrm{~T})$. The main properties of the selected works are summarized in the table 2 .

We first consider single doping. Theoretical calculation performed by Dixit et al [147] conclude that doping with P, $\mathrm{Co}, \mathrm{Al}, \mathrm{Ga}$, and Ti cations should increase the anisotropy constant and/or anisotropy field. The Al-doped ferrites are particularly interesting as in several cases [155-157], they exhibit $H_{\mathrm{C}}$ and induction magnetizations larger than those of $\mathrm{NdFeB}$ $\left(H_{\mathrm{C}} \sim 1.19 \mathrm{MA} \mathrm{m}^{-1}, 1.5 \mathrm{~T}\right.$, and $\left.\mu_{0} M_{\mathrm{S}}=1.6 \mathrm{~T}\right)$. Hence these materials will not be demagnetized by the stray field generated by the NdFeB magnets and can be included in magnetic designs in which RE magnets are present. In addition, as can be seen in figure 11 , the doping dependence of $H_{\mathrm{C}}$ exhibits peak variation which maximum $H_{\mathrm{C}}$ corresponds to different Al-doping, $x$, depending on the synthesis and treatment processes [155, 157, 159]. However all the works in table 2 and others [108, 154, 169-171] report that Al-SFO exhibits common features with the doping. First, the structure volume decreases as the $\mathrm{Al}$ contains increases remaining c/a ratio almost unchanged. This is expected considering the small ionic radius of $\mathrm{Al}^{3+}(0.5 \AA)$ in comparison with the $\mathrm{Fe}^{3+}(0.64 \AA)$. Second, the doping gives rise to a corresponding decreasing of the magnetization as well the $T_{\mathrm{C}}$. Most of the works discuss the decreasing of the magnetization in terms of the occupancy of the spin up $2 \mathrm{a}$ and $12 \mathrm{k}$ sites by non magnetic $\mathrm{Al}^{3+}$ cations $[108,159,160]$ even though it could be due also to the presence of secondary phases. Theoretical studies by Dixit et al [171] confirm the preferential occupancy of $\mathrm{Al}$ in those sites. The occupancy of the spin down $4 \mathrm{f}$ site has been also reported [154]. The occupancy by non magnetic ions also weakens the super-exchange interactions between the Fe ions that cause the decreasing of $T_{\mathrm{C}}$. This could cause the spin canting or the change of the anisotropy structure or strength. Regarding the anisotropy, the $H_{\mathrm{A}}$ of Al-doped ferrites was measured in single crystal [172]. A maximum $H_{\mathrm{A}}$ of 

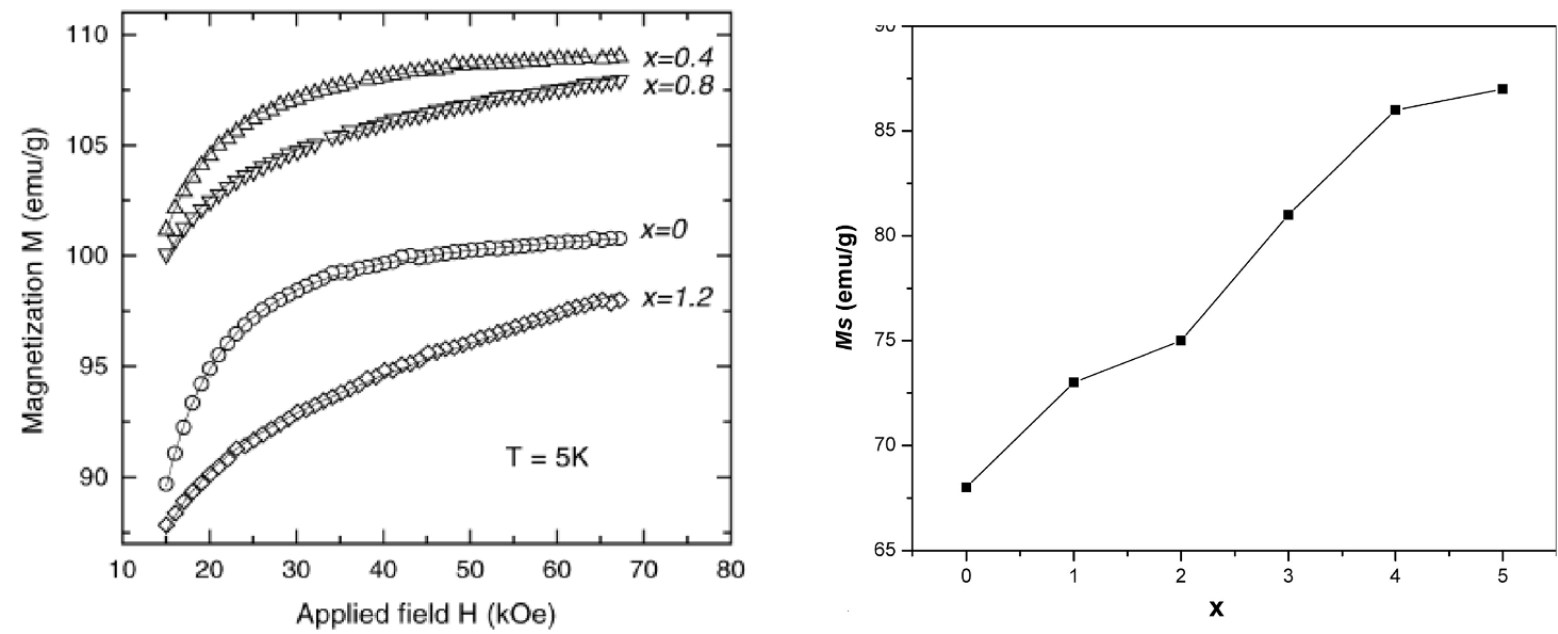

Figure 10. Left. Magnetization as a function of applied field at temperature of $5 \mathrm{~K}$ for $\mathrm{BaFe}_{12}{ }_{2 x} \mathrm{Zn}_{x} \mathrm{Ti}_{x} \mathrm{O}_{19}$ (Reprinted from [140], Copyright 1999, with permission from Elsevier). Right. Dependence of the $M_{\mathrm{S}}$ from substitution amount $x$ for $\mathrm{SrFe}_{12-2 x}\left(\mathrm{Sb}_{0.5} \mathrm{Zn}_{0.5}\right)_{x} \mathrm{O}_{19}$ (Reprinted from [142], with the permission of AIP Publishing).

Table 2. Data of doped-ferrites with $H_{\mathrm{c}}>0.5$ T. $x$ corresponds to the doping content with the maximum specific magnetization, $H_{\mathrm{C}}$, the coercive field, and $\sigma_{\mathrm{S}}$ the specific saturation magnetization. with the maximum specific magnetization.

\begin{tabular}{lllcrrr}
\hline Doping & Formula & Synthesis route & $x$ & $H_{\mathrm{C}}\left(\mathrm{MA} \mathrm{m}^{-1}\right)$ & $\sigma_{\mathrm{S}}\left(\mathrm{A} \mathrm{m}^{2} \mathrm{~kg}^{-1}\right)$ & $\mathrm{Ref}$ \\
\hline $\mathrm{Al}$ & $\mathrm{SrFe}_{12-x} \mathrm{Al}_{x} \mathrm{O}_{19}$ & Auto-combustion & 1.5 & 1.43 & 9 & {$[155]$} \\
& & Glycin-nitrate method & 4 & 1.39 & 7 & {$[156]$} \\
& & Glycin-nitrate method & 3 & 1.34 & 28 & {$[157]$} \\
& & Mechanochemical activation + calcination & 4 & 0.77 & 23 & {$[158]$} \\
& & Microwave assisted combustion & 1 & 0.59 & 35 & {$[159]$} \\
& & Glass vetrification & 1.4 & 0.48 & 36 & {$[160]$} \\
$\mathrm{Mn}$ & $\mathrm{SrFe}_{12-x} \mathrm{Mn}_{x} \mathrm{O}_{19}$ & Ceramics & 5 & 0.77 & 35 & {$[80]$} \\
& & Mechanosynthesis & 0.5 & 0.41 & 58 & {$[161]$} \\
$\mathrm{Cr}$ & $\mathrm{SrFe}_{12-x} \mathrm{Cr}_{x} \mathrm{O}_{19}$ & Microwave -hydrothermal & 0.3 & 0.58 & 30 & {$[162]$} \\
$\mathrm{Sm}$ & $\mathrm{SrFe}_{12-x} \mathrm{Cr}_{x} \mathrm{Sm}_{x} \mathrm{O}_{19}$ & Sol-gel & 0,1 & 0.48 & 10 & {$[163]$} \\
$\mathrm{Al}$ & $\mathrm{Ca}_{0.6} \mathrm{Sr}_{0,1} \mathrm{La}_{0,3}-\mathrm{Fe}_{12-x} \mathrm{Al}_{x} \mathrm{O}_{19}$ & Ceramics & 1.4 & 0.48 & 36 & {$[164]$} \\
$\mathrm{Ca}, \mathrm{Al}$ & $\mathrm{Sr}_{1-x} \mathrm{Ca}_{x / 12} \mathrm{Fe}_{12-x} \mathrm{Al}_{x} \mathrm{O}_{19}$ & Citrate melt autoignition method & 4 & 1.67 & 12.7 & {$[165]$} \\
& & & 5 & 2.86 & 2 & {$[166]$} \\
$\mathrm{Al}, \mathrm{Cr}$ & $\mathrm{Ca}_{0.33} \mathrm{Sr}_{0.66} \mathrm{FeFe}_{9} \mathrm{Al}_{x} \mathrm{Cr}_{4-x} \mathrm{O}_{19}$ & Sol-gel & 3.5 & 1.11 & 35 & {$[167]$} \\
$\mathrm{CrSnAl}$ & $\mathrm{SrAl}_{4}\left(\mathrm{Cr}_{0.5} \mathrm{Sn}_{0.5}\right)_{x} \mathrm{Fe}_{8-x} \mathrm{O}_{19}$ & Sol-gel auto-combustion & 0 & 1.43 & 12 & {$[168]$} \\
\hline
\end{tabular}

2.62 $\mathrm{MA} \mathrm{m}^{-1}$ is obtained in $\mathrm{SrFe}_{10} \mathrm{Al}_{2} \mathrm{O}_{19}, 1.8$ times larger than the corresponding value of SFO. However, the $\mu_{0} M_{\mathrm{S}}$ of this doped ferrite is $0.185 \mathrm{~T}$, less than the half of the SFO, what suggests a decreasing of the $K_{1}$. On the other hand, Behhera et al [170] report non monotonic but weak changes in $K_{1}$ as function of doping for $x<1$ while Dixit et al [171], through $a b$-initio calculations, also suggest small changes in $K_{1}$. Hence the large values of $H_{\mathrm{C}}$ and of $H_{\mathrm{A}}$ are explained from decreases in the magnetization (see figure 11).

Also, doping with magnetic $\mathrm{Mn}^{3+}[80,161]$ or $\mathrm{Cr}^{3+}$ $[153,154,162]$ cations has demonstrated to increase the $H_{\mathrm{c}}$ respect to the un-doped hexaferrites, which is correlated to the decrease of the magnetization. In the case of Mn cations $\left(\mathrm{Mn}^{3+}\right)$, early work of Obradors et al [173] show that the magnetic anisotropy field at low temperatures increases from 1.43 $\mathrm{MA} \mathrm{m}^{-1}$ of the SFO to $4.77 \mathrm{MA} \mathrm{m}^{-1}$ for high doping levels of $x=9$. Mn cations [80,161] occupy first the spin up $12 \mathrm{k}$ and $2 \mathrm{a}$ sites and later the $4 \mathrm{f}_{2}$ sites. Tenorio et al
[80] outlined that the $\mathrm{Mn}^{3+}$ ions occupy preferentially the 2a sites, up to the point of completely replacing Fe in those sites. If the Mn content increases further, Mn occupies first the $12 \mathrm{k}$ position and finally the $4 \mathrm{f}_{1}$ and $4 \mathrm{f}_{2}$ ones. Hence the main occupancy of spin-up sites is with $\mathrm{Mn}^{3+}$ which has a smaller magnetic moment $\left(3.5 \mu_{\mathrm{B}}\right)$ than $\mathrm{Fe}^{3+}$ that explains the decrease in magnetization. On the other hand, the same study reports that $\mu_{0} H_{\mathrm{C}}$ reaches $0.97 \mathrm{~T}$ for $x=5$ and a $\sigma_{\mathrm{S}}=35 \mathrm{~A} \mathrm{~m}^{2} \mathrm{~kg}^{-1}\left(\mu_{0} M_{\mathrm{S}}=0.18 \mathrm{~T}\right)$. The authors propose that structural microstrains lead to the increase in the magnetic anisotropy. $\mathrm{Cr}^{3+}$ doping shows similar phenomenology to $\mathrm{Mn}^{3+}$ doping. Katlakunta et al [162] reported a maximum $H_{\mathrm{C}}=580 \mathrm{kA} \mathrm{m}^{-1}$ with a $\sigma_{\mathrm{S}}=30 \mathrm{~A} \mathrm{~m}^{2} \mathrm{~kg}^{-1}$ for a doping $x=0.3$ in sintered materials obtained by microwavehydrothermal method. In the low $(x<0.5)$ doping regime the reduction of the magnetization is determined by the substitution of $\mathrm{Fe}$ at the $12 \mathrm{k}, 2 \mathrm{a}$ and $4 \mathrm{f}_{1}$ but for large doping $(x>0.4)$ also by the presence of non-magnetic impurities. 

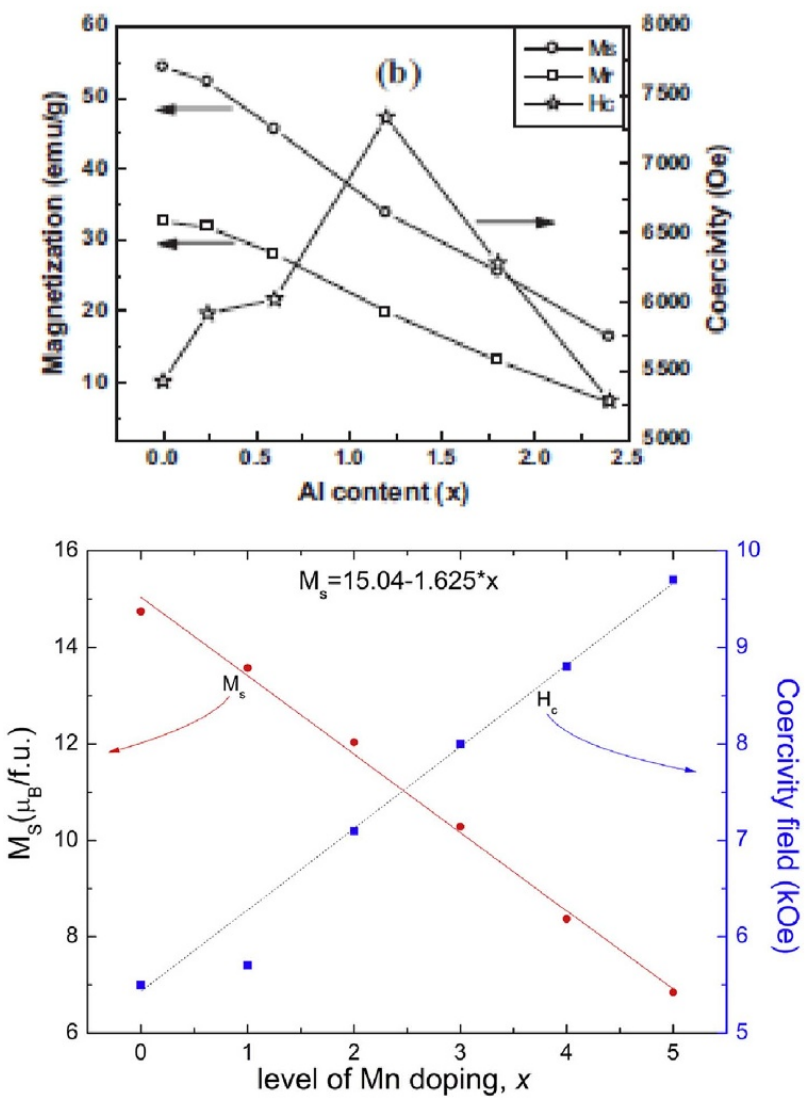
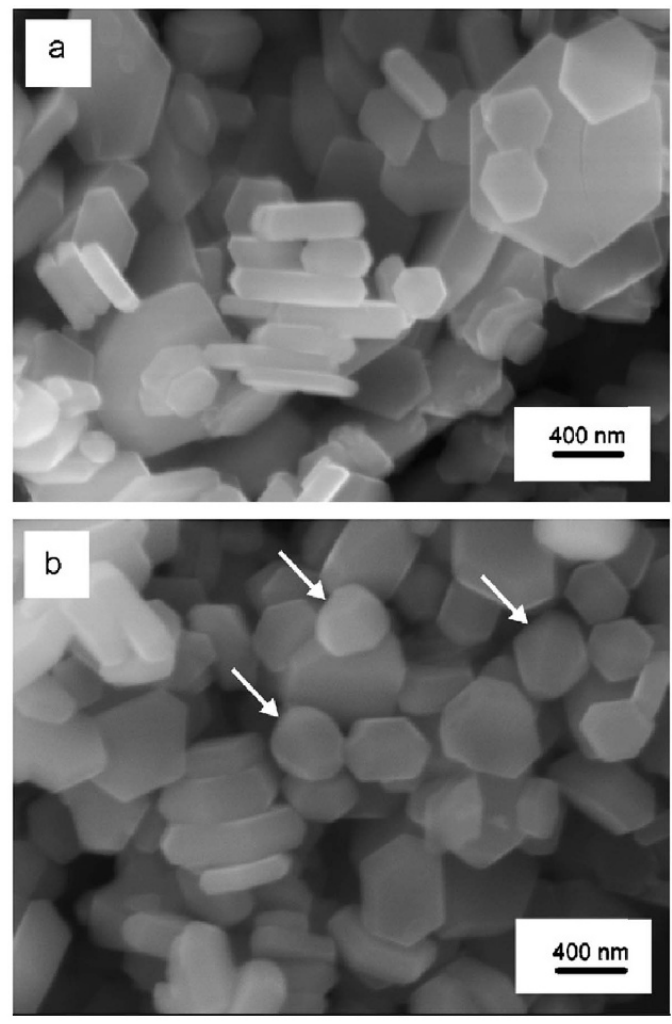

Figure 11. (Top left) The coercivity $\left(H_{\mathrm{c}}\right)$, specific magnetization at the field of $1.2 \mathrm{~T}$ and remanent magnetization for $\mathrm{SrFe}_{12}{ }_{x} \mathrm{Al}_{x} \mathrm{O}_{19}$ (Reprinted from [159], Copyright 2012, with permission from Elsevier). (Bottom left) Magnetic moment for unit formula and $H_{\mathrm{C}}$ of $\mathrm{SrFe}_{12-x} \mathrm{Mn}_{x} \mathrm{O}_{19}$ (Reprinted from [80], Copyright 2017, with permission from Elsevier). (Right) Secondary electron microscopy micrographs of Al hexaferrite powder: typical platelet particles (a) and equiaxed particles (b) (Reprinted from [160], Copyright 2008, with permission from Elsevier).

The substitution of Sr with RE can give rise to improvements in the coercivity. Mangai et al [163] report the substitution of $\mathrm{Sr}$ by $\mathrm{Sm}$. They observe the increase of $H_{\mathrm{C}}$ up to values around $477 \mathrm{kA} \mathrm{m}^{-1}$ but also the decrease of the magnetization.

Different doping approaches were investigated to improve the results obtained in $\mathrm{Al}$ doped hexaferrites [146, 164, 165, 167, 168] Trudel et al [146]. investigated the $\mathrm{Cr}$ doping of Al-SFO. This magnetic cation is slightly smaller than $\mathrm{Fe}^{3+}$ in fact the $\mathrm{CrAl}-$ ferrite structure is contracted under the substitution. However, the magnetization and coercive field exhibit a not linear dependence of the doping: the $\sigma_{\mathrm{S}}$ is large (over $80 \mathrm{~A} \mathrm{~m}^{2} \mathrm{~kg}^{-1}$ ) and $H_{\mathrm{C}}$ smaller than the corresponding values of the SFO. Trusov et al [165] and Gorbachev et al [166] investigate the simultaneous substitution of $\mathrm{Sr}$ for $\mathrm{Ca}$ and $\mathrm{Fe}$ for $\mathrm{Al}\left(\mathrm{Sr}_{1-x / 12} \mathrm{Ca}_{x / 12} \mathrm{Fe}_{12-x} \mathrm{Al}_{x} \mathrm{O}_{19}\right)$ and obtain the largest $H_{\mathrm{C}}$ of $2.86 \mathrm{MA} \mathrm{m}^{-1}$ for $x=5$ up to now published. However, the $\sigma_{\mathrm{s}}$ was very small, $2 \mathrm{~A} \mathrm{~m}^{2} \mathrm{~kg}^{-1}$. These studies consider that the decrease of the magnetization is correlated to the main occupancy of $12 \mathrm{k}$ and $2 \mathrm{a}$ sites by the $\mathrm{Al}^{3+}$, while the Ca doping enhances the contraction of the lattice structure, that leads to an increasement of the anisotropy field due to the enhancement of the crystal field. Stingaciu et al [167] perform similar studies by doping Ca Al-doped ferrites with the magnetic $\mathrm{Cr}$ to increase the magnetization
$\left(\mathrm{Ca}_{0.33} \mathrm{Sr}_{0.66} \mathrm{Fe}_{9} \mathrm{Al}_{3-x} \mathrm{Cr}_{x} \mathrm{O}_{19}\right)$. They found that the $\mathrm{Cr}$ doping produces an increment of the magnetization but a decreasing of the coercive field. The study supports the statement that the doping does not modify significantly the anisotropy of these ferrites. Shekhawat et al [168] consider the Fe substitution with $\mathrm{Cr}^{3+}$ and $\mathrm{Sn}^{4+}$ producing $\mathrm{SrAl}_{4}\left(\mathrm{Cr}_{0.5} \mathrm{Sn}_{0.5}\right)_{x} \mathrm{Fe}_{8-x} \mathrm{O}_{19}$ ferrites by sol-gel auto-combustion method. The doping with these two elements decreases the $H_{\mathrm{C}}$ values but the $H_{\mathrm{C}}$ are always above $796 \mathrm{kA} \mathrm{m}^{-1}(1 \mathrm{~T})$. These oxides exhibit unprecedented high saturation magnetizations, larger than $0.5 \mathrm{~T}$, even in Al-SFO, much larger than previously reported in Al-doped ferrites and even in bulk SFO.

Finally, we should consider the influence of other factors in the hysteresis loop. As it can be deduced from table 2, different synthesis routes give rise to different doping-dependent magnetic properties. On one hand, this might be due to differences in the doping and the cation occupancy. Furthermore, the resulting material is affected by the nucleation and growth conditions that depend on the synthesis conditions or of the physicochemical changes induced by the post-annealing treatments. On the other hand, as discussed in the previous section, the particle size also determines the magnetic properties. For example, for Al-doped powders, the single domain length is around $600 \mathrm{~nm}$ [155]. We note that in most works reported in 
table 2 the $H_{\mathrm{C}}$ is high, likely related to particles in the submicrometric regime. Finally, most of these studies show that ferrites particles exhibit a platelet morphology (see figure 11), and hence $H_{\mathrm{C}}$ and $H_{\mathrm{A}}$ are determined both by the compositiondependent magnetocrystalline anisotropy and the shape anisotropy term coming from the morphology and magnetization.

In summary, the strategy of ferrite doping allows obtaining advances in the properties of the M-type hexaferrites, increasing magnetization or coercive field. $\mathrm{Zn}$ and $\mathrm{Ni}$ based doped ferrites exhibit larger magnetizations due to the cationic occupancy of the spin-down sites. In contrast, Al based ferrites exhibit large $H_{\mathrm{c}}$ due to their low magnetization as the cations occupy spin up sites. Commercial LaCo doped ferrites are an intermediate case in which Co cations occupy both spin-up and down sites giving a weak change of the magnetization but the La induced contraction of the crystal structure and the orbital moment of the $\mathrm{Co}^{2+}$ induce an increase of the anisotropy and hence of the coercive field. In addition, the submicrometric dimension of the powders and the platelet morphology determine the final hysteresis of the magnets. The fact that LaCo ferrites, that exhibit a weak improvement of the $B_{\mathrm{R}}$ and $H_{\mathrm{C}}$ with respect to undoped ferrites, have found their way into commercial applications demonstrates the important impact that mild improvements in the properties of hexaferrites can have.

\section{Hard-soft composites}

Given the limits of single phase improvements of hexaferrites, another venue to get better performance from ferritebased magnets consists of fabricating composites of the hard hexaferrite with a soft magnetic material [174]. Hard magnetic materials exhibit a robust resistance to demagnetization due to their large magnetocrystalline anisotropy and are the base for permanent magnets. However, their saturation magnetization is often moderate, as is the case for ferrites which are ferrimagnetic materials. On the other hand, soft magnets such as metals ( $\mathrm{Fe}, \mathrm{Co})$ or soft ferrites $\left(\mathrm{Fe}_{3} \mathrm{O}_{4}, \mathrm{MnFe}_{2} \mathrm{O}_{4}\right.$, etc) present larger magnetization values than hexaferrites but their often cubic structure only allows for reduced magnetocrystalline anisotropies that lead to small coercivity and remanence values. The underlying idea is that as long as both materials are exchange-coupled, the spins of the soft phase align with that of the hard at remanence, therefore exploiting the larger magnetization of the soft phase to improve the remanence of the composite. The drawback is that the overall coercivity decreases as a consequence of the inclusion of a soft phase, but the model predicted an effective enhancement of the energy product even for lowered coercivities. A plethora of experimental efforts over the last three decades have exploited this effect in order to improve the magnetic properties of composites based on all the hard magnets [175], including of course ferrites. We will review in section 4.2 the main results obtained in systems based on hexaferrites as the hard phase.

In the absence of exchange-coupling, the possibility of exploiting the magnetodipolar interactions inside the magnetic material to align the soft spins with the hard phase has been discussed for a number of years as well [176-178], with a

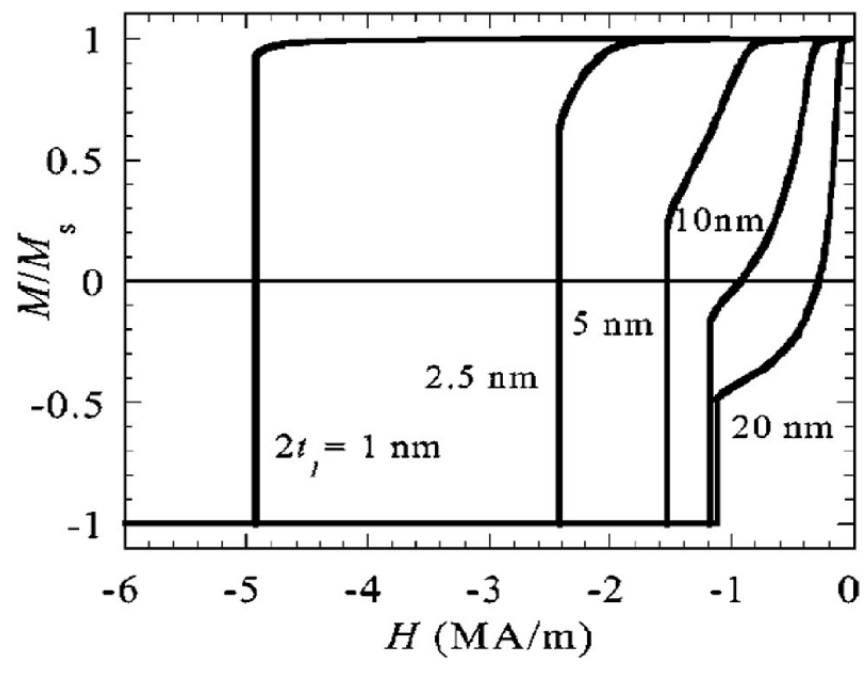

Figure 12. Hysteresis loops corresponding to rigid and spring type magnetic coupling. (b) Scheme of the spring magnet. Reprinted figure with permission from [67], Copyright 2004 by the American Physical Society.

recent interest in this approach fueled by the European project AMPHIBIAN [179]. Several strategies and the main results obtained thus far using this approach will be reviewed in section 4.2.

Finally, in section 5, the future prospects for hard-soft magnetic composites for use in novel permanent magnets will be discussed.

\subsection{Exchange-coupling}

Achieving an efficient and robust exchange-coupling at the interface has represented the main challenge. This is due to the fact that orbital overlap and thus structural coherency at the interfaces is required on one hand; and on the other the soft phase size has to be below a certain threshold, indicated by the exchange length of the hard phase. This is typically of the order of a few nanometers for systems based on ferrites as a hard phase, which entails that these strict structural requirements are not straightforward to fulfill, especially in bulk systems on which industrial magnet production relies.

Based on the strength of the exchange interaction at the dissimilar interfaces, three types or regimes of coupling can be defined [67, 180-187]: Rigid, Spring and Decoupled. Figure 12 portrays the resulting hysteresis loops of each regime.

In the rigid coupling regime, the spins of the soft phase are completely and rigidly coupled to the hard spins and magnetization reversal occurs as a collective whole. It is equivalent to having a single magnetic phase with properties averaged between both phases.

In the spring-magnet case, both phases are effectively exchange-coupled at the interface but some of the spins of the soft, generally located further from the interface, are not rigidly coupled to the hard spins. This results in a magnetization reversal where low fields reverse those 'loose' soft phase spins, while higher negative fields are needed to reverse 

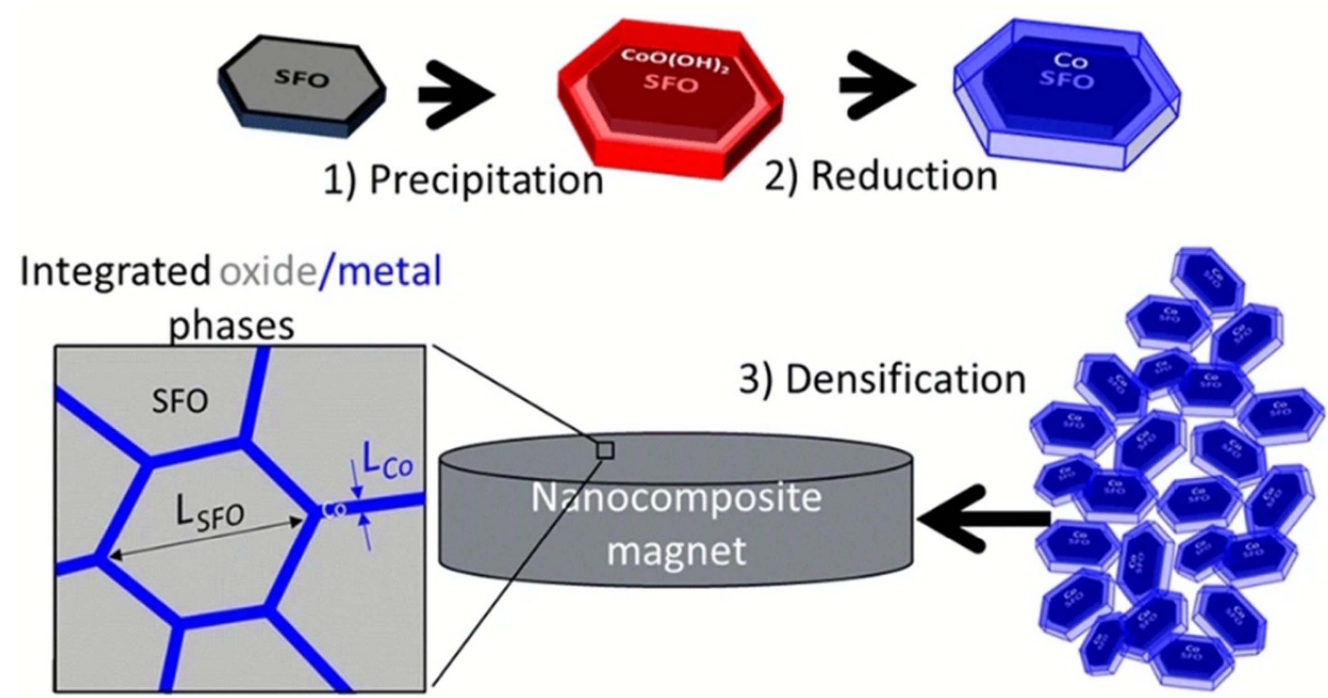

Figure 13. Scheme of the synthesis process of a SFO/Co composite with a microstructure involving a soft nanosized Co phase. Reprinted by permission from Springer Nature Customer Service Centre GmbH: Springer Nature, Journal of Materials Science, [68], Copyright 2019.

the hard phase and rigidly coupled soft spins. In this regime, remanence is increased with the presence of the soft phase as negative fields are required to partially misalign the soft spins. In fact, if a negative field between the switching field of the hard and the soft is applied and subsequently removed, the soft 'loose' spins first reverse and then, upon field removal, return back to being aligned with the hard phase. This behavior resembles that of a spring, hence the name of the regime.

The third regime corresponds to the situation where there is absence of exchange-coupling between hard and soft constituents. In this case, magnetization reversal occurs as two completely independent phases. It is important to remark that from a single hysteresis loop, as in figure 12 , it is difficult to discern between the spring and uncoupled regimes. In principle, in a spring magnet, an increased remanence $M_{\text {comp }}$ with respect to that of the hard phase $M_{\mathrm{H}}$ should be observed; whereas in a decoupled system, the remanence value should comply with $M_{\mathrm{H}}<M_{\text {comp }}<M_{\mathrm{S}}$. However, differences in the alignment of the hard and soft particles could yield misleading observations, such as increases in $M_{\text {comp }}$ in an uncoupled system, and additional means of verification should be implemented. One option is to measure the soft switching field $H_{\text {sw-s }}$ for different soft contents or thicknesses. If the system is in the decoupled/spring regime, $H_{\mathrm{sw}-\mathrm{s}}$ should be independent/dependent on the soft concentration, respectively. In the following, we will review the main results and developments obtained in recent years in hard-soft composites based on hexaferrites as the hard phase. The section will be divided in non-oxide soft phases and oxide soft phases.

4.1.1. Non-oxide-oxide composites. The use of metals as the soft compound presents the advantage of potentially reaching much higher magnetization values, due to the large magnetization of $\mathrm{Fe}, \mathrm{Co}$ and their alloys. However, in order to stay within the rigid coupling regime, the soft phase must have a size below a certain threshold, given by twice the domain wall thickness of the ferrite. This quantity is equal to the exchange length $L_{\mathrm{ex}}$ of the hard phase, in this case SFO or BFO. This is a relatively strict requirement for metals, as the ferrite's exchange stiffness and magnetocrystalline anisotropy values leads to threshold sizes of the order of $2 L_{\mathrm{ex}}=21 \mathrm{~nm}[68,185]$. The challenge from a synthesis and processing point of view is considerable, especially taking into account that the permanent magnet industry produces thousands of tons of material per year [7]. First of all, a soft phase in the nanoscale has to be produced and supplied. Second, an intimate and coherent contact at the interface has to be achieved, as exchange-coupling demands the presence of chemical bonds and orbital overlap between hard and soft phases. In this framework, novel materials and innovative design, together with sophisticated synthesis and processing methods are needed.

Volodchenkov et al [68] have contributed to the field by designing and synthesizing the microstructures shown in figure 13, consisting of platelet shaped SFO particles surrounded by a thin metal layer, where the SFO platelet-shaped particles have an average size of approximately $1 \mu \mathrm{m}$. The process involves the precipitation of a Co precursor, $\mathrm{Co}-\mathrm{O}-$ $\mathrm{OH}$, on the SFO surfaces and the subsequent reduction to metallic Co.

Based on these structures, their work develops a dense specimen where the Co is indeed observed to be located at the grain boundaries acting as a shell of thickness in the tens of nanometers range, as shown in figure 14.

The precipitated composite presents a substantial increase in remanence while keeping coercivity very close to that of the pure SFO control sample. The authors quantify the improvement in $(\mathrm{BH})_{\max }$ as $70 \%$, although the dense samples have not been magnetically oriented. Interestingly, they compare the magnetic properties of their novel microstructure to those of a composite of the same composition but fabricated by simply mixing hard and soft powders, with a soft Co phase that is 

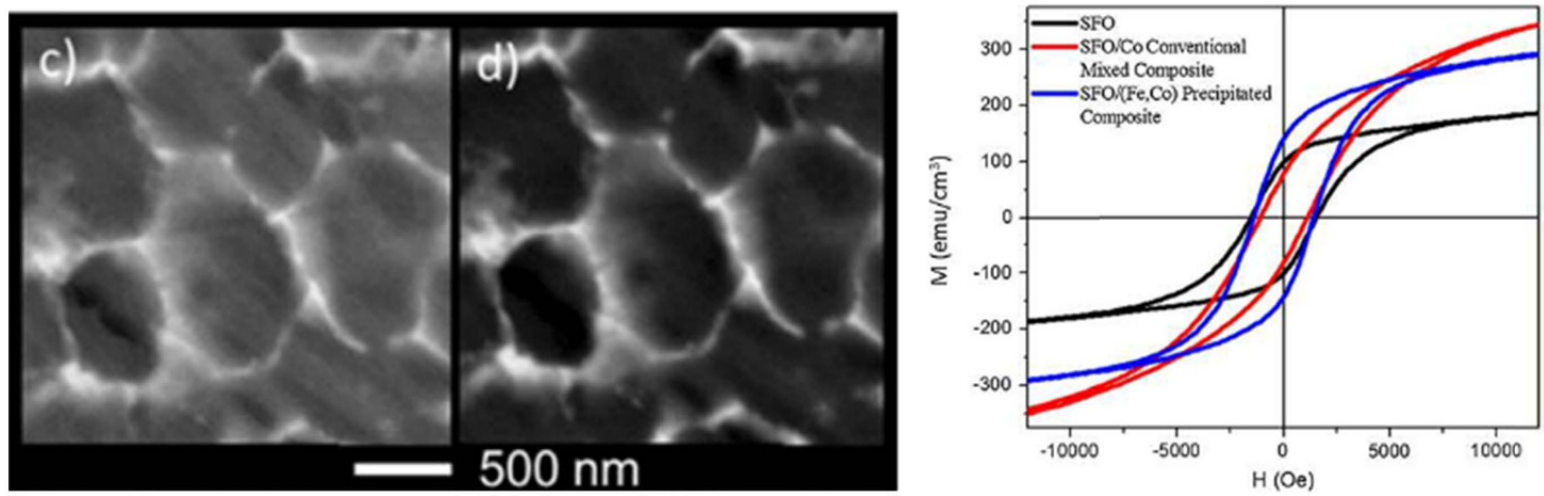

Figure 14. Scheme of the synthesis process of a SFO/Co composite with a microstructure involving a soft nanosized Co phase. Reprinted by permission from Springer Nature Customer Service Centre GmbH: Springer Nature, Journal of Materials Science, [68], Copyright 2019.

not in the nanoscale and not in close contact with the SFO. The marked decrease in remanence and coercivity compared to both the precipitated composite and the pure SFO sample is a clear indication of the threshold size effect of the soft phase.

Several authors have reported on hard-soft composite systems that reverse as a single magnetic phase [188-190]. Single-step reversal or the absence of discontinuities in the demagnetization curve is one of the fingerprints of rigid exchange-coupling in hard-soft composites. Li et al [189] report on exchange-coupled $\mathrm{SFO} / \mathrm{Fe}-\mathrm{B}$ composites. A marked increase in magnetization is observed, along with a substantial decrease in coercivity reaching $H_{\mathrm{C}}=49.1 \mathrm{kA} \mathrm{m}^{-1}$, which brings forward one of the fundamental issues associated with robust exchange-coupling: the collapse of coercivity [191]. Zhang et al [190] fabricate structures based on SFO particles between 100 and $200 \mathrm{~nm}$ surrounded by FeN nanoparticles smaller than $20 \mathrm{~nm}$. In their case, $H_{\mathrm{C}}>320 \mathrm{kA} \mathrm{m}^{-1}$ for the exchange-coupled composites, probably due to the small size of the soft phase. In addition, they report mild enhancements of remanence. Xu et al [188] study a very similar microstructure although consisting of FeCo nanoparticles as the soft phase. They also observe slightly lower $H_{\mathrm{c}}$ and a mild increase in remanence. Although results are in all these three cases promising, all studies are performed in non-oriented specimensi.e. no magnetic field was applied to orient the particles prior to the measurement. It is therefore difficult to exactly quantify what the increase in real remanence and energy product is.

An interesting strategy towards achieving structural coherency and small particle sizes is to produce core-shell hard-soft nanostructures. Several authors have studied these systems using SFO as the hard phase and FeCo as the soft shell. Xu et al [192, 193] confirm that the core-shell structures present better properties than simple mixtures of both types of particles, confirming the importance of small soft particle sizes, close contact between phases and avoiding agglomerates. However, no clear improvement in remanence with respect to pure SFO samples is observed. Dong et al [194] focus on core-shell microfibers where the robust exchange-coupling is again seen to lead to a relatively drastic decay in $H_{\mathrm{c}}$. The samples studied in these articles are not magnetically oriented either.

It is important to keep in mind as well that relatively broad distributions of coercivities can exist, for both phases, in polycrystalline powder samples, as a consequence of the particle size distributions. A broad distribution of switching events can lead to seemingly smooth demagnetization curves that are single-phase like, in systems that are in fact exchangedecoupled [195]. Henkel plots are often employed to further discern the existence of exchange-coupling in these systems [196]. Unfortunately, the study of the magnetic interactions in Henkel plots are only really applicable to Stoner-Wohlfart systems consisting of single-domain isolated particles with a very narrow size distribution [197]. In this framework, careful analysis of the $\mathrm{d} M / \mathrm{d} H$ derivative can help reveal the switching events in the system.

4.1.2. All-oxide composites. All oxide hard-soft composites, based on SFO and a soft ferrite, have the advantage of being slightly easier to process and densify as a magnet since no oxidation vs reduction issues are to be faced. Sintering can be performed in air atmosphere, contrary to the case of metaloxide composites. On the other hand, the best magnetization values of soft ferrites $\sigma_{\mathrm{S}}=100 \mathrm{~A} \mathrm{~m}^{2} \mathrm{~kg}^{-1}$ is approximately half the one of $\mathrm{Fe}$ and $\mathrm{FeCo} \sigma_{\mathrm{S}}=220 \mathrm{~A} \mathrm{~m}^{2} \mathrm{~kg}^{-1}$, which makes it challenging to improve the magnetization of SFO by adding moderate amounts of soft phase.

Work has focused on a powder sample of different morphologies and dense sintered specimens. In the case of the former, Afshar et al [198] recently studied $\mathrm{SFO} / \mathrm{Ni}_{0.6} \mathrm{Zn}_{0.4} \mathrm{Fe}_{2} \mathrm{O}_{4}$ composite samples annealed at $700{ }^{\circ} \mathrm{C}-800{ }^{\circ} \mathrm{C}$. The demagnetization curves show two-step reversal, strongly suggesting that the magnetic phases are not exchange-coupled. As relatively high temperature is applied, there is a good chance that chemical bonds between hard and soft particles exist, but the particle sizes observed in their SEM images show particles that are clearly above the rigid coupling threshold size of $20 \mathrm{~nm}$ [68]. As a consequence, coercivity drops from $H_{\mathrm{C}}=358 \mathrm{kA} \mathrm{m}{ }^{-1}$ for pure SFO to $H_{\mathrm{C}}=88,1 \mathrm{kA} \mathrm{m}^{-1}$ for $30 \mathrm{wt} \% \quad \mathrm{Ni}_{0.6} \mathrm{Zn}_{0.4} \mathrm{Fe}_{2} \mathrm{O}_{4}$; while magnetization negligibly improves. Dahal et al [199] synthesize SFO/LaSrMnO 3 nanoparticulated composites with single-step reversal curves and supposedly good exchange-coupling between the phases, which may be the consequence of the small particle size. Although improvements in the remanence-to-saturation ratio 

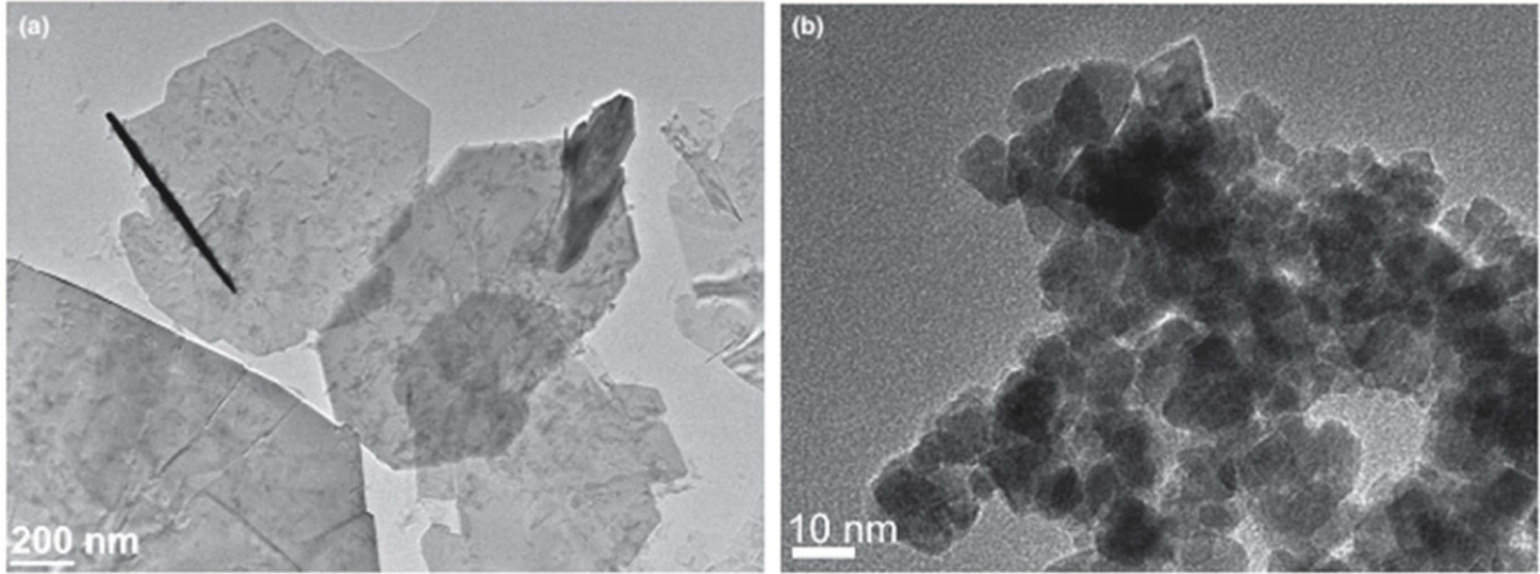

Figure 15. TEM images of the as-synthesized SFO particles (left) and Co-ferrite particles (right). [69] John Wiley \& Sons. @ 2016 The American Ceramic Society.
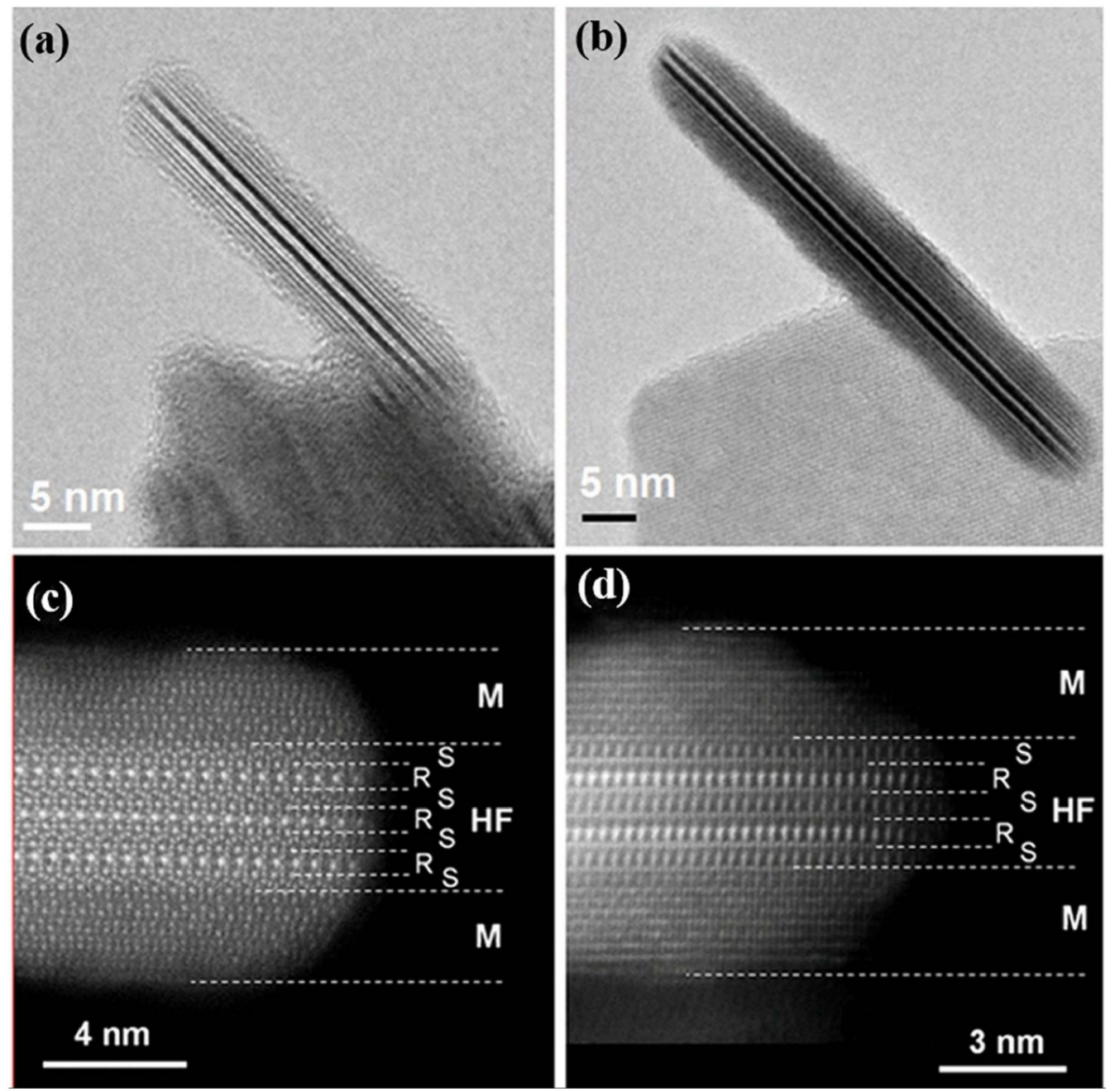

Figure 16. TEM and HAADF STEM images of bi-magnetic M/BHF/M sandwich composite nanoplatelets with $1.9 \mathrm{~nm}$ ((a) and (c)) and $2.5 \mathrm{~nm}$ ((b) and (d)) thick M layer. Adapted from [70] with permission of The Royal Society of Chemistry.

are observed, unfortunately the magnetization of the soft phase is lower than that of SFO, leading to decreases in both coercivity and remanence in the composites.
More sophisticated nanostructures have been investigated as well. Song et al [200] studied $\mathrm{SFO} / \mathrm{Ni}_{0.5} \mathrm{Zn}_{0.5} \mathrm{Fe}_{2} \mathrm{O}_{4}$ hollow microfibers. Although small crystallites were obtained, no 


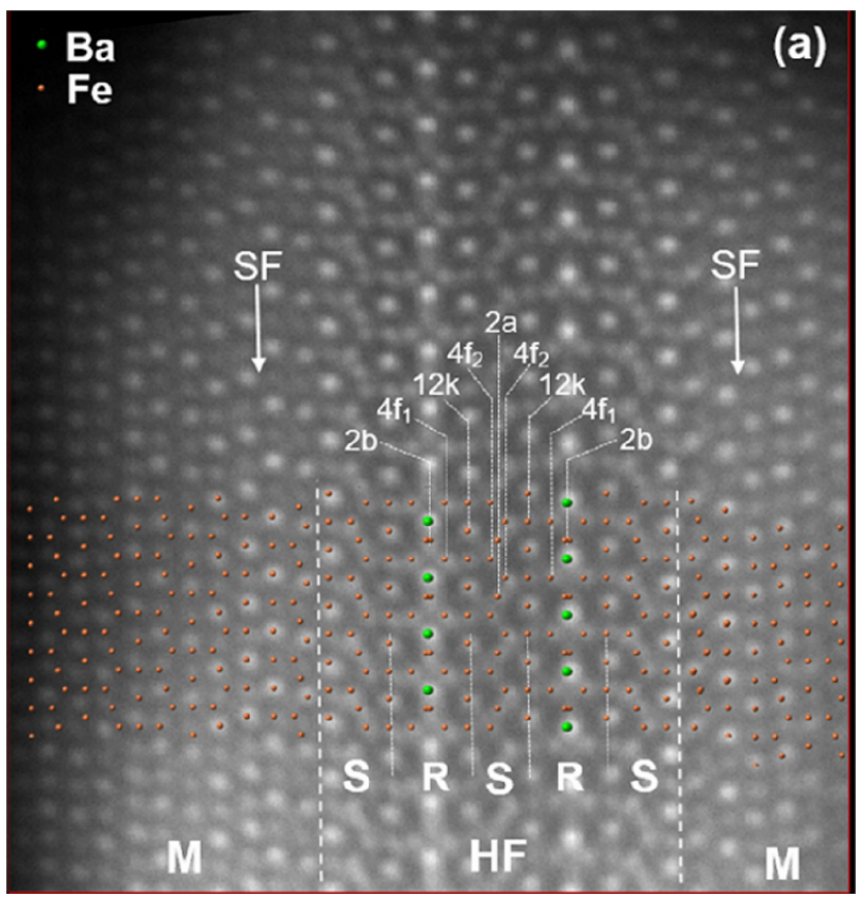

Figure 17. HAADF STEM image of composite $\mathrm{M} / \mathrm{BFO} / \mathrm{M}$ sandwich nanoplatelet. The projected structures along [10-10] HF and maghemite along [101]M) are superimposed over the images to illustrate the position of $\mathrm{Ba}^{2+}$ and $\mathrm{Fe}^{3+}$ ions. Different Fe lattice sites and the HF structure (trigonal $2 \mathrm{~b}$, tetrahedral $4 \mathrm{f} 1$, octahedral $12 \mathrm{k}, 2 \mathrm{a}$ and $4 \mathrm{f}_{2}$ ) are marked. Adapted from [70] with permission of The Royal Society of Chemistry.

clear improvements in remanence are reported and the composites appear to be decoupled based on the demagnetization curves. Core-shell $\mathrm{BFO} / \mathrm{Fe}_{3} \mathrm{O}_{4}$ core-shell-like particles were the focus of Mohseni et al work [201]. Larger BFO particles are seen to have their surface covered by small magnetite nanoparticles. The samples show promising results in the sense of a significant increase in overall remanence while coervivity remains roughly unchanged. The authors claim there is hard-soft exchange-coupling but two of the three composite studies clearly show two peaks in the $\mathrm{d} M / \mathrm{d} H$ derivative while the third one, at a 9:1 hard:soft ratio seems to show a kink in the demagnetization curve. An increase in the energy product is claimed as well, although the samples are not magnetically oriented. Volodchenkov et al [202] replicated the interesting microstructure discussed in section 4.1.1. and shown in figure 13, this time using $\mathrm{Fe}_{3} \mathrm{O}_{4}$ instead of $\mathrm{Co}$ as the soft phase. A $37 \%$ improvement in $(\mathrm{BH})_{\max }$ is reported, which is indeed supported by a remarkable increase in remanence and an almost negligible decrease in coercivity. Unfortunately once again, the samples are not magnetically oriented which prevents a full assessment of their improved properties.

As far as sintered samples are concerned, Jenus et al [69] report on $\mathrm{SFO} / \mathrm{CoFe}_{2} \mathrm{O}_{4}$ composites. This system cannot be strictly considered a hard-soft composite since $\mathrm{CoFe}_{2} \mathrm{O}_{4}$ is magnetically hard, although its magnetization value $\sigma_{\mathrm{S}}=82 \mathrm{~A} \mathrm{~m}^{2} \mathrm{~kg}^{-1}$ is indeed higher than that of SFO. By using SPS, the particle size of both phases, shown in figure 15, is maintained small while achieving a competitive relative density of $93 \%$. In addition, the samples of this study are magnetically oriented, which allow accurately establishing a remarkable $22 \%$ increase in energy product with respect to the pure SFO specimen: from $(\mathrm{BH})_{\max }=21.9 \mathrm{~kJ} \mathrm{~m}^{-3}$ to $(\mathrm{BH})_{\max }=26.1 \mathrm{~kJ} \mathrm{~m}^{-3}$.

4.1.3. Hexaferrite/maghemite bi-magnetic platelets. The research group (Department for Materials Synthesis) from Jožef Stefan Institute, Slovenia, used a simple water-based method for synthesis of the hard-soft exchange coupled nanoparticles composed of soft-magnetic spinel ferrite (maghemite-M) layers deposited on hard-magnetic BFO platelet cores [70, 71]. Even the composite nanoplatelets were developed for advanced medical applications; they can also be relevant as building blocks for production of permanent magnets. The synthesis is performed at relatively low temperature $\left(60{ }^{\circ} \mathrm{C}\right)$, it is environmentally friendly, inexpensive, relies on abundant raw materials and is also appropriate for scaling up to an industrial scale. Nevertheless, it enables excellent control of the composite structure. The spinel ferrite is deposited with a controlled co-precipitation of the ions from aqueous suspension containing the core nanoparticles [203]. For example, the $\mathrm{M}$ was deposited with the co-precipitation of $\mathrm{Fe}^{2+} / \mathrm{Fe}^{3+}$ ions using weak hydroxide under an inert atmosphere. The deposition process is controlled by the supersaturation of the precipitating iron species, which is enabled by immobilization of the highly reactive $\mathrm{Fe}^{3+}$ ions into the coordination compound with urea $\left.\left[\left(\mathrm{Fe}\left(\mathrm{CO}\left(\mathrm{NH}_{2}\right)_{2}\right)_{6}\right)\left(\mathrm{NO}_{3}\right)_{3}\right)\right][204]$ and their controlled release with thermal decomposition of the complex. The precipitating iron species heterogeneously nucleates and the $\mathrm{M}$ grows exclusively on the basal surfaces of core BFO nanoplatelets present in the reaction suspension. Thus, the product nanoplatelets exhibited an incredibly uniform $\mathrm{M} / \mathrm{BFO} / \mathrm{M}$ sandwich-type structure (figure 16). The thickness of the $\mathrm{M}$ layers was very uniform, equal on the both sides of the cores. For lower layer thicknesses, the thickness can be controlled simply by adjusting the ratio between the iron ions and the surface area of the BFO core nanoplatelets (Fe/BFO ratio). For example, by adjusting the Fe/BFO ratio the thickness of deposited $\mathrm{M}$ surface layers on the BFO core nanoplatelets, $42 \mathrm{~nm}$ wide and $\sim 3 \mathrm{~nm}$ thick, was successfully controlled up to $\sim 2 \mathrm{~nm}$ (see figures 16(a) and (c)). For even thicker M layers the deposition had to be conducted in the two consecutive steps. Namely, with the increased Fe/BFO ratio, the supersaturation of the precipitating iron species increases until individual separated $\mathrm{M}$ nanoparticles are formed. The composite nanoplatelets with layer thickness of $2.5 \mathrm{~nm}$ were obtained by the deposition in the two steps. The product was fairly homogeneous (see figures 16(b) and (d)), even sometimes the larger composite platelets with much thicker layer $(>10 \mathrm{~nm})$ grown on one side of the core were also present in a very low concentration.

Importantly, the co-precipitation method is not limited to co-precipitation of $\mathrm{Fe}^{2+}$ and $\mathrm{Fe}^{3+}$ ions. With some adaptation to the process, the $\mathrm{Fe}^{2+}$ ions can be exchanged with some other 2-valent ions constituting the spinel ferrites, for example $\mathrm{Zn}^{2+}$ 

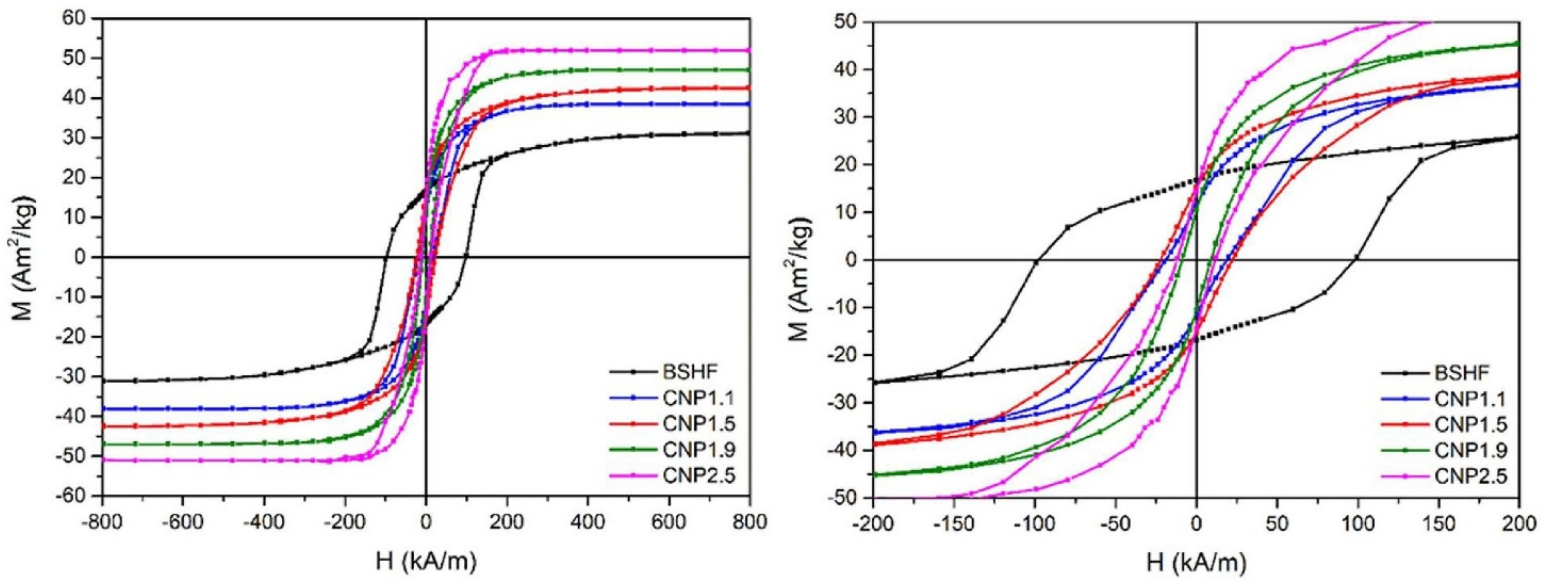

Figure 18. Magnetic hysteresis loops for randomly oriented Sc substituted BFO and composite nanoplatelets with different thicknesses of the M layers (the M/BFO/M platelets are referred to as CNPX.X, where 'X.X' marks the thickness of M layer in nm). Adapted from [70] with permission of The Royal Society of Chemistry.
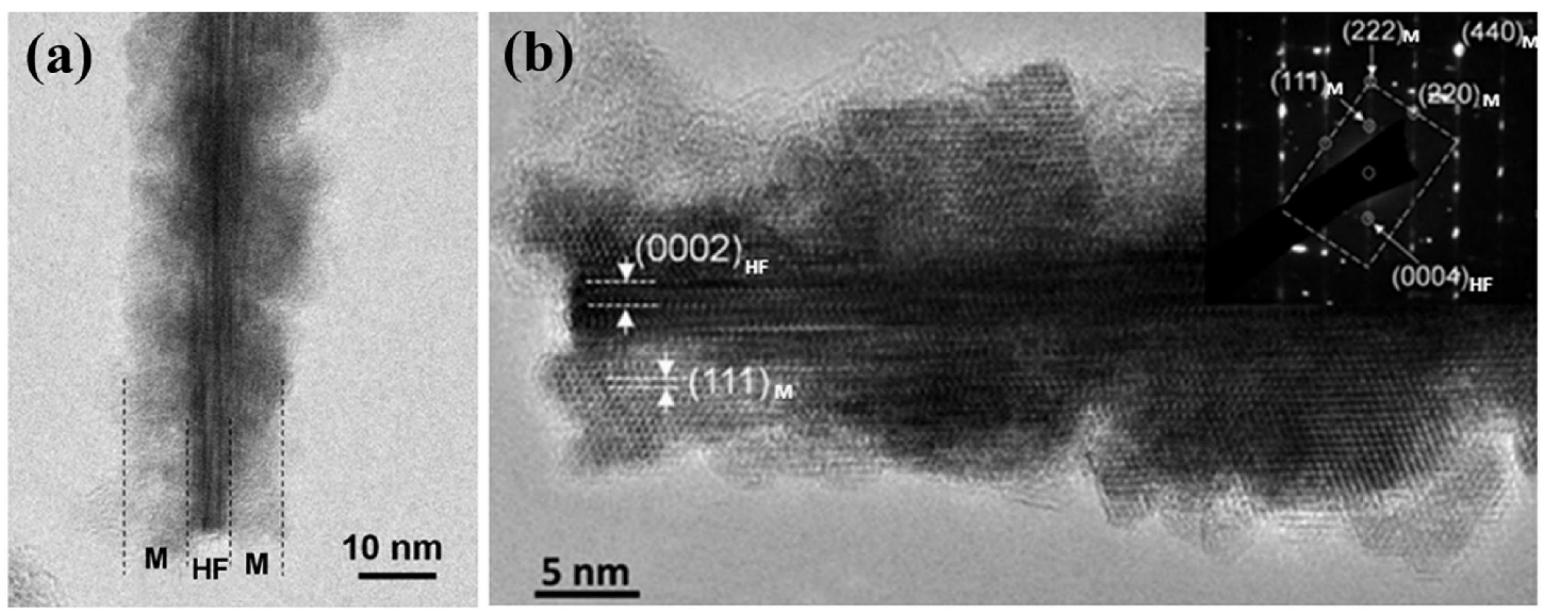

Figure 19. (a) TEM image of composite nanoplatelet synthesized by deposition of maghemite layers onto the larger hexagonal BFO core nanoplatelets, and (b) HREM image with corresponding electron diffraction pattern. Adapted from [71] with permission of The Royal Society of Chemistry.

and $\mathrm{Mn}^{2+}$. For example, zinc-ferrite $\left(\mathrm{ZnFe}_{2} \mathrm{O}_{4}\right)$ layers were deposited just by exchanging $\mathrm{Fe}^{2+}$ with $\mathrm{Zn}^{2+}$ [70].

Details of the unique structure of composite nanoplatelets were revealed based on direct atomic-resolution high-angle annular dark field (HAADF) imaging with a probe aberration corrected STEM [70]. The M was deposited onto the Sc-substituted BFO core nanoplatelets, with relatively narrow distribution of widths, $42 \pm 12 \mathrm{~nm}$. Remarkably, the inspection of a large number of the sandwich M/BFO/M composite nanoplatelets revealed that the vast majority of the BFO cores exhibited equal structure across the nanoplatelet. In terms of two structural blocks usually used to describe the BFO structure: a cubic spinel $\left(\left(\mathrm{Fe}_{6} \mathrm{O}_{8}\right)^{2+}\right)$ ' $\mathrm{S}$ ' block and a hexagonal $\left(\left(\mathrm{BaFe}_{6} \mathrm{O}_{11}\right)^{2-}\right)$ ' $\mathrm{R}$ ' block, the structure of a vast majority of the BFO core nanoplatelets can be presented with the SRS* R*S stacking sequence across the nanoplatelet (figure 17). The structure closely defines the thickness of the nanoplatelets at $3.0 \mathrm{~nm}$. As the BFO nanoplatelets terminate at the basal surfaces with the Fe-only $\mathrm{S}$ block, their composition is Fe-rich corresponding to $\mathrm{BaFe}_{15} \mathrm{O}_{23}$ theoretical chemical formula. Only seldom the core nanoplatelets contained three $\mathrm{R}$ blocks (figure 16(c)); they were $4.2 \mathrm{~nm}$ thick and exhibited the $\mathrm{BaFe}_{14} \mathrm{O}_{22}$ theoretical composition. Later, systematic study showed that during hydrothermal growth, the BFO nanoplatelets crystalline structure of nanoplatelets always thicken with in a step-wise addition of the RS segments to their initial SRS* structure [39].

Given the cubic $\mathrm{S}$ block termination, the structure of core nanoplatelets closely match with the spinel structure of M layers at the $(0001)_{\mathrm{HF}} \|(111)_{\mathrm{M}}$ interface. The $\mathrm{S}$ block of BFO structure is actually a slice of the cubic spinel structure. Formation of the low-energy coherent interface promotes heterogeneous nucleation and epitaxial growth of the M exclusively at the basal surfaces of the core nanoplatelets. The $M$ was never deposited at the side surfaces of nanoplatelets, where the two structures do not match. Despite good matching between the two structures, the interface was always clearly visible on the STEM images, suggesting presence of strains. The M layer 


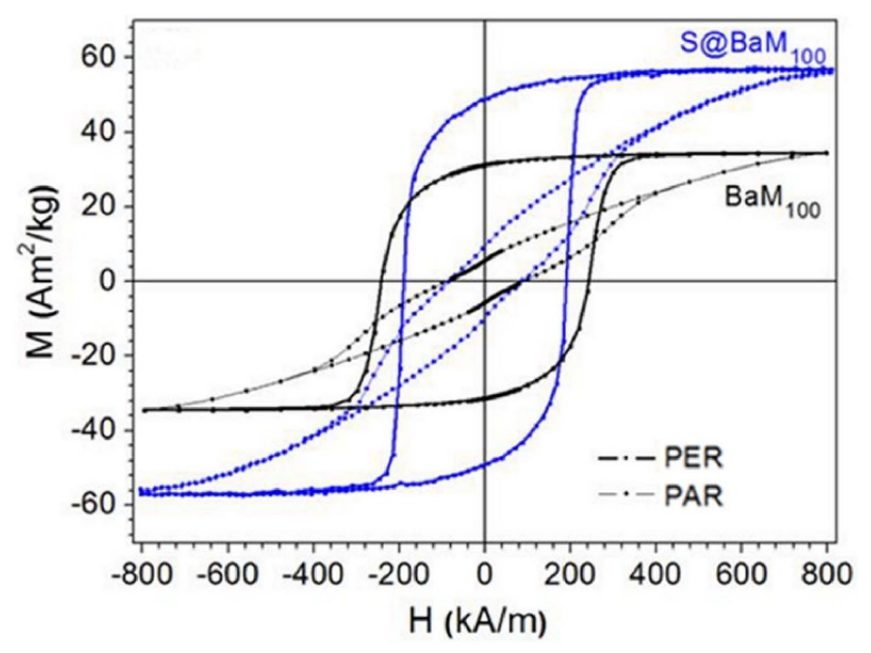

Figure 20. Comparison of the magnetic hysteresis for BHF core nanoplatelets $(\sim 100 \mathrm{~nm}$ wide and $\sim 8 \mathrm{~nm}$ thick, BaM 100 and corresponding composite nanoplatelets (S@BaM 100 measured PER and PAR to their basal surfaces. Adapted from [71] with permission of The Royal Society of Chemistry.

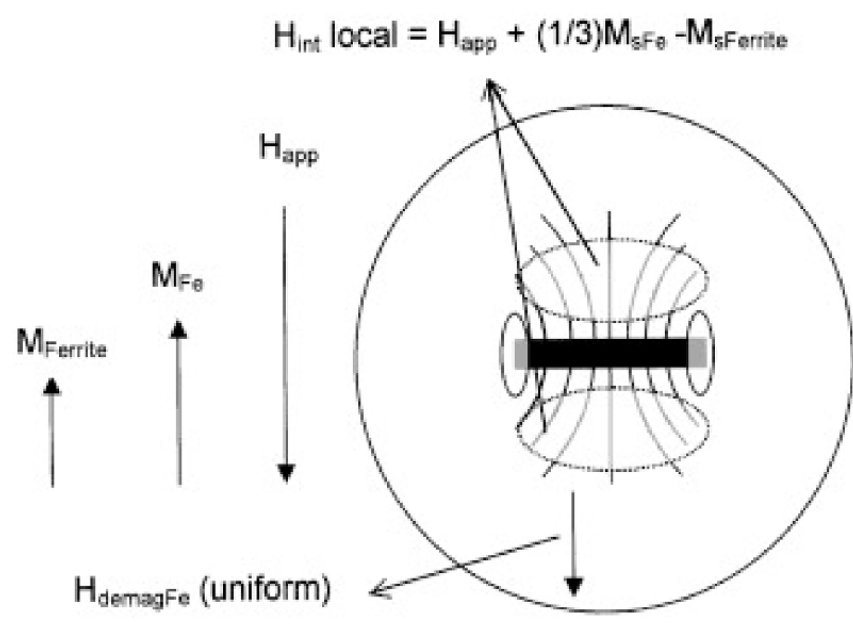

Figure 21. Simplified scheme of the internal fields of a BFO platelet placed inside a Fe particle. [69] John Wiley \& Sons. (c) 2016 The American Ceramic Society.

was always slightly shifted along the interface relative to the structure of HF core.

The BFO nanoplatelets used as the cores of composite nanoplatelets display strongly anisotropic magnetic properties. Because of the strong uniaxial magnetocrystalline anisotropy, the BFO retains the easy axis oriented parallel to the crystallographic $c$-axis even when in the form of thin nanoplatelets, that is perpendicular to the nanoplatelet. Actually, the HF nanoplatelets are the only accessible platelet magnetic nanoparticles exhibiting such perpendicular easy axes $[18,66]$. The $\sim 50 \mathrm{~nm}$ wide and $3 \mathrm{~nm}$ thick Sc-substituted BFO nanoplatelets exhibited the $M_{\mathrm{S}}$ over $30 \mathrm{~A} \mathrm{~m}^{2} \mathrm{~kg}^{-1}$ and $H_{\mathrm{C}}$ of $\sim 150 \mathrm{kA} \mathrm{m}^{-1}[73,205]$. The properties of the nanoplatelets are actually substantial, when we consider the very small thickness of the nanoplatelets, which is just over one-unit cell in the corresponding $c$-direction of the BFO structure. After the deposition of $\mathrm{M}$ layers, the $\mathrm{M} / \mathrm{BFO} / \mathrm{M}$ composite nanoplatelets retained the single-phase hysteresis loops without any constriction or kink, indicating rigid exchange coupling of the two magnetically-different phases [174, 206, 207]. Figure 18 shows the hysteresis loops for the BFO core nanoplatelets and the composite nanoplatelets with different thicknesses of the M layers [70]. A slightly constricted loop was only observed for the composites with the thickest M layer (CNP2.5). However, the two-phase behaviour was ascribed to the presence of a small amount of the nanoplatelets, which showed much thicker M layers; too thick to maintain the complete coupling with the core. As expected, the $\sigma_{\mathrm{S}}$ of the composite nanoplatelets increased proportionally to the $\mathrm{M}$ layer thickness, from $30 \mathrm{~A} \mathrm{~m}^{2} \mathrm{~kg}^{-1}$ for the BFO core nanoplatelets to $52 \mathrm{~A} \mathrm{~m}^{2} \mathrm{~kg}^{-1}$ for the thickest layer of the CNP2.5 composite. However, the $H_{\mathrm{C}}$ strongly decreased with the deposition of epitaxial M layers. The decrease of $H_{\mathrm{C}}$ was non-proportionally large, much larger than expected according to theory presented by Kneller in 1991 [174]. The $H_{C}$ decreased for $\approx 80 \%$ already for the composite with the thinnest M layer (CNP1.1), where the content of the soft-magnetic phase was only $\sim 33 \%$. The decrease in $H_{\mathrm{C}}$ was ascribed to changes in the magnetic properties of BHF cores with the deposition of epitaxial M layers [70]. The changes in the properties of the BFO cores were first suggested from high-temperature measurements of the magnetization. The nanoplatelets were coated with a silica shell prior to the measurement to minimize interparticle interactions and block particle growth. The measurements showed that the Curie temperature $\left(T_{\mathrm{C}}\right)$ of the BFO nanoplatelets significantly decreased after deposition of the $1.1 \mathrm{~nm}$ thick $\mathrm{M}$ layers $\left(T_{\mathrm{C}}\right.$ before and after the deposition was $\sim 450{ }^{\circ} \mathrm{C}$ and $\sim 310{ }^{\circ} \mathrm{C}$, respectively). Since the $T_{\mathrm{C}}$ is an intrinsic property reflecting the magnetic structure of the material, it was concluded that the structure changed after the deposition because of internal stresses induced in the cores by the epitaxial $M$ layers. The influence of internal stresses was confirmed by deposition of weakly magnetic zinc-ferrite layers onto the BFO cores [70]. Expectedly, the deposition of the zinc ferrite decreased the $M_{\mathrm{S}}$ almost proportionally to its content, whereas the $H_{\mathrm{C}}$ of composite strongly decreased, confirming that the internal stresses induced in the core nanoplatelets by the epitaxial layers are very probable reason for the non-proportionally-high decrease in $H_{\mathrm{C}}$ of the $\mathrm{M} / \mathrm{BFO} / \mathrm{M}$ composites.

The large decrease in $H_{\mathrm{C}}$ was not observed when the epitaxial M layers (approximately $5 \mathrm{~nm}$ thick) were deposited onto larger BFO core nanoplatelets (approximately $100 \mathrm{~nm}$ wide and $8 \mathrm{~nm}$ thick) (figure 19). The nanoplatelets were measured after they were aligned with exposing their suspension in a liquid wax to a magnetic field, followed by solidification of the wax with cooling. Figure 20 shows the hysteresis loops for the core and the composite nanoplatelets measured with the magnetic field applied perpendicular (PER) and parallel (PAR) to the nanoplatelets' basal surfaces. The composite nanoplatelets exhibited significantly increased the $M_{\mathrm{S}}$ and $M_{\mathrm{R}}$, while the $H_{\mathrm{C}}$ was only slightly lower than the $H_{\mathrm{C}}$ of cores. We assume that due to the larger thickness the structure of larger cores was more rigid and therefore less susceptible to stresses compared to the structure of smaller BFO nanoplatelets. Moreover, due 

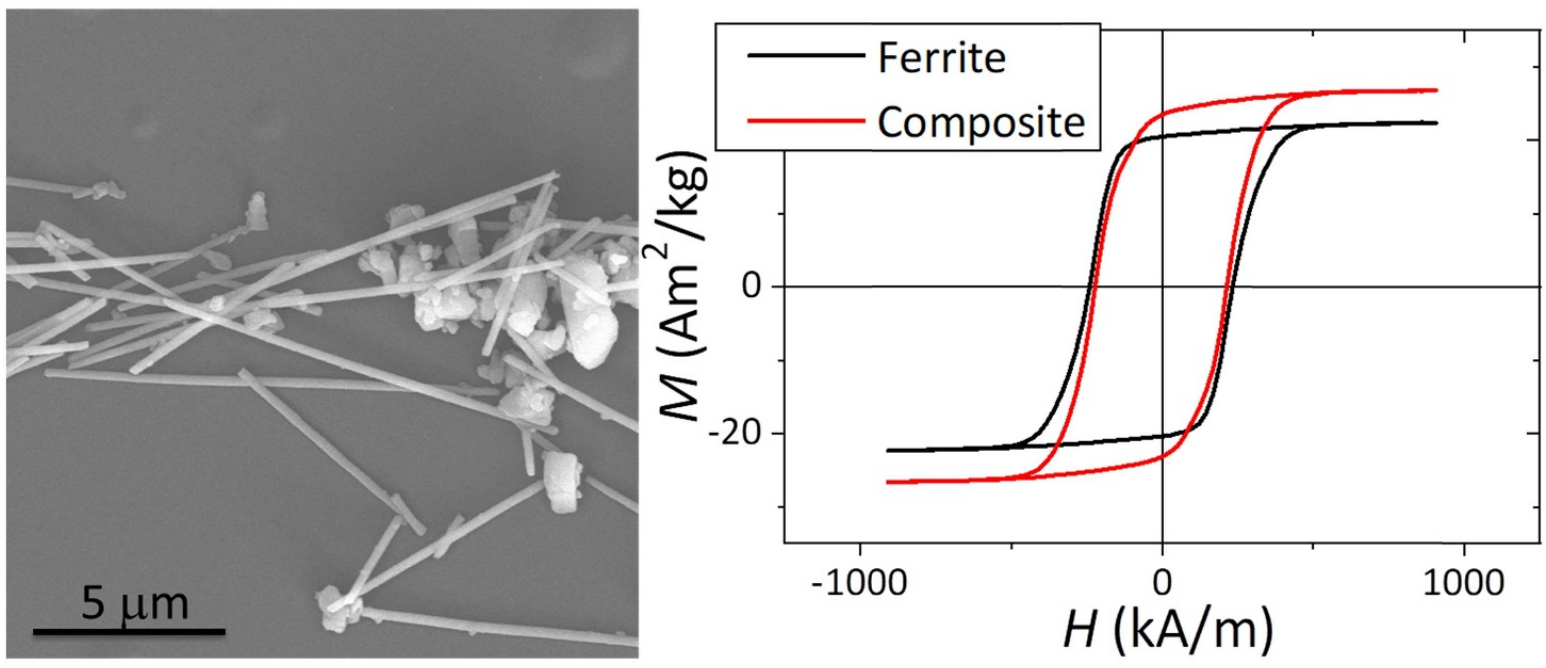

Figure 22. (Left) SEM image showing the SFO particles and the FeCo nanowire and (right) magnetization curves of an oriented ferrite bonded magnet (black curve) and a $70 \mathrm{wt} \%$ ferrite - $30 \mathrm{wt} \%$ FeCo composite bonded magnet (red). Reprinted with permission from [209]. Copyright 2020 American Chemical Society.

to the larger area the nucleation of the $\mathrm{M}$ at the larger cores started at several spots on the basal surfaces. With growth the continuous $\mathrm{M}$ layers formed, however, they contained a high concentration of structural defects (figure 19(a)). In such a structure it is likely that the stresses due to the mismatch on the interface will be relaxed in the M layers, not significantly influencing the core. The improved $M_{\mathrm{S}}$ and $M_{\mathrm{R}}$ of the bimagnetic composite nanoplatelets resulted in a large increase of the $(\mathrm{BH})_{\max }$, which was more than two times larger compared to that of the BFO cores (the $(\mathrm{BH})_{\max }$ was $7.2 \mathrm{~kJ} \mathrm{~m}^{-3}$ and $15.2 \mathrm{~kJ} \mathrm{~m}^{-3}$ for the cores and the composites, respectively) [71]. The result is very encouraging from the perspective of possible use of the composite nanoparticles as building blocks of permanent magnets. With optimization of the size of BFO core platelets and the composition and thickness of the spinel-ferrite shell the properties of the composite can be further improved.

\subsection{Dipolar coupling}

The third coupling discussed in the introduction corresponds to the absence of exchange-coupling between hard and soft phases. In this scenario, the internal dipolar interactions and the demagnetizing fields, especially of the high magnetization soft phases, normally lead to a substantial decrease of both remanence and coercivity. However, in certain conditions, the interphase dipolar interactions have been reported to lead to a shift in the hysteresis loop that entails an increase in remanence and energy product [176]. The idea is that mixing hard and soft with appropriate material's parameters, particle sizes, shapes and distribution, a certain fraction of the soft spins align with the effective $\mathrm{H}$ field created by the aligned SFO particles. A competition between the self-demagnetizing field of the soft and the effective 'external' field of the hard occurs.

This strategy has been scarcely pursued, although the idea pioneered by González, Montero and collaborators
$[176,177,208]$ has led to the recently finished European project AMPHIBIAN further studying its potential. In their work from 1998, Montero et al explain how a BFO platelet inside a bigger Fe particle would create an internal field that, after being magnetized, would oppose the self-demagnetizing field of Fe. Figure 21 schematizes the situation. The simplified picture allows bringing forward the fact that the dipolar energy of the system is clearly lowered if the hard and soft magnetic moments are aligned. As a consequence, the demagnetization is shifted in an exchange-bias-like type of effect. Of course, the magnitude of this effect strongly depends on the size and shape of the particles involved, as the stray field lines distribution will be greatly affected by it, but also on the specific geometrical arrangement of hard and soft particles inside the system [176, 177, 208].

Recent unpublished work by our group has led to the observation of an increase in remanence in perfectly decoupled $\mathrm{SFO} / \mathrm{Fe}$ magnetically oriented composite powders and injection molded magnets. With the aid of micromagnetic simulations, the results are interpreted as a consequence of a certain degree of alignment of the soft moments in the center of the Fe particles with the internal magnetic field lines of the hard. Unfortunately, the absence of exchange-coupling produces a loss of the squareness in the demagnetization curves that leads to a worse energy product even if remanence is increased.

An indirect way of exploiting the internal magnetodipolar interactions, in this case within the soft phase itself, is to fabricate composites based on high aspect-ratio soft nanostructures. Shape anisotropy can help stabilize large remanence values that can be exploited to fabricate permanent magnets. Recently accepted work [209] by the authors demonstrates a $40 \%$ increase in the energy product of $\mathrm{SFO} / \mathrm{FeCo}$ bonded magnets (with respect to pure SFO bonded magnets), based on nearly spherical SFO particles and a $30 \mathrm{wt} \%$ addition of $\mathrm{FeCo}$ nanowires. Figure 22 summarizes the main result.

Hard and 'soft' phases are completely decoupled in such a system, with the improvement of properties relying on 
the competitive properties of the $\mathrm{FeCo}$ nanowires themselves. This work constitutes an extremely promising strategy towards the development of rare-earth-free bonded magnets with improved properties.

\section{Conclusions and prospects}

In this review, we have gone over recent work dedicated to improving what is arguably the most popular material for permanent magnets, the M-type hexaferrites. Among the different methods that have been proposed, we have first considered the control of the nanoscale size and shape of the constituent particles. Engineering of both holds the promise of increasing coercivity. We believe that the main obstacles concern the realization of bulk magnets while preserving the advantage provided by nanostructuration and the need to find costefficient methods for the required size and shape control. So far, the promise of this approach remains to be fulfilled for real world materials.

Apparently the simpler route to improve the properties of M-hexaferrites for use in permanent magnet applications is to substitute cations that replace specific sites of the magnetoplumbite structure. This has produced the current best materials commercially available, the LaCo-doped ferrites, even if the increase of the $(\mathrm{BH})_{\max }$ is small $(10 \%)$. While further improvements are sought, the results are somewhat disappointing in terms of the published effort and reproducibility. This can be attributed to the difficulty in populating specific cation sites, a problem which is common to many other dopedoxides. Even if such a goal is achieved, the doping approach is hampered by how interrelated the magnetic properties are. Increasing the magnetization or the coercivity by substituting some cations in specific sites usually decreases the anisotropy or the magnetization, giving rise in both cases to modest improvements in the $(\mathrm{BH})_{\max }$ energy factor. The positive results obtained so far in terms of $M_{\mathrm{S}}$ and $H_{\mathrm{C}}$ enhancement leave room for improvement. This will probably require considering the structural and magnetic design with multi-cationic oxides, controlling the preparation route to get materials with suitable morphology to play with the shape anisotropy, and reducing the particle size in the submicrometric region to obtain higher coercivity. This will be helped by the ability to perform first principles calculations to guide the experiments. It is clear that the developed doped materials such as the Aldoped hexaferrites with high coercivity should be considered in application design to substitute rare earth magnets. We note that hybrid sintered magnets of Al-SFO and SFO have been recently obtained [210].

Concerning exchange-coupled hard/soft magnetic systems, promising results have been obtained both based on metals and oxides as the soft phase. Unfortunately, and this is a factor shared also by doping experiments, most of the reports focus on non-oriented, often not dense samples. In this scenario, a real assessment of the potential of these materials is lacking at the moment. The nature of the interphase magnetic coupling strongly depends on particle size, shape and bonding to the dissimilar phase, and thus the processing of the specimens to obtain dense oriented magnets is a critical step that needs to be addressed urgently.

As is the case for many other hard/soft systems based on other hard phases, it can be stated that results have been slightly disappointing thus far. It is the opinion of the authors of this review that the fact that interphase exchange-coupling can lead to a substantial decay of the coercivity $[5,37,38]$ may explain part of the situation. The soft phase acts as an extremely effective source of domain walls in the reversal process that rapidly propagate and produce this collapse. In this sense, strategies towards implementing lower degrees of exchange-coupling that do not facilitate domain wall propagation from the soft to the hard particles are very interesting. These observations contradict many of the initial theories developed for hard-soft composites, which brings forward the challenge associated with properly modelling these systems. Up to now, models have been either too simplistic or too complicated to effectively predict behavior. The future may lie in the hands of analytical models in this sense.

Another reason for the disappointing results may come from the extremely severe structural and geometrical requirements that have to be met in order to obtain effective and robust exchange-coupling. In hexaferrite based composites, the soft phase has to have a size below $20 \mathrm{~nm}$ and be coherently bonded to the ferrite particles. In addition, the advances in synthesis techniques of nanostructures has led to beautiful work and sophisticated systems that hold promise for the future. In this sense, the synthesis and processing challenge to realize such structures at thousands of tons per year rate is huge. In general, scaling up the synthesis of the next generation ferritebased systems may be the single most important challenge to address, and collaborations involving both research and industrial players are crucial in order to be successful.

The development of improved ferrite-based magnets needs to take into account the importance of fabricating materials that are orientable by a magnetic field as well. The raw materials powders have to be in an de-aggregated state and, ideally, the individual particles have to be single-crystalline or at least host a stable single-domain with uniaxial anisotropy. This will enable effective orientation under an external magnetic field before/during consolidation onto a dense body, which is crucial to ensure large energy products.

Also, the consolidation/densification step needs to be considered carefully. This is especially relevant for multiphase systems such as the composites discussed in section 3, as the processing needs to preserve the different phases. For instance, in the case of metal-oxide composites, novel sintering processes (cold sintering, pressure assisted methods) that prevent metal oxidation have to be implemented.

A hot topic is the design of 3D magnetic materials and magnets in particular [211,212]. Additive manufacturing will allow the development of novel magnets and implement them in different applications for electronics, sensing, medicine and automotive. Polymer-bonded technology is employed in some of these applications, but the 3D printing is being considered to get better near-net features and it could allow creating complex molded structures coupled to other properties like shape memory [213]. In addition, additive manufacturing is focused 
also on the development of 3D sintered ones. Advanced ferrites, as those here discussed, will allow the replacement of RE-compounds but also the design of the structures with different properties (higher remanence, higher coercivity or different magnetic orientation) to be incorporated in the 3D structures. Actually, early in-lab tests employ bulk ferrite [214] but optimized rheological properties of inks and precursor fibres could be obtained with the nanoparticles.

As a general prospect from the application point of view, it is worth noting that due to the promising results obtained in recent years related to the development of ferrite-based technologies, even moderate improvements in ferrite magnets could lead to substantial substitution of rare-earths in the market. In motors and generators, mild remanence enhancements can lead to significantly increased power output. In this sense, joint efforts both from the magnet side and the application side are important, as the ultimate goal of substitution will be achieved by fabricating a competitive final device.

Permanent magnets play a crucial role in low carbon technologies such as renewable energy generators and electric car motors and components. Thus, the pressing transition to a greener, more sustainable, future is expected to boost the demand in the next 10 years. This transition will be incomplete if we solely rely on rare-earth magnets due to the environmental impact associated with their mining. For these reasons, we expect ferrite-based motors for future mobility and generators for renewable energies to proliferate in the next few years.

\section{Acknowledgments}

This work was supported by the Slovenian Research Agency through research programs Nos. P2-0089 and P2-0412 and project J2-8166, by the Spanish Ministry of Science and Innovation through projects RTI2018-095303-BC51 and RTI2018-095303-A-C52, by the European Commission through Project H2020 No. 720853 (Amphibian) and by the Regional Government of Madrid through project S2018-NMT-4321. Authors want to thank Dr Darinka Primc and other colleagues who contributed to the research of bi-magnetic nanoplatelets at the Department for Materials Synthesis.

\section{ORCID iDs}

B Belec (D) https://orcid.org/0000-0001-5286-1871

A Quesada (D) https://orcid.org/0000-0002-6994-0514

\section{References}

[1] Carlson J B 1975 Lodestone compass: Chinese or Olmec primacy? Science $189753-60$

[2] Buschow K H J 1986 New permanent magnet materials Mater. Sci. Rep. 1 1-63

[3] Campbell P 1996 Permanent Magnet Materials and Their Application (Cambridge: Cambridge University Press)

[4] Smit H P J and Wijn J 1959 Ferrites (London: Cleaver-Hume)
[5] Okamoto A 2009 The invention of ferrites and their contribution to the miniaturization of radios 2009 IEEE Globecom Workshops pp 1-6

[6] Hitachi catalogue (http://www.hitachimetals.co.jp/e/products/auto/el/p03_05.html)

[7] Anon 2020 Permanent Magnets Market Size, Share \& Trends Analysis Report by Material (Ferrite, NdFeB, Alnico, SmCo), by Application (Medical, Consumer Goods \& Electronics), by Region, and Segment Forecasts, 2020-2027 (Grand View Research)

[8] Goldman A 2006 Modern Ferrite Technology (New York: Springer)

[9] Mahmood S H and Abu-Aljarayesh I 2016 Hexaferrite Permanent Magnetic Materials (Millersville, PA: Materials Research Forum )

[10] Odenbach S 2002 Magnetoviscous Effects in Ferrofluids (Berlin: Springer)

[11] Cao G 2004 Nanostructures and Nanomaterials: Synthesis, Properties and Applications (London: Imperial College Press)

[12] Skumryev V, Stoyanov S, Zhang Y, Hadjipanayis G, Givord D and Nogués J 2003 Beating the superparamagnetic limit with exchange bias Nature 423 850-3

[13] Massart R, Roger J and Cabuil V 1995 New trends in chemistry of magnetic colloids: polar and non polar magnetic fluids, emulsions, capsules and vesicles Braz. J. Phys. 257

[14] Blums E, Cebers A and Maiorov M 1997 Magnetic Fluids (Berlin: Walter de Gruyter)

[15] Borlido L, Azevedo A M, Roque A C A and Aires-Barros M R 2013 Magnetic separations in biotechnology Biotechnol. Adv. 31 1374-85

[16] Rosensweig R E 2014 Ferrohydrodynamics (Mineola, NY: Courier Corporation)

[17] Ditsch A, Yin J, Laibinis P E, Wang D I C and Hatton T A 2006 Ion-exchange purification of proteins using magnetic nanoclusters Biotechnol. Prog. 22 1153-62

[18] Lisjak D and Mertelj A 2018 Anisotropic magnetic nanoparticles: a review of their properties, syntheses and potential applications Prog. Mater. Sci. 95 286-328

[19] Thanh N T 2012 Magnetic Nanoparticles: From Fabrication to Clinical Applications (Boca Raton, FL: CRC Press)

[20] Khandhar A P, Ferguson R M, Simon J A and Krishnan K M 2012 Tailored magnetic nanoparticles for optimizing magnetic fluid hyperthermia J. Biomed. Mater. Res. A 100A 728-37

[21] Gonzales-Weimuller M, Zeisberger M and Krishnan K M 2009 Size-dependent heating rates of iron oxide nanoparticles for magnetic fluid hyperthermia J. Magn. Magn. Mater. 321 1947-50

[22] Jordan A, Scholz R, Wust P and Fa H 1999 Magnetic fluid hyperthermia (MFH): cancer treatment with $\mathrm{AC}$ magnetic field induced excitation of biocompatible superparamagnetic nanoparticles J. Magn. Magn. Mater. 7 413

[23] Babes L, Denizot B, Tanguy G, Le Jeune J J and Jallet P 1999 Synthesis of iron oxide nanoparticles used as MRI contrast agents: a parametric study J. Colloid Interface Sci. 212 474-82

[24] Hee Kim E, Sook Lee H, Kook Kwak B and Kim B-K 2005 Synthesis of ferrofluid with magnetic nanoparticles by sonochemical method for MRI contrast agent J. Magn. Magn. Mater. 289 328-30

[25] McCarthy J and Weissleder R 2008 Multifunctional magnetic nanoparticles for targeted imaging and therapy $A d v$. Drug Deliv. Rev. $601241-51$

[26] Kralj S, Potrc T, Kocbek P, Marchesan S and Makovec D 2017 Design and fabrication of magnetically responsive nanocarriers for drug delivery Curr. Med. Chem. 24 454-69 
[27] Pankhurst Q A, Thanh N T K, Jones S K and Dobson J 2009 Progress in applications of magnetic nanoparticles in biomedicine J. Phys. Appl. Phys. 42224001

[28] Kostevšek N 2020 A review on the optimal design of magnetic nanoparticle-based T2 MRI contrast agents Magnetochemistry 611

[29] Mertelj A, Lisjak D, Drofenik M and Čopič M 2013 Ferromagnetism in suspensions of magnetic platelets in liquid crystal Nature $\mathbf{5 0 4} 237-41$

[30] Medle Rupnik P, Lisjak D, Čopič M and Mertelj A 2015 Ferromagnetic liquid crystals for magnetic field visualisation Liq. Cryst. 42 1684-8

[31] Xuan R, Wu Q, Yin Y and Ge J 2011 Magnetically assembled photonic crystal film for humidity sensing $J$. Mater. Chem. 213672

[32] Ge J, He L, Hu Y and Yin Y 2011 Magnetically induced colloidal assembly into field-responsive photonic structures Nanoscale 3 177-83

[33] Ferk G, Krajnc P, Hamler A, Mertelj A, Cebollada F, Drofenik M and Lisjak D 2015 Monolithic magneto-optical nanocomposites of barium hexaferrite platelets in PMMA Sci. Rep. 511395

[34] Mertelj A, Osterman N, Lisjak D and Čopič M 2014 Magneto-optic and converse magnetoelectric effects in a ferromagnetic liquid crystal Soft Matter 10 9065-72

[35] Kushnir S E, Gavrilov A I, Kazin P E, Grigorieva A V, Tretyakov Y D and Jansen M 2012 Synthesis of colloidal solutions of $\mathrm{SrFe}_{12} \mathrm{O}_{19}$ plate-like nanoparticles featuring extraordinary magnetic-field-dependent optical transmission J. Mater. Chem. 22 18893-901

[36] Rožič B, Jagodič M, Gyergyek S, Drofenik M, Kralj S, Jagličić Z and Kutnjak Z 2012 Mixtures of magnetic nanoparticles and the ferroelectric liquid crystal: new soft magnetoelectrics Ferroelectrics 431 150-3

[37] Obradors X, Solans X, Collomb A, Samaras D, Rodriguez J, Pernet M and Font-Altaba M 1988 Crystal structure of strontium hexaferrite $\mathrm{SrFe}_{12} \mathrm{O}_{19}$ J. Solid State Chem. 72 218-24

[38] Holtstam D and Hålenius U 2020 Nomenclature of the magnetoplumbite group Mineral. Mag. 84 376-80

[39] Makovec D, Belec B, Goršak T, Lisjak D, Komelj M, Dražić $\mathrm{G}$ and Gyergyek S 2018 Discrete evolution of the crystal structure during the growth of Ba-hexaferrite nanoplatelets Nanoscale 10 14480-91

[40] Soria G D et al 2019 Strontium hexaferrite platelets: a comprehensive soft x-ray absorption and Mössbauer spectroscopy study Sci. Rep. 9 1-13

[41] Momma K and Izumi F 2011 VESTA3 for three-dimensional visualization of crystal, volumetric and morphology data J. Appl. Crystallogr. 44 1272-6

[42] Kojima H 1982 Chapter 5 fundamental properties of hexagonal ferrites with magnetoplumbite structure Handbook of Ferromagnetic Materials vol 3 (Amsterdam: Elsevier) pp 305-91

[43] Asti G, Bolzoni F and Cabassi R 1993 Singular point detection in multidomain samples J. Appl. Phys. $73323-33$

[44] Bolzoni F 1993 Magnetocrystalline anisotropy measurements in static or quasistatic magnetic fields Rev. Sci. Instrum. 64 1569-75

[45] Pieper M W, Kools F and Morel A 2002 NMR characterization of Co sites in $\mathrm{La}+\mathrm{Co}$-doped $\mathrm{Sr}$ hexaferrites with enhanced magnetic anisotropy Phys. Rev. B 65184402

[46] Grössinger R 1981 A critical examination of the law of approach to saturation. I. Fit procedure Phys. Status Solidi a 66 665-74
[47] Lewis L H and Jiménez-Villacorta F 2013 Perspectives on permanent magnetic materials for energy conversion and power generation Metall. Mater. Trans. A $442-20$

[48] Kittel C 1949 Physical theory of ferromagnetic domains Rev. Mod. Phys. 21 541-83

[49] Kitakami O, Goto K and Sakurai T 1988 A study of the magnetic domains of isolated fine particles of $\mathrm{Ba}$ ferrite Japan. J. Appl. Phys. 27 2274-7

[50] Shirk B T and Buessem W R 1970 Magnetic properties of barium ferrite formed by crystallization of a glass $J$. Am. Ceram. Soc. $\mathbf{5 3}$ 192-6

[51] Hirayama T, Ru Q, Tanji T and Tonomura A 1993 Observation of magnetic-domain states of barium ferrite particles by electron holography Appl. Phys. Lett. $63418-20$

[52] Wohlfarth E P 1983 Magnetic properties of single domain ferromagnetic particles J. Magn. Magn. Mater. 39 39-44

[53] Guo Z-B, Ding W-P, Zhong W, Zhang J-R and Du Y-W 1997 Preparation and magnetic properties of $\mathrm{SrFe}_{12} \mathrm{O}_{19}$ particles prepared by the salt-melt method J. Magn. Magn. Mater. 4333

[54] González J M, de Julián C, Giri A K, Castro S, Gayoso M and Rivas J 1996 Magnetic viscosity and microstructure: particle size dependence of the activation volume $J$. Appl. Phys. 795955

[55] Chen Y, Yang W, Lambeth D N and Kryder M H 1997 Incoherent rotation in barium ferrite thin film recording media IEEE Trans. Magn. 33 2998-3000

[56] Kubo O, Ido T, Yokoyama H and Koike Y 1985 Particle size effects on magnetic properties of $\mathrm{BaFe}_{12-2 \mathrm{x}} \mathrm{Ti}_{\mathrm{x}} \mathrm{Co}_{\mathrm{x}} \mathrm{O}_{19}$ fine particles J. Appl. Phys. 57 4280-2

[57] Chang T, Zhu J G and Judy J H 1993 Method for investigating the reversal properties of isolated barium ferrite fine particles utilizing magnetic force microscopy (MFM) J. Appl. Phys. 73 6716-8

[58] Tyagi S, Agarwala R C and Agarwala V 2010 Microwave absorption and magnetic studies of strontium hexaferrites nanoparticles synthesized by modified flux method $J$. Nano Res. 10 19-27

[59] Ghasemi A, Šepelák V, Liu X and Morisako A 2010 Mössbauer spectroscopy and magnetic susceptibility studies of $\mathrm{Cr}-\mathrm{Al}$ substituted strontium ferrite particles $J$. Appl. Phys. 107 09A743

[60] Lascialfari A, Filibian M, Sangregorio C and Caretta P 2013 In vivo biomedical applications of magnetic resonance and magnetic materials Riv. Nuovo Cimento 36 211-71

[61] Dho J, Lee E K, Park J Y and Hur N H 2005 Effects of the grain boundary on the coercivity of barium ferrite $\mathrm{BaFe}_{12} \mathrm{O}_{19}$ J. Magn. Magn. Mater. 285 164-8

[62] Saura-Múzquiz M, Granados-Miralles C, Andersen H L, Stingaciu M, Avdeev M and Christensen M 2018 Nanoengineered high-performance hexaferrite magnets by morphology-induced alignment of tailored nanoplatelets ACS Appl. Nano Mater. 1 6938-49

[63] Jing P, Du J, Wang J, Wei J, Pan L, Li J and Liu Q 2015 Width-controlled M-type hexagonal strontium ferrite $\left(\mathrm{SrFe}_{12} \mathrm{O}_{19}\right)$ nanoribbons with high saturation magnetization and superior coercivity synthesized by electrospinning Sci. Rep. 515089

[64] Zhang J, Fu J, Li F, Xie E, Xue D, Mellors N J and Peng Y $2012 \mathrm{BaFe}_{12} \mathrm{O}_{19}$ single-particle-chain nanofibers: preparation, characterization, formation principle, and magnetization reversal mechanism ACS Nano 6 2273-80

[65] Stoner E C and Wohlfarth P 1948 A mechanism of magnetic hysteresis in heterogeneous alloys Philos. Trans. R. Soc. A 240 599-642

[66] Pullar R 2012 Hexagonal ferrites: a review of the synthesis, properties and applications of hexaferrite ceramics Prog. Mater. Sci. 57 1191-334 
[67] Asti G, Solzi M, Ghidini M and Neri F M 2004 Micromagnetic analysis of exchange-coupled hard-soft planar nanocomposites Phys. Rev. B 691744401

[68] Volodchenkov A D, Kodera Y and Garay J E 2019 Nanoscale integration of oxides and metals in bulk $3 \mathrm{D}$ composites: leveraging $\mathrm{SrFe}_{12} \mathrm{O}_{19} / \mathrm{Co}$ interfaces for magnetic exchange coupling J. Mater. Sci. 54 8276-88

[69] Jenuš P, Topole M, McGuiness P, Granados-Miralles C, Stingaciu M, Christensen M, Kobe S, Žužek Rožman K and Belik A 2016 Ferrite-based exchange-coupled hard-soft magnets fabricated by spark plasma sintering $J$. Am. Ceram. Soc. 99 1927-34

[70] Belec B, Dražić G, Gyergyek S, Podmiljšak B, Goršak T, Komelj M, Nogués J and Makovec D 2017 Novel Ba-hexaferrite structural variations stabilized on the nanoscale as building blocks for epitaxial bi-magnetic hard/soft sandwiched maghemite/hexaferrite/maghemite nanoplatelets with out-of-plane easy axis and enhanced magnetization Nanoscale 9 17551-60

[71] Primc D and Makovec D 2015 Composite nanoplatelets combining soft-magnetic iron oxide with hard-magnetic barium hexaferrite Nanoscale 7 2688-97

[72] Kiani E, Rozatian A S H and Yousefi M H 2013 Synthesis and characterization of $\mathrm{SrFe}_{12} \mathrm{O}_{19}$ nanoparticles produced by a low-temperature solid-state reaction method J. Mater. Sci. Mater. Electron. 24 2485-92

[73] Lisjak D and Drofenik M 2012 Chemical substitution-an alternative strategy for controlling the particle size of barium ferrite Cryst. Growth Des. 12 5174-9

[74] Zhong W, Ding W, Zhang N, Hong J, Yan Q and Du Y 1997 Key step in synthesis of ultrafine $\mathrm{BaFe}_{12} \mathrm{O}_{19}$ by sol-gel technique J. Magn. Magn. Mater. 168 196-202

[75] Pullar R C and Bhattacharya A K 2002 Crystallisation of hexagonal $\mathrm{M}$ ferrites from a stoichiometric sol-gel precursor, without formation of the $\alpha-\mathrm{BaFe}_{2} \mathrm{O}_{4}$ intermediate phase Mater. Lett. 57 537-42

[76] Roos W 1980 Formation of chemically coprecipitated barium ferrite J. Am. Ceram. Soc. 63 601-3

[77] Lisjak D and Drofenik M 2007 The mechanism of the low-temperature formation of barium hexaferrite $J$. Eur. Ceram. Soc. 27 4515-20

[78] Dudziak S, Ryżyńska Z, Bielan Z, Ryl J, Klimczuk T and Zielińska-Jurek A 2020 Pseudo-superparamagnetic behaviour of barium hexaferrite particles $R S C A d v$. 10 18784-96

[79] Ding J, Miao W F, McCormick P G and Street R 1998 High-coercivity ferrite magnets prepared by mechanical alloying J. Alloys Compd. 281 32-36

[80] Tenorio-González F N, Bolarín-Miró A M, Sánchez-De Jesús F, Vera-Serna P, Menéndez-González N and Sánchez-Marcos J 2017 Crystal structure and magnetic properties of high Mn-doped strontium hexaferrite $J$. Alloys Compd. 695 2083-90

[81] Pillai V, Kumar P and Shah D O 1992 Magnetic properties of barium ferrite synthesized using a microemulsion mediated process J. Magn. Magn. Mater. 116 L299-304

[82] Xu P, Han X and Wang M 2007 Synthesis and magnetic properties of $\mathrm{BaFe}_{12} \mathrm{O}_{19}$ hexaferrite nanoparticles by a reverse microemulsion technique J. Phys. Chem. C $1115866-70$

[83] González-Carreño T, Morales M P and Serna C J 2000 Barium ferrite nanoparticles prepared directly by aerosol pyrolysis Mater. Lett. 43 97-101

[84] Martirosyan K S, Galstyan E, Hossain S M, Wang Y-J and Litvinov D 2011 Barium hexaferrite nanoparticles: synthesis and magnetic properties Mater. Sci. Eng. B $1768-13$
[85] Rezlescu L, Rezlescu E, Popa P D and Rezlescu N 1999 Fine barium hexaferrite powder prepared by the crystallisation of glass J. Magn. Magn. Mater. 193 288-90

[86] Müller R, Hiergeist R, Steinmetz H, Ayoub N, Fujisaki M and Schüppel W 1999 Barium hexaferrite ferrofluids - preparation and physical properties J. Magn. Magn. Mater. 201 34-37

[87] Barb D, Diamandescu L, Rusi A, Tărăbăsanu-mihăilă D, Morariu M and Teodorescu V 1986 Preparation of barium hexaferrite by a hydrothermal method: structure and magnetic properties J. Mater. Sci. 21 1118-22

[88] Ataie A, Harris I R and Ponton C B 1995 Magnetic properties of hydrothermally synthesized strontium hexaferrite as a function of synthesis conditions J. Mater. Sci. 30 1429-33

[89] Ataie A, Piramoon M R, Harris I R and Ponton C B 1995 Effect of hydrothermal synthesis environment on the particle morphology, chemistry and magnetic properties of barium hexaferrite J. Mater. Sci. 30 5600-6

[90] Drofenik M, Kristl M, Žnidaršič A, Hanžel D and Lisjak D 2007 Hydrothermal synthesis of Ba-hexaferrite nanoparticles J. Am. Ceram. Soc. 90 2057-61

[91] Drofenik M, Ban I, Ferk G, Makovec D, Žnidaršič A, Jagličić $\mathrm{Z}$ and Lisjak D 2010 The concept of a low-temperature synthesis for superparamagnetic $\mathrm{BaFe}_{12} \mathrm{O}_{19}$ particles $J$. Am. Ceram. Soc. 93 1602-7

[92] Li Y, Wang Q and Yang H 2009 Synthesis, characterization and magnetic properties on nanocrystalline $\mathrm{BaFe}_{12} \mathrm{O}_{19}$ ferrite Curr. Appl. Phys. 9 1375-80

[93] Sözeri H, Durmuş Z, Baykal A and Uysal E 2012 Preparation of high quality, single domain $\mathrm{BaFe}_{12} \mathrm{O}_{19}$ particles by the citrate sol-gel combustion route with an initial $\mathrm{Fe} / \mathrm{Ba}$ molar ratio of 4 Mater. Sci. Eng. B 177 949-55

[94] Meng Y Y, He M H, Zeng Q, Jiao D L, Shukla S, Ramanujan R V and Liu Z W 2014 Synthesis of barium ferrite ultrafine powders by a sol-gel combustion method using glycine gels J. Alloys Compd. 583 220-5

[95] Sudakar C, Subbanna G N and Kutty T R N 2003 Wet chemical synthesis of multicomponent hexaferrites by gel-to-crystallite conversion and their magnetic properties J. Magn. Magn. Mater. 263 253-68

[96] Nga T T V, Duong N P, Loan T T and Hien T D 2014 Key step in the synthesis of ultrafine strontium ferrite powders $\left(\mathrm{SrFe}_{12} \mathrm{O}_{19}\right)$ by sol-gel method J. Alloys Compd. 610 630-4

[97] Suastiyanti D, Sudarmaji A and Soegijono B 2011 Influence of $\mathrm{Ba} / \mathrm{Fe}$ mole ratios on magnetic properties, crystallite size and shifting of $\mathrm{x}$-ray diffraction peaks of nanocrystalline $\mathrm{BaFe}_{12} \mathrm{O}_{19}$ powder, prepared by sol gel auto combustion AIP Conf. Proc. 1454 238-41

[98] Yu H F and Liu P C 2006 Effects of pH and calcination temperatures on the formation of citrate-derived hexagonal barium ferrite particles J. Alloys Compd. 416 222-7

[99] Xia A, Hu X, Li D, Chen L, Jin C, Zuo C and Su S 2014 Hydrothermal hexagonal $\mathrm{SrFe}_{12} \mathrm{O}_{19}$ ferrite powders: phase composition, microstructure and acid washing Electron. Mater. Lett. 10 423-6

[100] Zhang T et al 2016 Platelet-like hexagonal $\mathrm{SrFe}_{12} \mathrm{O}_{19}$ particles: hydrothermal synthesis and their orientation in a magnetic field J. Magn. Magn. Mater. 412 102-6

[101] Raghuram N, Rao T S and Naidu K C B 2019 Magnetic properties of hydrothermally synthesized $\mathrm{Ba}_{1-\mathrm{x}} \mathrm{Sr}_{\mathrm{x}} \mathrm{Fe}_{12} \mathrm{O}_{19}$ ( $\mathrm{x}=0.0-0.8)$ nanomaterials Appl. Phys. A 125839

[102] Al-Hwaitat E S, Dmour M K, Bsoul I, Al-Buqain R and Mahmood S H 2020 A comparative study of $\mathrm{Ba}_{\mathrm{x}} \mathrm{Sr}_{1-\mathrm{x}} \mathrm{Fe}_{12} \mathrm{O}_{19}$ ferrite permanent magnets prepared by ball milling and sol-gel routes J. Phys. Appl. Phys. 53364001 
[103] Koutzarova T, Kolev S, Grigorov K, Ghelev C, Zaleski A, Vandenberghe R E, Ausloos M, Henrist C, Cloots R and Nedkov I 2010 Structural and magnetic properties of nanosized barium hexaferrite powders obtained by microemulsion technique Solid State Phenom. 159 57-62

[104] Petrecca M, Muzzi B, Oliveri S M, Albino M, Yaacoub N, Peddis D, de Julián Fernández C, Innocenti C and Sangregorio C 2020 Optimizing the magnetic properties of hard and soft materials for producing exchange spring permanent magnets J. Phys. D: Appl. Phys (https://doi.org/10.1088/1361-6463/abd354)

[105] Fayling R E 1978 Relationship between coercive force and anisotropy field for oriented barium ferrite tapes and magnets J. Appl. Phys. 49 1823-5

[106] Liu G F, Fan R H, Zhang Z D, Li J, Chen M, Li Q Q, Lu L and Xie P T 2017 Magnetic properties and special morphology of barium ferrite via electrospinning Rare Met. 36 113-7

[107] Dionne G F 2009 Magnetic Oxides (New York: Springer)

[108] Albanese G and Deriu A 1979 Magnetic properties of Al, Ga, Sc, In substituted barium ferrites: a comparative analysis Ceramurg. Int. 5 3-10

[109] Trukhanov S V, Trukhanov A V, Turchenko V A, Kostishyn V G, Panina L V, Kazakevich I S and Balagurov A M 2016 Structure and magnetic properties of $\mathrm{BaFe}_{11.9} \mathrm{In}_{0.1} \mathrm{O}_{19}$ hexaferrite in a wide temperature range J. Alloys Compd. 689 383-93

[110] Trukhanov A V, Kostishyn V G, Panina L V, Jabarov S H, Korovushkin V V, Trukhanov S V and Trukhanova E L 2017 Magnetic properties and Mössbauer study of gallium doped M-type barium hexaferrites Ceram. Int. 43 12822-7

[111] Coey J M D 2010 Magnetism and Magnetic Materials (Cambridge: Cambridge University Press)

[112] Stevens K W H and Bates C A 1975 Crystal field theory Magnetic Oxides ed D J Craik (Bristol: Willey) pp 141-80

[113] Obradors X, Collomb A, Pernet M and Samaras D 1985 $\mathrm{X}$-ray analysis of the structural and dynamic properties of $\mathrm{BaFe}_{12} \mathrm{O}_{19}$ hexagonal ferrite at room temperature $J$. Solid State Chem. 56 171-81

[114] Ounnunkad S 2006 Improving magnetic properties of barium hexaferrites by La or Pr substitution Solid State Commun. 138 472-5

[115] Lechevallier L, Le Breton J M, Morel A and Tenaud P 2008 On the solubility of rare earths in M-type $\mathrm{SrFe}_{12} \mathrm{O}_{19}$ hexaferrite compounds J. Phys. Condens. Matter 20175203

[116] TDK Electronics Ferrite Materials Catalog (https://www.tdkelectronics.tdk.com/en/529404/products/productcatalog/ferrites-and-accessories/epcos-ferrites-andaccessories/ferrite-materials)

[117] Yamamoto H, Nagakura M and Terada H 1990 Magnetic properties of anisotropic Sr-La system ferrite magnets IEEE Trans. Magn. 26 1144-8

[118] Kools F, Morel A, Grössinger R, Le Breton J M and Tenaud P 2002 LaCo-substituted ferrite magnets, a new class of high-grade ceramic magnets; intrinsic and microstructural aspects J. Magn. Magn. Mater. 242-5 1270-6

[119] Küpferling M, Grössinger R, Flores V C and Aquino J M Magnetization and magnetocrystalline anisotropy of $\mathrm{LaFe}_{12} \mathrm{O}_{19}$ hexaferrite $\mathrm{p} 6$

[120] Grössinger R, Tellez Blanco C, Küpferling M, Müller M and Wiesinger G 2003 Magnetic properties of a new family of rare-earth substituted ferrites Physica B 327 202-7

[121] Iida K, Minachi Y, Masuzawa K, Kawakami M, Nishio H and Taguchi H 1999 High-performance ferrite magnets: M-type Sr-ferrite containing lanthanum and cobalt $J$. Magn. Soc. Japan 23 1093-6
[122] Morel A, Breton J M L, Kreisel J, Wiesinger G, Kools F and Tenaud P 2002 Sublattice occupation in $\mathrm{Sr}_{1-\mathrm{x}} \mathrm{La}_{\mathrm{x}} \mathrm{Fe}_{12-\mathrm{x}} \mathrm{Co}_{\mathrm{x}} \mathrm{O}_{19}$ hexagonal ferrite analyzed by Mössbauer spectrometry and Raman spectroscopy $J$. Magn. Magn. Mater. 31405

[123] Nishio H, Minachi Y and Yamamoto H 2009 Effect of factors on coercivity in $\mathrm{Sr}-\mathrm{La}-\mathrm{Co}$ sintered ferrite magnets IEEE Trans. Magn. 45 5281-8

[124] Kikuchi T, Nakamura T, Yamasaki T, Nakanishi M, Fujii T, Takada J and Ikeda Y 2010 Magnetic properties of La-Co substituted M-type strontium hexaferrites prepared by polymerizable complex method J. Magn. Magn. Mater. 322 2381-5

[125] Asti G, Bolzoni F, Le Breton J M, Ghidini M, Morel A, Solzi M, Kools F and Tenaud P 2004 Magnetic anisotropy of LaCo-substituted $\mathrm{SrFe}_{12} \mathrm{O}_{19}$ ferrites J. Magn. Magn. Mater. 272-6 E1845-6

[126] Tenaud P, Morel A, Kools F, Le Breton J M and Lechevallier L 2004 Recent improvement of hard ferrite permanent magnets based on La-Co substitution J. Alloys Compd. $370331-4$

[127] Lechevallier L and Le Breton J M 2005 Substitution effects in M-type hexaferrite powders investigated by Mössbauer spectrometry J. Magn. Magn. Mater. 290-1 1237-9

[128] Kobayashi Y, Oda E, Nishiuchi T and Nakagawa T 2011 Cation distribution analysis of Sr-La-Co M-type ferrites by neutron diffraction, extended $\mathrm{x}$-ray absorption fine structure and x-ray magnetic circular dichroism J. Ceram. Soc. Japan 119 285-90

[129] Shimoda A, Takao K, Uji K, Waki T, Tabata Y and Nakamura H 2016 Flux growth of magnetoplumbite-type strontium ferrite single crystals with $\mathrm{La}-\mathrm{Co}$ co-substitution J. Solid State Chem. 239 153-8

[130] Ueda H, Tanioku Y, Michioka C and Yoshimura K 2017 Magnetocrystalline anisotropy of La- and Co-substituted M-type strontium ferrites: role of $\mathrm{Co}^{2+}$ and $\mathrm{Fe}^{2+}$ Phys. Rev. B 95224421

[131] Givord D, Rossignol M and Barthem V M T S 2003 The physics of coercivity J. Magn. Magn. Mater. 258-9 1-5

[132] Tyrman M, Pasko A, De La Barrière O and Mazaleyrat F 2015 Structural and magnetic properties of an anisotropic M-type LaCo-substituted strontium hexaferrite Eur. Phys. J. Appl. Phys. 7220601

[133] Brady L J 1975 The determination of the demagnetization factor resulting from shape anisotropy in ferrite magnets $J$. Mater. Sci. 10 697-704

[134] Huang X et al 2015 Microstructure and magnetic properties of Ca-substituted M-type SrLaCo hexagonal ferrites $J$. Magn. Magn. Mater. 378 424-8

[135] Chen Z, Wang F, Yan S and Feng Z 2014 Microstructure and magnetic properties of M-type $\mathrm{Sr}_{0.61-\mathrm{x}} \mathrm{La}_{0.39} \mathrm{Ca}_{\mathrm{x}} \mathrm{Fe}_{11.7} \mathrm{Co}_{0.3} \mathrm{O}_{19}$ hexaferrite prepared by microwave calcination Mater. Sci. Eng. B 182 69-73

[136] Chen Z, Wang F, Yan S, Nie Y, Feng Z, Chen Y and Harris V G 2014 Enhanced coercivity of CaLaCo-doped SrM hexaferrites by microwave-calcination technique $J$. Am. Ceram. Soc. 97 1873-7

[137] Yang Y, Wang F, Shao J, Huang D, Liu X, Feng S and Wen C 2015 The impact of $\mathrm{Co} / \mathrm{La}$ ratios on microstructure and magnetic properties of the $\mathrm{Sr}_{0.75-\mathrm{x}} \mathrm{Ca}_{0.25} \mathrm{La}_{\mathrm{x}} \mathrm{Fe}_{12-\mathrm{y}} \mathrm{Co}_{\mathrm{y}} \mathrm{O}_{19}$ hexaferrites J. Magn. Magn. Mater. 384 64-69

[138] Du Y, Liu Y, Lian L and Du J 2019 Structural and magnetic properties of $\mathrm{Sr}_{0.8} \mathrm{La}_{0.2} \mathrm{Co}_{0.2} \mathrm{Fe}_{11.8} \mathrm{Al} \mathrm{O}_{19}$ hexaferrite particles prepared via sol-gel auto-combustion method $J$. Magn. Magn. Mater. 469 189-95

[139] Wang M, Xu Q, Liu J, Wang Z, Ma N and Du P 2019 Extra up-spin magnetic moments and extraordinary high saturation magnetization of $\mathrm{Ni}^{2+}$ doped barium ferrite in $4 \mathrm{f}_{2}$ site Mater. Res. Express 6086104 
[140] Wartewig P, Krause M K, Esquinazi P, Rösler S and Sonntag R 1999 Magnetic properties of $\mathrm{Zn}$ - and Ti-substituted barium hexaferrite J. Magn. Magn. Mater. 192 83-99

[141] Abdellahi M, Najfinezhad A, Saber-Samanadari S, Khandan A and Ghayour H $2018 \mathrm{Zn}$ and Zr co-doped M-type strontium hexaferrite: synthesis, characterization and hyperthermia application Chin. J. Phys. 56 331-9

[142] Ghasemi A, Šepelák V, Liu X and Morisako A 2010 The role of cations distribution on magnetic and reflection loss properties of ferrimagnetic $\mathrm{SrFe}_{12-\mathrm{x}}\left(\mathrm{Sn}_{0.5} \mathrm{Zn}_{0.5}\right)_{\mathrm{x}} \mathrm{O}_{19} J$. Appl. Phys. 107 09A734

[143] Widyastuti , Sasria N, Alviani A M, Febri R M D and Vania Mitha P $2017 \mathrm{Ni}$ and Zn substituted M-type barium hexaferrite processed by sol-gel auto combustion method J. Phys. Conf. Ser. 877012015

[144] Sapoletova N, Kushnir S, Ahn K, An S Y, Choi M, Kim J Y, Choi $\mathrm{C}$ and Wi S $2016 \mathrm{M}-\mathrm{Zn}(\mathrm{M}=\mathrm{Sb}, \mathrm{V}$, and $\mathrm{Nb})$ substituted strontium hexaferrites with enhanced saturation magnetization for permanent magnet applications J. Magn. 21 315-21

[145] Taguchi H 1997 Recent improvements of ferrite magnets $J$. Phys. IV 07 C1-299-302

[146] Carol Trudel T T, Mohammed J, Hafeez H Y, Bhat B H, Godara S K and Srivastava A K 2019 Structural, dielectric, and magneto-optical properties of Al-Cr substituted M-type barium hexaferrite Phys. Status Solidi a 2161800928

[147] Dixit V, Kim S-G, Park J and Hong Y-K 2017 Effect of ionic substitutions on the magnetic properties of strontium hexaferrite: a first principles study AIP Adv. 7115209

[148] Li Z W, Ong C K, Yang Z, Wei F L, Zhou X Z, Zhao J H and Morrish A H 2000 Site preference and magnetic properties for a perpendicular recording material:

$\mathrm{BaFe}_{12-\mathrm{x}} \mathrm{Zn}_{2} \mathrm{Zr}_{\mathrm{x}} 2 \mathrm{O}_{19}$ nanoparticles Phys. Rev. B 62 6530-7

[149] Fang H C, Yang Z, Ong C K, Li Y and Wang C S 1998 Preparation and magnetic properties of $(\mathrm{Zn}-\mathrm{Sn})$ substituted barium hexaferrite nanoparticles for magnetic recording J. Magn. Magn. Mater. 187 129-35

[150] Bsoul I, Mahmood S H and Lehlooh A-F 2010 Structural and magnetic properties of $\mathrm{BaFe}_{12-2 \mathrm{x}} \mathrm{Ti}_{\mathrm{x}} \mathrm{Ru}_{\mathrm{x}} \mathrm{O}_{19} \mathrm{~J}$. Alloys Compd. 498 157-61

[151] Bsoul I, Mahmood S H, Lehlooh A-F and Al-Jamel A 2013 Structural and magnetic properties of $\mathrm{SrFe}_{12-2 \mathrm{x}} \mathrm{Ti}_{\mathrm{x}} \mathrm{Ru}_{\mathrm{x}} \mathrm{O}_{19}$ J. Alloys Compd. $\mathbf{5 5 1}$ 490-5

[152] Soman V V, Nanoti V M, Kulkarni D K and Soman V V 2014 Effect of substitution of $\mathrm{Zn}-\mathrm{Ti}$ on magnetic and dielectric properties of $\mathrm{BaFe}_{12} \mathrm{O}_{19}$ Phys. Procedia 54 30-37

[153] Ben Ghzaiel T, Dhaoui W, Pasko A and Mazaleyrat F 2016 Effect of non-magnetic and magnetic trivalent ion substitutions on BaM-ferrite properties synthesized by hydrothermal method J. Alloys Compd. 671 245-53

[154] Awawdeh M, Bsoul I and Mahmood S H 2014 Magnetic properties and Mössbauer spectroscopy on $\mathrm{Ga}, \mathrm{Al}$, and $\mathrm{Cr}$ substituted hexaferrites J. Alloys Compd. 585 465-73

[155] Luo H, Rai B K, Mishra S R, Nguyen V V and Liu J P 2012 Physical and magnetic properties of highly aluminum doped strontium ferrite nanoparticles prepared by auto-combustion route J. Magn. Magn. Mater. $3242602-8$

[156] Wang H Z et al 2012 Improvement of the coercivity of strontium hexaferrite induced by substitution of $\mathrm{Al}^{3+}$ ions for $\mathrm{Fe}^{3+}$ ions J. Alloys Compd. 537 43-49

[157] Wang H Z, Hai Y N, Yao B, Xu Y, Shan L, Xu L, Tang J L and Wang Q H 2017 Tailoring structure and magnetic characteristics of strontium hexaferrite via $\mathrm{Al}$ doping engineering J. Magn. Magn. Mater. 422 204-8

[158] Rhein F, Karmazin R, Krispin M, Reimann T and Gutfleisch O 2017 Enhancement of coercivity and saturation magnetization of $\mathrm{Al}^{3+}$ substituted M-type Sr-hexaferrites J. Alloys Compd. 690 979-85

[159] Sahu R K, Mohanta O and Pramanik A K 2012 XPS study on the correlation of magnetic properties and site occupancy of $\mathrm{Al}$ doped $\mathrm{SrFe}_{12} \mathrm{O}_{19}$ J. Alloys Compd. 532 114-20

[160] Kazin P E, Trusov L A, Zaitsev D D, Tretyakov Y D and Jansen M 2008 Formation of submicron-sized $\mathrm{SrFe}_{12-\mathrm{x}} \mathrm{Al}_{\mathrm{x}} \mathrm{O}_{19}$ with very high coercivity J. Magn. Magn. Mater. 320 1068-72

[161] Sharma P, Rocha R A, Medeiros S N, Hallouche B and Paesano A 2007 Structural and magnetic studies on mechanosynthesized $\mathrm{BaFe}_{12-\mathrm{x}} \mathrm{Mn}_{\mathrm{x}} \mathrm{O}_{19}$ J. Magn. Magn. Mater. 316 29-33

[162] Katlakunta S, Meena S S, Srinath S, Bououdina M, Sandhya R and Praveena K 2015 Improved magnetic properties of $\mathrm{Cr}^{3+}$ doped $\mathrm{SrFe}_{12} \mathrm{O}_{19}$ synthesized via microwave hydrothermal route Mater. Res. Bull. 63 58-66

[163] Alamenu Mangai K, Selvi K T and Priya M 2020 Effect of Co and Sm substitutions on the magnetic interactions of M-type strontium hexaferrite nanoparticles J. Supercond. Nov. Magn. 33 713-20

[164] Yang Y, Wang F, Liu X, Shao J and Huang D 2017 Magnetic and microstructural properties of Al substituted M-type $\mathrm{Ca}-\mathrm{Sr}$ hexaferrites J. Magn. Magn. Mater. 421 349-54

[165] Trusov L A, Gorbachev E A, Lebedev V A, Sleptsova A E, Roslyakov I V, Kozlyakova E S, Vasiliev A V, Dinnebier R E, Jansen M and Kazin P E 2018 Ca-Al double-substituted strontium hexaferrites with giant coercivity Chem. Commun. 54 479-82

[166] Gorbachev E A et al 2020 Hexaferrite materials displaying ultra-high coercivity and sub-terahertz ferromagnetic resonance frequencies Mater. Today 32 13-18

[167] Stingaciu M, Mishra D, de Julián Fernández C, Cabassi R, Eikeland A Z, Christensen M and Deledda S 2020 High magnetic coercive field in $\mathrm{Ca}-\mathrm{Al}-\mathrm{Cr}$ substituted strontium hexaferrite Acta Mater.

[168] Shekhawat D, Prajapati S and Roy P K 2019 Influence of site preferences on structural and magnetic properties of $\mathrm{Cr}-\mathrm{Sn}$ substituted $\mathrm{SrAl}_{4} \mathrm{Fe}_{8} \mathrm{O}_{19}$ hexa-ferrite, an improved ceramic permanent magnet J. Appl. Phys. 126063903

[169] Dhage V N, Mane M L, Keche A P, Birajdar C T and Jadhav K M 2011 Structural and magnetic behaviour of aluminium doped barium hexaferrite nanoparticles synthesized by solution combustion technique Physica B 406 789-93

[170] Behera P and Ravi S 2017 Influence of Al substitution on structural, dielectric and magnetic properties of M-type barium hexaferrite J. Supercond. Nov. Magn. 30 1453-61

[171] Dixit V, Nandadasa C N, Kim S-G, Kim S, Park J, Hong Y-K, Liyanage L S I and Moitra A 2015 Site occupancy and magnetic properties of Al-substituted M-type strontium hexaferrite J. Appl. Phys. 117243904

[172] Ustinov A B, Tatarenko A S, Srinivasan G and Balbashov A M 2009 Al substituted Ba-hexaferrite single-crystal films for millimeter-wave devices J. Appl. Phys. $\mathbf{1 0 5} 023908$

[173] Obradors X, Collomb A, Pernet M and Joubert J C 1984 Structural and magnetic properties of $\mathrm{BaFe}_{1-\mathrm{x}} \mathrm{Mn}_{\mathrm{x}} \mathrm{O}_{19}$ hexagonal ferrites J. Magn. Magn. Mater. 44 118-28

[174] Kneller E F and Hawig R 1991 The exchange-spring magnet: a new material principle for permanent magnets IEEE Trans. Magn. 27 3588-3560

[175] Ma Y L, Liu X B, Gandha K, Vuong N V, Yang Y B, Yang J B, Poudyal N, Cui J and Liu J P 2014 Preparation and magnetic properties of MnBi-based hard/soft composite magnets J. Appl. Phys. 115 99-102

[176] Montero M I, Cebollada F, Morales M P, González J M and Hernando A 1998 Magnetic interactions in $\mathrm{Fe}-\mathrm{Ba}$ hexaferrite nanocomposite materials J. Appl. Phys. 836277 
[177] González J M, Montero M I, Raposo V, Crespo P, Marín P and Hernando A 2000 Dipolar interactions in hard-soft nanocomposites Interactions 36 3342-4

[178] Arcas J, Hernando A, Barandiarán J, Prados C, Vázquez M, Marín P and Neuweiler A 1998 Soft to hard magnetic anisotropy in nanostructured magnets Phys. Rev. B 58 5193-6

[179] AMPHIBIAN AnisoMetric permanent hybrid magnets based on inexpensive and non-critical materials H2020-NMBP-2016-720853

[180] Jensen P J, Dreysse H and Bennemann K H 1992 Calculation of the film-thickness-dependence of the curie temperature in thin transition metal films EPL 18 463-8

[181] Shen Yan S, Ting Xu F, Weston J L, Zangari G and Barnard J A 2001 Critical dimension of the transition from single switching to an exchange spring process in hard/soft exchange-coupled bilayers Phys. Rev. B 64 1-6

[182] Viart N, Hassan R S, Mény C, Panissod P, Ulhaq-Bouillet C, Loison J L, Versini G, Huber F and Pourroy G 2005 Diversity of the magnetic coupling behaviors in the $\mathrm{CoFe}_{2} / \mathrm{CoFe}_{2} \mathrm{O}_{4}$ system Appl. Phys. Lett. 86192514

[183] Asti G, Solzi M and Ghidini M 2001 Reversal modes of the multilayer exchange-spring magnet J. Magn. Magn. Mater. 226 1464-6

[184] Asti G, Ghidini M, Pellicelli R, Pernechele C, Solzi M, Albertini F, Casoli F, Fabbrici S and Pareti L 2006 Magnetic phase diagram and demagnetization processes in perpendicular exchange-spring multilayers Phys. Rev. B $731-16$

[185] Quesada A et al 2018 Exchange-spring behavior below the exchange length in hard-soft bilayers in multidomain configurations Phys. Rev. B 98 1-7

[186] Hirosawa S, Nishino M and Miyashita S 2017 Perspectives for high-performance permanent magnets: applications, coercivity, and new materials Adv. Nat. Sci. Nanosci. Nanotechnol. 8013002

[187] Viart $\mathrm{N}$ et al 2006 Oxidation processes at the metal/oxide interface in $\mathrm{CoFe}_{2} / \mathrm{CoFe}_{2} \mathrm{O}_{4}$ bilayers deposited by pulsed laser deposition Acta Mater. 54 191-6

[188] Xu X, Hong Y K, Park J, Lee W and Lane A M 2016 Ex situ synthesis of magnetically exchange coupled $\mathrm{SrFe}_{12} \mathrm{O}_{19} / \mathrm{Fe}-\mathrm{Co}$ composites AIP Adv. 6056026

[189] Li D, Wang F, Xia A, Zhang L, Li T, Jin C and Liu X 2016 A facile way to realize exchange coupling interaction in hard/soft magnetic composites J. Magn. Magn. Mater. $417355-8$

[190] Zhang H 2020 Magnetic properties and thermal stability of $\mathrm{SrFe}_{12} \mathrm{O}_{19} / \gamma-\mathrm{Fe}_{4} \mathrm{~N}$ composites with effective magnetic exchange coupling Ceram. Int. 46 9972-7

[191] Quesada A et al 2016 Energy product enhancement in imperfectly exchange-coupled nanocomposite magnets Adv. Electron. Mater. 21500365

[192] Xu X, Hong Y K, Park J, Lee W and Lane A M 2015 Exchange coupled $\mathrm{SrFe}_{12} \mathrm{O}_{19} / \mathrm{Fe}-\mathrm{Co}$ core/shell particles with different shell thickness Electron. Mater. Lett. 11 1021-7

[193] Xu X, Park J, Hong Y K and Lane A M 2015 Magnetically self-assembled $\mathrm{SrFe}_{12} \mathrm{O}_{19} / \mathrm{Fe}-\mathrm{Co}$ core/shell particles Mater. Chem. Phys. 152 9-12

[194] Dong J, Zhang Y, Zhang X, Liu Q and Wang J 2014 Improved magnetic properties of $\mathrm{SrFe}_{12} \mathrm{O}_{19} / \mathrm{FeCo}$ core-shell nanofibers by hard/soft magnetic exchange-coupling effect Mater. Lett. 120 9-12

[195] Quesada A, Rubio-Marcos F, Marco J F, Mompean F J, García-Hernández M and Fernández J F 2014 On the origin of remanence enhancement in exchange-uncoupled $\mathrm{CoFe}_{2} \mathrm{O}_{4}$-based composites Appl. Phys. Lett. 105202405
[196] Xia A, Li Y, Li T, Su S, Jin C and Liu X 2016 The availability of Henkel plots for sintered hard/soft magnetic composite ferrites Physica B 493 14-16

[197] Cullity B D and Graham C D 2008 Ferromagnetism Introduction to Magnetic Materials (Hoboken, NJ: Wiley) pp 115-49

[198] Saeedi Afshar S R, Masoudpanah S M and Hasheminiasari M 2020 Effects of calcination temperature on magnetic and microwave absorption properties of $\mathrm{SrFe}_{12} \mathrm{O}_{19}$ / $\mathrm{Ni}_{0.6} \mathrm{Zn}_{0.4} \mathrm{Fe}_{2} \mathrm{O}_{4}$ composites J. Electron. Mater. 49 1742-8

[199] Dahal J N, Neupane D and Poudel T P 2019 Synthesis and magnetic properties of 4:1 hard-soft $\mathrm{SrFe}_{12} \mathrm{O}_{19}-\mathrm{La}_{1-\mathrm{x}} \mathrm{Sr}_{\mathrm{x}} \mathrm{MnO}_{3}$ nanocomposite prepared by auto-combustion method AIP Adv. 9075308

[200] Song F, Shen X, Liu M and Xiang J 2011 Magnetic hard/soft nanocomposite ferrite aligned hollow microfibers and remanence enhancement J. Colloid Interface Sci. 354 413-6

[201] Mohseni F, Pullar R C, Vieira J M and Amaral J S 2019 Enhancement of maximum energy product in exchange-coupled $\mathrm{BaFe}_{12} \mathrm{O}_{19} / \mathrm{Fe}_{3} \mathrm{O}_{4}$ core-shell-like nanocomposites J. Alloys Compd. 806 120-6

[202] Volodchenkov A D, Kodera Y and Garay J E 2016 Coupled nano-powders with improved energy product for rare earth free permanent magnet applications J. Mater. Chem. C $45593-601$

[203] Primc D, Belec B and Makovec D 2016 Synthesis of composite nanoparticles using co-precipitation of a magnetic iron-oxide shell onto core nanoparticles $J$. Nanoparticle Res. 1864

[204] Asuha S, Zhao S, Wu H Y, Song L and Tegus O 2009 One step synthesis of maghemite nanoparticles by direct thermal decomposition of $\mathrm{Fe}$-urea complex and their properties J. Alloys Compd. $472 \mathrm{~L} 23-5$

[205] Makovec D, Komelj M, Dražić G, Belec B, Goršak T, Gyergyek S and Lisjak D 2019 Incorporation of Sc into the structure of barium-hexaferrite nanoplatelets and its extraordinary finite-size effect on the magnetic properties Acta Mater. 172 84-91

[206] Zeng H, Li J, Liu J P, Wang Z L and Sun S 2002 Exchange-coupled nanocomposite magnets by nanoparticle self-assembly Nature 420 395-8

[207] Sellmyer D J 2002 Strong magnets by self-assembly Nature $420374-5$

[208] González J M, Montero M I, Raposo V and Hernando A 2000 On the relationship between the hysteresis loop shift and the dipolar interactions in hard-soft nanocomposite samples J. Magn. Magn. Mater. 221 187-95

[209] Guzmán-Mínguez J C et al 2020 FeCo nanowire-strontium ferrite powder composites for permanent magnets with high-energy products ACS Appl. Nano Mater. 3 9842-51

[210] Rhein F, Helbig T, Neu V, Krispin M and Gutfleisch O 2018 In-situ magnetic force microscopy analysis of magnetization and demagnetization behavior in $\mathrm{Al}^{3+}$ substituted Sr-hexaferrite Acta Mater. 146 85-96

[211] Lamichhane T N, Sethuraman L, Dalagan A, Wang H, Keller $\mathrm{J}$ and Paranthaman M P 2020 Additive manufacturing of soft magnets for electrical machines-a review Mater. Today Phys. 15100255

[212] Huber C et al 2016 3D print of polymer bonded rare-earth magnets, and 3D magnetic field scanning with an end-user 3D printer Appl. Phys. Lett. 109162401

[213] Brito-Pereira R, Ribeiro C, Peřinka N, Lanceros-Mendez S and Martins P 2020 Reconfigurable 3D-printable magnets with improved maximum energy product J. Mater. Chem. C 8 952-8

[214] Peng E, Wei X, Herng T S, Garbe U, Yu D and Ding J 2017 Ferrite-based soft and hard magnetic structures by extrusion free-forming $R S C A d v .7$ 27128-38 